Portland State University

PDXScholar

Spring 5-23-2013

\title{
Materialism, Personal Food Projects, and \\ Satisfaction: A Phenomenological Study of Urban Gardening in Portland, Oregon
}

Robin René Wikoff

Portland State University

Follow this and additional works at: https://pdxscholar.library.pdx.edu/open_access_etds

Part of the Leisure Studies Commons

Let us know how access to this document benefits you.

\section{Recommended Citation}

Wikoff, Robin René, "Materialism, Personal Food Projects, and Satisfaction: A Phenomenological Study of Urban Gardening in Portland, Oregon" (2013). Dissertations and Theses. Paper 1039.

https://doi.org/10.15760/etd.1039

This Dissertation is brought to you for free and open access. It has been accepted for inclusion in Dissertations and Theses by an authorized administrator of PDXScholar. Please contact us if we can make this document more accessible: pdxscholar@pdx.edu. 
Materialism, Personal Food Projects, and Satisfaction: A Phenomenological Study of Urban Gardening in Portland, Oregon

\title{
by
}

Robin René Wikoff

A dissertation submitted in partial fulfillment of the requirements for the degree of

\author{
Doctor of Philosophy \\ in \\ Systems Science
}

Dissertation Committee:

Wayne Wakeland, Chair

Madeleine Pullman

Betty Izumi

Heather Burns

Portland State University

2013 
(c) 2013 Robin René Wikoff 


\section{Abstract}

Nonmarket activities such as gardening and cooking are often correlated with increased well-being and happiness. Additionally, nonmarket, casual activities such as gardening and food preparation are often internally motivated, and provide observable examples of self-concordant experiences. Self-concordance, i.e., internalized motivation, has been shown to increase satisfaction and increase efficacy of goal attainment. Further, experiential hobbies such as gardening may help individuals feel more satisfied, adopt more intrinsic life aspirations, and be less materialistic.

This study explored satisfaction, materialism, and food activities by focusing on first-person, lived experiences of eight urban gardeners in Portland Oregon who grow, prepare, and eat their own food. Little is known about what specific food experiences lead to increased feelings of well-being and satisfaction. Whereas previous research focused on defining and assessing materialism based on life aspiration measures, this study explored how intrinsic life aspirations translate into concrete, lived experiences expressed through food activities. The goal of the current study was to gain a deeper understanding of how food experiences satisfied the psychological needs of urban gardeners.

Qualitative analysis of interviews and other data revealed that food experiences: 1) were motivated by intrinsic reasons, such as competency, creativity, and curiosity, and also sometimes for extrinsic reasons such as status and security, 2) were affected by enabling factors such as social relationships, and disabling factors such as time, energy, 
and financial limitations, and 3) resulted in increased life satisfaction, and feelings of strength, and confidence. Additionally, participants' level of general materialism often corresponded with their level of materialism regarding their food experiences.

The results indicated that individually tailored experiential long-term food related hobbies are highly valued and a source of great satisfaction for a variety of psychological needs, such as relatedness, connection, work-life balance, and abundance. These results show that food activities can be intrinsically satisfying and can mitigate the negative effects of materialism. The findings from this study build theory and provide direction for potential future research in reducing materialism by developing measures for types of satisfaction from food activities and testing correlations with materialism and life satisfaction. 


\section{Acknowledgments}

My heartfelt thanks to everyone who supported me in this long, exciting, and, at times arduous academic adventure. I especially want to thank the following people:

My husband, Eric, for converting our front yard into a garden for me, having faith in my commitment to finish my dissertation, and so much more. My parents, for helping me figure out what my questions were, teaching me how to answer them, and encouraging my insatiable curiosity so I never run out of questions. My sisters, for reminding me how to be the most awesome version of myself. My new parents-in-law, for welcoming me with open arms, and for so much zucchini bread.

Wayne Wakeland, for his amazing advisory skills from the moment I was interested in the program all the way through to my defense. Mellie Pullman, for being the best surprise mentor and friend a woman in graduate school could ask for, and excellent supplier of fresh ideas for research-making and fresh milk for cheese-making. My dissertation committee, for challenging me to not bite off more than I could chew while also seeking high research standards.

To my Systems Science classmates, especially Cecily, my exam buddy, and Susan, my statistics and modeling buddy. Martin Zwick for all the engaging lectures and conversations on reconstructability analysis that have forever changed the way my brain works. Patrick Hill, rest in peace, and my ruthlessly compassionate dialoguers at The Evergreen State College. Donald Morisato, for assuming that I would go to graduate school. And last, but certainly not least, my friends, for keeping me laughing, listening 
to my rants, and helping me have a life away from my computer. I couldn't have done it without all of you. 


\section{Table of Contents}

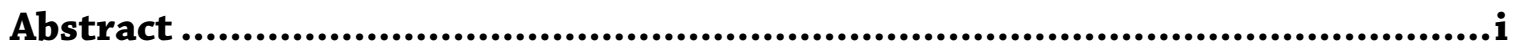

Acknowledgments .....................................................................iii

List of Tables .......................................................................... vii

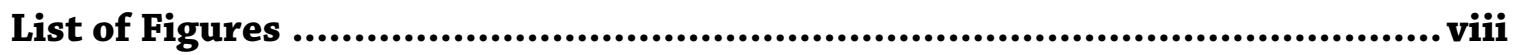

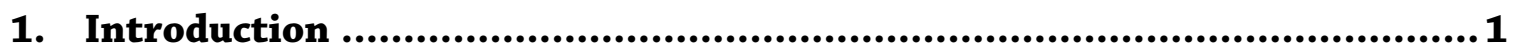

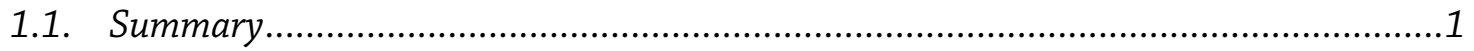

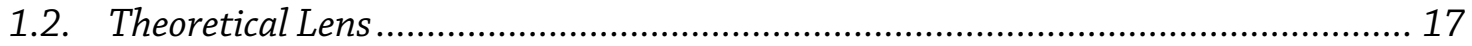

2. Article 1 - "Every day there is a food project": exploring the phenomenon of self-concordance for urban gardeners ................................................ 34

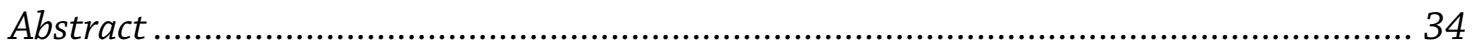

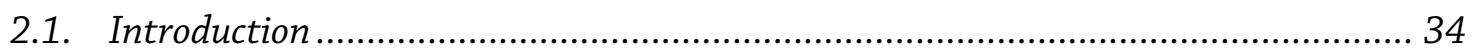

2.2. Methods ................................................................................................. 41

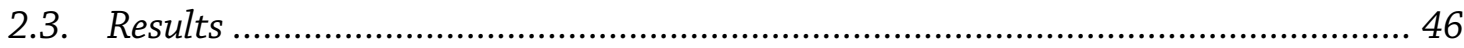

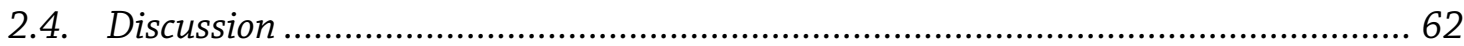

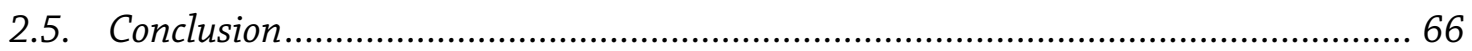

3. Article 2 - Mitigating the negative psychological effects of materialism through experiential hobbies: A phenomenological exploration of material possessions of urban gardeners .......................................................69 69

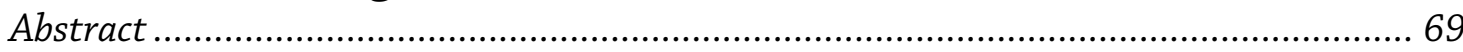

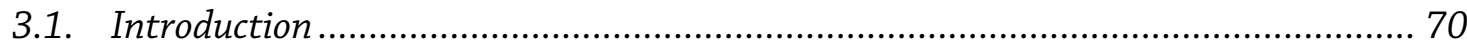

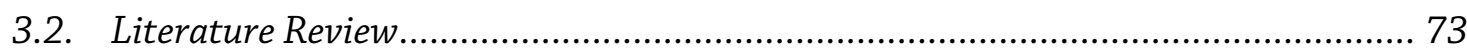

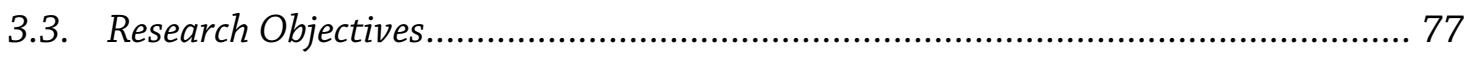

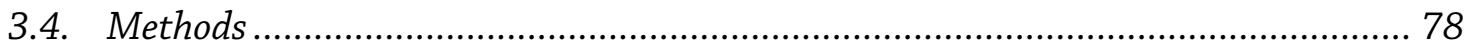

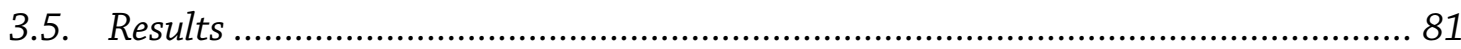

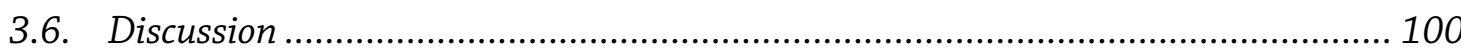

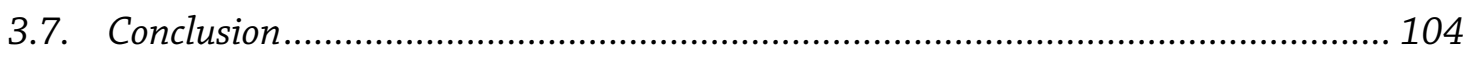

4. Article 3 - "I grow for flavor": A phenomenological study of urban gardening and satisfying food experiences............................................ 106

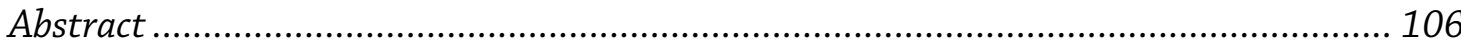

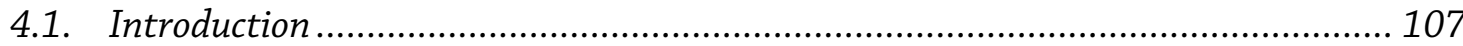

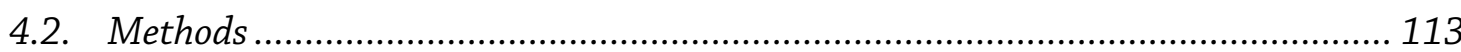

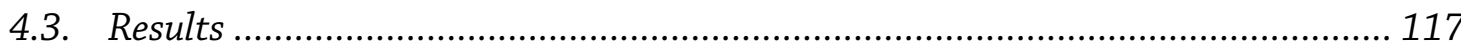

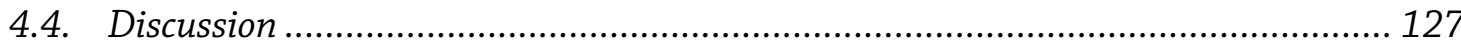

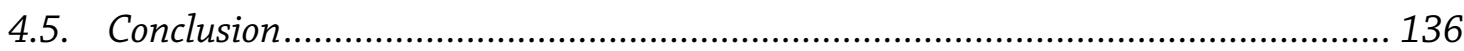

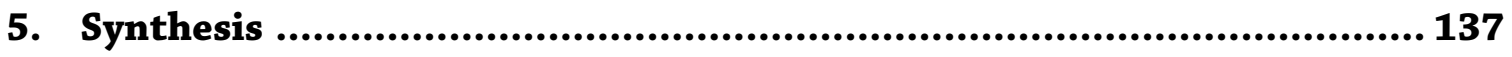

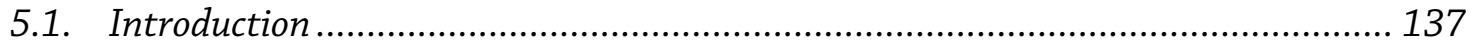

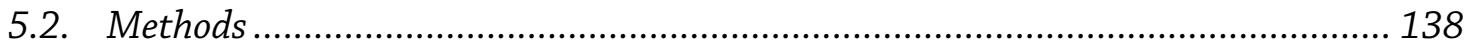

Materialism, Food, and Satisfaction v 


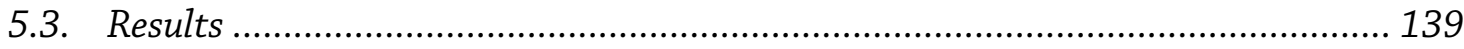

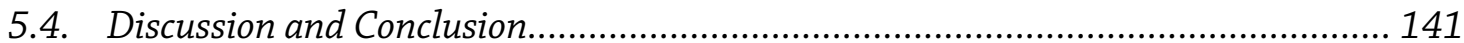

5.4.1. Limitations of Current Study and Contributions to Literature .......................... 143

5.4.2. Recommendations for Future Research ..................................................... 145

5.4.3. Recommendations for Policy and Existing Practice ........................................ 149

References..................................................................................... 151

Appendix: Methods ........................................................................... 163

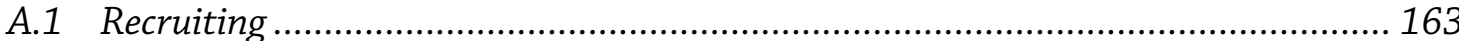

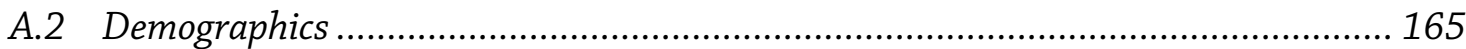

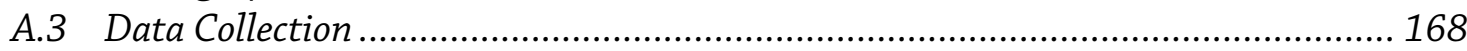




\section{List of Tables}

Table 2.1. Self-Concordance in terms of motivations and goals...................................37

Table 2.2 Demographics of study participants .........................................................43

Table 2.3. Themes: Motives, facilitators, and outcomes of self-concordant food projects

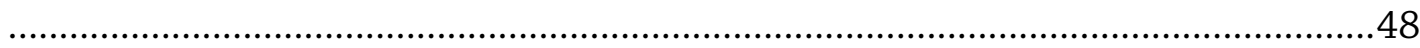

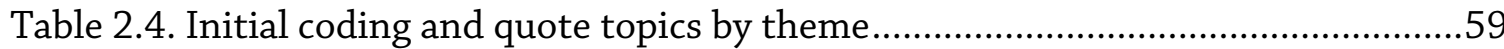

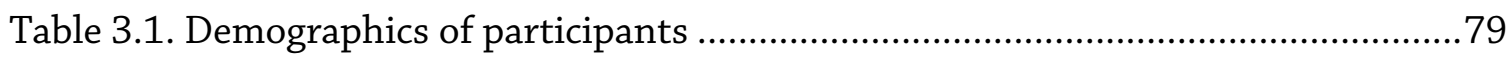

Table 3.2. Initial coding and short description of quotes, sorted by materialism

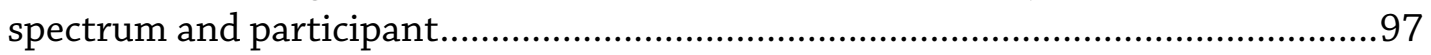

Table 4.1 Demographics of study participants .......................................................... 114

Table 4.2. Personal meanings of specific food experiences, by theme ........................ 126

Table 4.3. Shared meanings themes and feelings of satisfaction meta-themes ........... 130 


\section{List of Figures}

Figure 1.1. Possible progression towards a more post-materialistic lifestyle ..................6

Figure 1.2. Concepts and themes of the journal articles presented in Chapters 2, 3, and

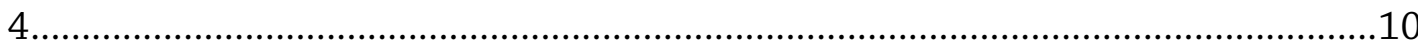

Figure 1.3. Concepts and themes in the first journal article, presented in Chapter 2

Figure 1.4. Concepts and themes in the second journal article, presented in Chapter 3

Figure 1.5. Concepts and themes in the third journal article, presented in Chapter 4

Figure 2.1. Self-concordance in the context of motivations, goals, and life satisfaction

Figure 2.2. Themes: Motives, facilitators, and outcomes of self-concordant food projects

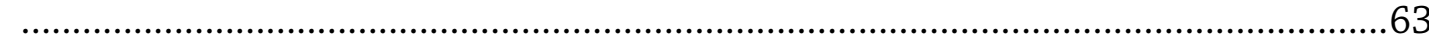

Figure 3.1. Materialism framework ......................................................................... 71

Figure 4.1. Shared meaning themes mapped onto feelings of satisfaction meta-themes 


\section{Introduction}

As our understanding of the scale of environmental challenges deepens, so we are also forced to contemplate the inadequacy of the current responses to these challenges. By and large, these responses retreat from engaging the values that underpin our decisions as citizens, voters, and consumers: mainstream approaches to tackling environmental threats do not question the dominance of today's individualistic and materialistic values (Crompton, 2008).

The tragedy of consumerism: one acquires more and more things without taking the time to ever see and know them, and thus one never truly enjoys them. One has without truly having. The consumer is right-there is pleasure to be had in good things, a sacred and almost unspeakable pleasure, but the consumer wrongly thinks that one finds this pleasure by having more and more possessions instead of possessing them more truly through grateful contemplation. And here we are, living in an economy that perpetuates this tragedy. An outrage! A pity (McLaren, 2004).

Eating with the fullest pleasure - pleasure, that is, that does not depend on ignorance is perhaps the profoundest enactment of our connection with the world. In this pleasure we experience and celebrate our dependence and our gratitude, for we are living from mystery, from creatures we did not make and powers we cannot comprehend (Berry, 1990).

\subsection{Summary}

This topic grew out of my personal convictions about sustainability and materialism, my more recent involvement in food research, my love of gardening and cooking, and my insatiable curiosity about how and why people make decisions. My studies in Systems Science powered my search for understanding the complex connections between individual's decision-making processes and sustainability.

The more I researched sustainability, the more I became interested in a systems perspective involving connections between individual's decision-making processes, behaviors, impacts of those behaviors on their own personal happiness, and impacts of the individual's behaviors on cultural, economic, and natural mechanism that are 
unsustainable. My concerns with sustainability kept coming back to the same questions: Why and how do people reorient themselves away from the never-ending cycle of consuming, status-seeking and wealth-seeking? How can this change be done in a way that creates more satisfying lives for people?

High consumption of resources is the reason for the current and dire need for sustainability, and the materialistic mindset and lifestyle are feeding unsustainable behaviors across all sectors of resource use (Bin \& Dowlatabadi, 2005; Crompton, 2008; de Geus, 2003). The environmental movement has tasked themselves with motivating individuals, governments, and society as a whole to change their behaviors and adopt pro-environment values (Crompton, 2008). But environmentalists and other social change agents are quickly realizing that sustainable behavior change without value change isn't effective, value change is very difficult, and individuals are much more motivated to change their values if the change increases their personal well-being (Crompton, 2008; Doppelt, 2010; Ehrenfeld, 2008; Shellenberger \& Nordhaus, 2004).

Fortunately for the sustainability of our environment, materialism (and the overconsumptive behaviors it leads to) has not been shown to facilitate psychological wellbeing, so there is an opportunity to decrease consumption while increasing psychological well-being (Belk, 1985; De Graaf, Wann, \& Naylor, 2001; Kasser, 2003; Kasser \& Ryan, 1996; Richins \& Dawson, 1992; Richins \& Rudmin, 1994; Schwartz, 2004; Van Boven, 2005). Studies have shown that purchases that are experiential instead of based on acquisition (that are for doing instead of having) lead to greater 
satisfaction of psychological needs (Huneke, 2005; Van Boven, 2005). Also, individuals who focus more on intrinsic aspirations, e.g., self-acceptance, affiliation, community feeling, and physical fitness, have greater psychological well-being compared to those who focus more on extrinsic aspirations associated with materialism, e.g., financial success, attractive appearance, and social recognition (Grouzet et al., 2005; Kasser \& Ryan, 1996).

Previous research has shown that non-materialist aspirations also leads to greater well-being in the goal attainment process (Niemiec, Ryan, \& Deci, 2009). Based on the Self-Determination Theory (Deci \& Ryan, 2000), individuals set goals based on aspirations, choose behaviors that move towards those goals, attain the goals, and experience increased satisfaction and self-efficacy because of this process. Individuals who pursue goals for either enjoyable or personally important reasons (i.e., with selfconcordance) instead of shame or guilt or pressure from other people or situations attain their goals with greater ease and goal attainment leads to more positive increases in well-being than goal attainment without self-concordance (Sheldon \& Elliot, 1999; Sheldon et al., 2004). Further, self-concordance positively reinforces the aspiration $\rightarrow$ goal-seeking $\rightarrow$ goal attainment $\rightarrow$ increased satisfaction process. Positively reinforcing elements are also known as feedback loops in Systems Science. Feedback loops are important to be aware of, within systems, because the behavior of these elements can strongly impact and complicate the behavior of the entire system or process. In this process, self-concordance increases the effectiveness of goal attainment, which leads to 
increased self-concordance and intrinsic aspirations (Sheldon \& Houser-Marko, 2001).

This process of change gives a promising model of social change at the personal level, away from materialism and high consumption towards increased sustainability and personal well-being, through intrinsic aspirations and self-concordant goal attainment. Figure 1.1 illustrates this proposed cycle, where food activities, experiences, and projects that are internally motivated can lead to feelings of satisfaction and increases in psychological well-being. Food activities, experiences and projects can also become positively reinforcing when they lead to increased subjective well-being. Increased feelings of satisfaction and psychological well-being from internally motivated activities can motivate increased commitment to an adoption of intrinsic aspirations and self-concordance. Increased intrinsic aspirations have been shown to be correlated with increased satisfaction of psychological needs and increased psychological well-being.

Increased commitment to and adoption of self-concordance and intrinsic aspirations is a shift in values that could lead to changes in lifestyle choices and behaviors, which can be called a post-materialism lifestyle. This change in lifestyle will likely be characterized by a shift away from material high consumption, which will be less resource intense, more sustainable, and may even contribute to paradigm and behavior shifts beyond the consumer sector. Shifts in lifestyle may also lead to significant increases in food activities, experiences, and projects. It should be noted, however, that not all behavior changes from materialistic to intrinsically satisfying 
activities are sustainable. For example, traveling and driving a car for pleasure are more resource-intensive than taking public transit or avoiding air travel. Individuals who have intrinsic life aspirations do not consume for the sake of material possession attainment, so they may not be consuming as many goods, but still must be encouraged to make sustainable choices in their intrinsically satisfying activities. 


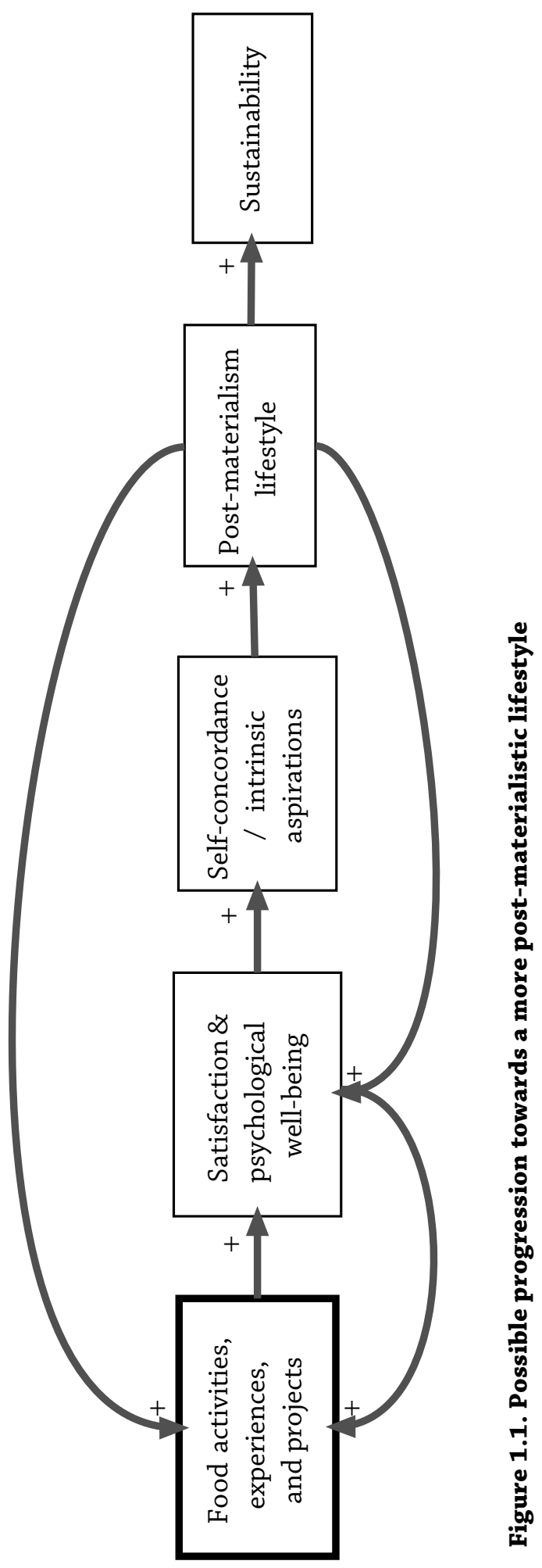

Introduction

Materialism, Food, and Satisfaction 
For this study, the process of goal attainment was explored in a specific context that was rich with experiential activities, intrinsic aspirations, and self-concordant goal attainment processes: growing, preparing, and eating one's own food. Although there may be some personal variation, people generally agree on what types of activities are experiential and not motivated by acquiring (Van Boven, 2005). Gardening, preparing, and eating are all (in general) doing activities, focused on experiences, not acquisitions (Kaplan, 1973; Wakefield, Yeudall, Taron, Reynolds, \& Skinner, 2007).

The larger research question (not fully addressed in this research) is: "Do intrinsic goal-seeking activities such as gardening, preparing, and eating one's own food help individuals become less materialistic and more satisfied?" For the purpose of this study, a social constructivist worldview and a phenomenological approach was adopted. Interests in inferential and causal results were set aside and exploratory, descriptive, and qualitative data of constructed meanings of objects and life experiences was the focus. The data was allowed to emerge, with the goal of capturing "rich descriptions of phenomena and their settings" (Groenwald, 2004). Focusing on the phenomenon, the research question for this current research was: "Given that food activities are generally non-materialist, how do gardeners perceive and describe their experiences of food projects, including the aspirations and goal attainment of those projects, and their resulting feelings of satisfaction?"

This study was exploratory, in preparation for confirmatory quantitative research to show factors that contribute to individuals transitioning away from materialistic to 
more sustainable and more psychologically healthy lifestyles.

This qualitative study was used to inform three journal articles, Chapters 2, 3, and 4 of this dissertation. Each article is focused on a unique aspect of the study: 1) changes in the experiences of goal attainment among gardeners, 2) materialism through the phenomenological lens, and 3) food activities and satisfaction. Figure 1.2 shows all the concepts explored in this study, and is a way to show how the concepts relate across the three journal articles. This figure shows the relationship between well-being, materialism, intrinsic and extrinsic aspirations, self-concordance, experiential and material purchases, and sustainability in the context of urban gardening and food experiences, activities, and projects, and through the phenomenological lens. The relationships are summarized described here, and explored in more detail in the literature reviews of the journal articles.

When an individual has a low sense of well-being, they may adopt extrinsic aspirations and materialism values as a strategy to satisfy their psychological needs. Over-consumption and other materialistic behaviors may result from attempts to increase well-being when individuals have extrinsic aspirations. These overconsumptive behaviors lead to unsustainable environmental degradation, and are not effective at meeting psychological needs.

Alternatively, an individual with a low sense of well-being may adopt intrinsic aspirations and post-materialism values as a strategy to satisfy their psychological needs. Intrinsic aspirations, self-concordance, and post-materialism values may lead to 
non-material activities and experiential purchases, which are less resource intensive, more sustainable, and often lead to increased psychological well-being. Experiential purchases and non-material activities can be positively reinforced by increased wellbeing, as can post-materialism values, intrinsic aspirations, and self-concordance. 


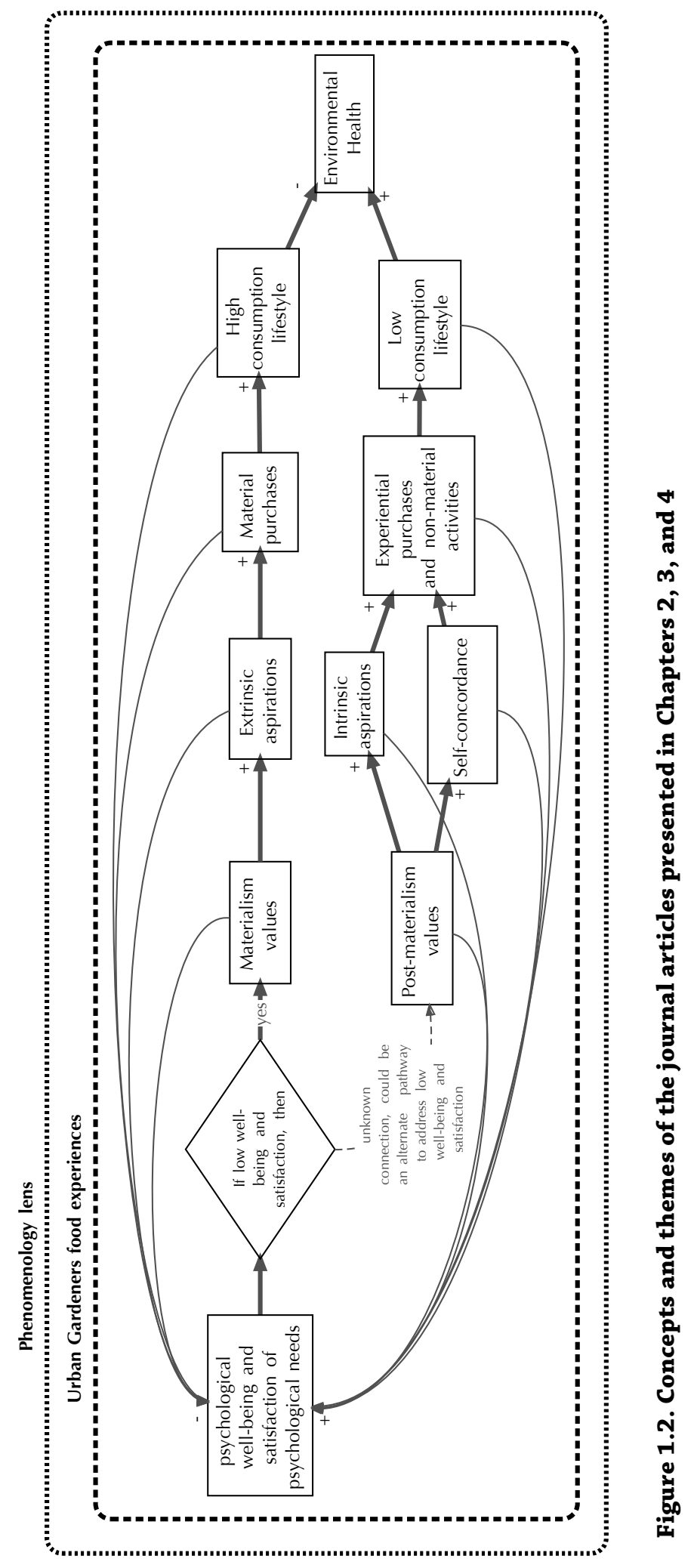

Introduction

Materialism, Food, and Satisfaction 10 
The first article, involving changes in goal-attainment, was directly linked to current research on self-concordance, goal attainment, and increasing well-being (Sheldon \& Elliot, 1999; Sheldon \& Houser-Marko, 2001), while exploring these concepts within the experiences of gardeners, and from a phenomenological lens. Figure 1.3 shows the key concepts and relationships that were explored in the first journal article. Individuals with low psychological well-being may be motivated by self-concordance in their food projects, such as gardening, preparing, and eating food. Projects motivated by selfconcordance often lead to increased psychological needs, which can positively reinforce adoption and commitment to self-concordance. Phenomenology provided rich exploratory data on experiences of food projects, motivation, and well-being. These concepts are explored more in the journal article in Chapter 2 of this dissertation. 


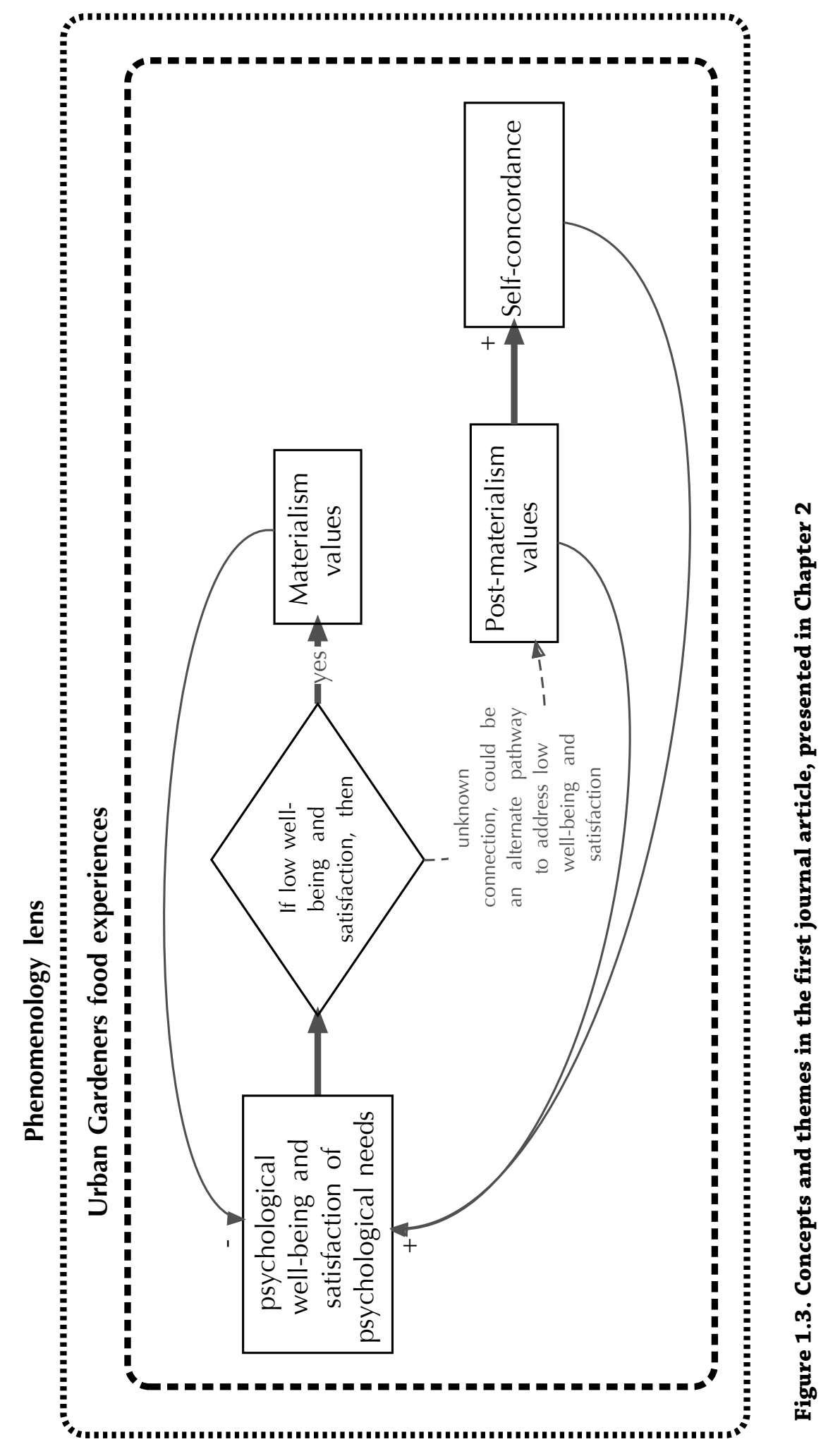

Introduction 
The second article, materialism through the phenomenological lens, explored how phenomenology can contribution to consumer studies, materialism, and sustainability research by bringing in the first-person, lived experience of consumers (de Geus, 2003; Editorial, 2007; Essoussi \& Zahaf, 2008; Leonard-Barton, 1981; Shaw \& Newholm, 2002). Figure 1.4 shows the key concepts and relationships that were explored in the second journal article. This article was more focused on materialism and experiential purchases, and less focused on food activities or projects than the previous article.

As described before, individuals with low well-being may adopt materialism values and extrinsic aspirations, choose material purchases, and be unable to fulfill their psychological needs, or they can adopt post-materialism values, intrinsic aspirations, and choose experiential purchases and non-material activities, which may have less environmental impact and lead to increased psychological well-being. In turn, increased well-being and satisfaction of psychological needs may positively reinforce postmaterialism values and experiential purchases. Phenomenology provided much needed insight into consumer studies, the impact of alternative activities to consumption, and well-being. 


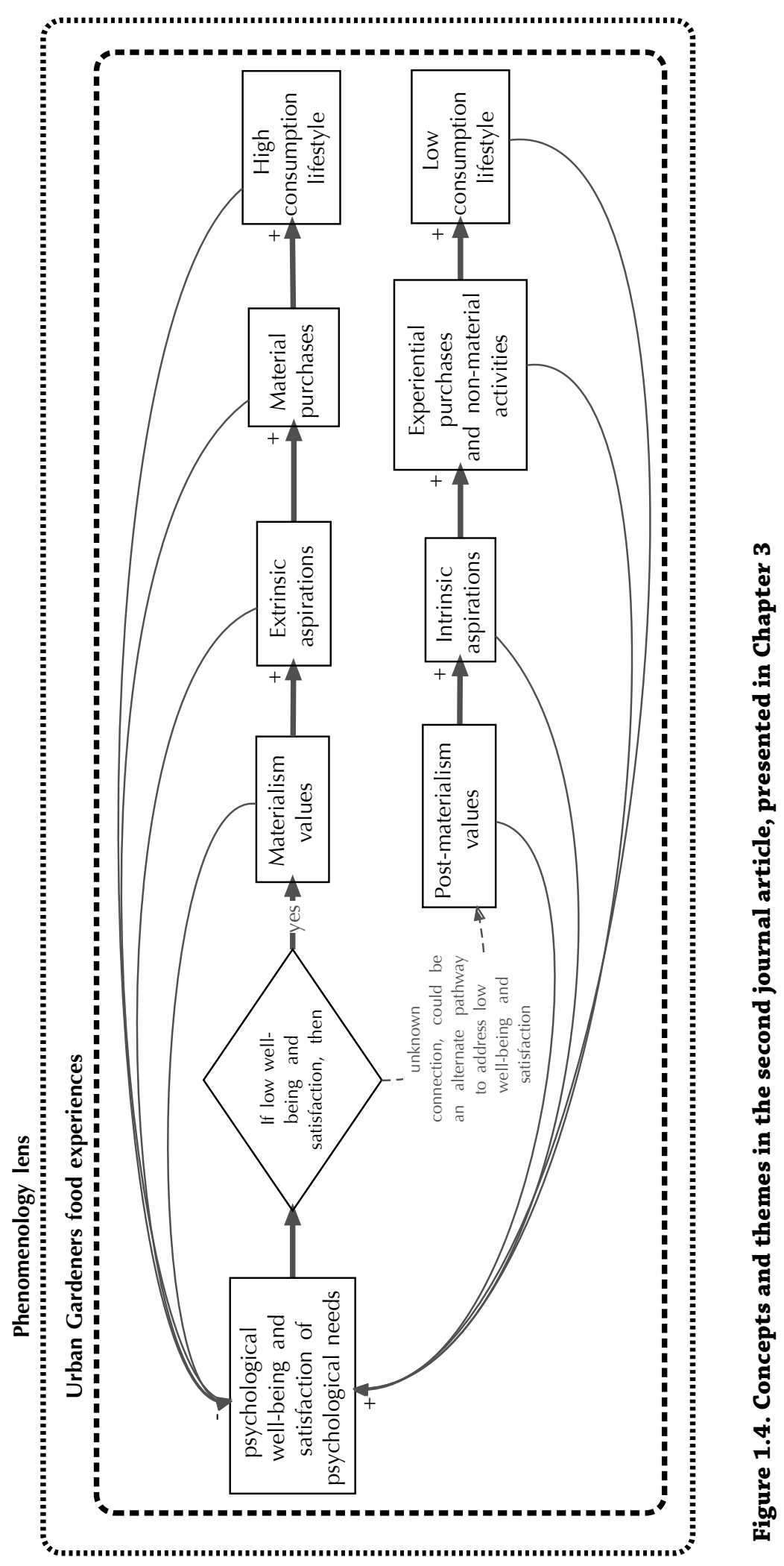

Introduction

Materialism, Food, and Satisfaction 
The third article, food activities and satisfaction, explored how food activities contribute to the satisfaction of psychological needs, building on research on intrinsic aspirations (Grouzet, et al., 2005; Kasser, 2003; Kasser \& Ryan, 1993, 1996), experiential purchases (Van Boven, 2005), and experiential food research (Kristeller, 2003; Petrini \& Padovani, 2006; Trubek, 2008, 2009; Wakefield, et al., 2007). Figures 1.5 shows the key concepts and relationships that were explored in the third journal article. This article focused more on food activities and satisfying psychological needs, as a way of acting on intrinsic aspirations than the previous articles. Urban gardeners had frequent and diverse food experiences that are motivated by intrinsic aspirations. These food experiences contributed to increased well-being and life satisfaction, which may positively reinforce food activities. The phenomenological lens provided insight into food experiences and satisfaction. 


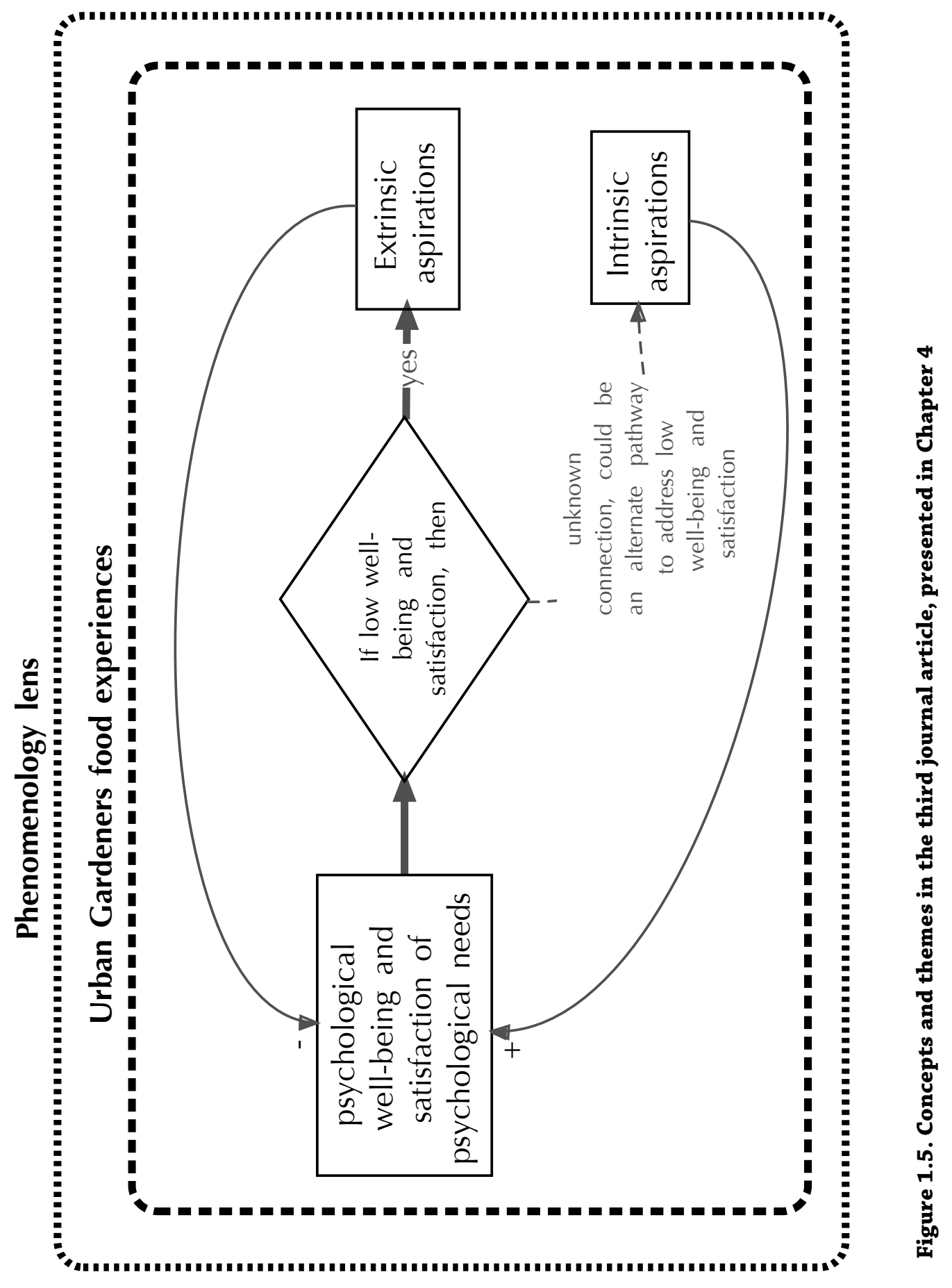

Introduction 
While each journal article presents background information and methods, some additional details on methods may be helpful. For more in-depth methods information, regarding recruiting, demographics, and data collection see the Appendix. The remainder of the Introduction presents the theoretical lens guiding this research.

\subsection{Theoretical Lens}

The limits of the current growth regime are becoming apparent year by year. As we travel along the planet's shutdown path, food, energy, transport, and consumer goods will become more expensive. Jobs and incomes will be less available, and the usual way out - a debt-financed consumer boom - is unaffordable for households and the planet. With familiar opportunities deterioration, we'll be hamstrung if we limit ourselves to past practice. It's time to leapfrog over the unpalatable trade-offs currently on offer and embrace a new economy. True wealth can be attained by mobilizing and transforming the economies of time, creativity, community, and consumption.

- Juliet Schor, Plentitude (Schor, 1999)

This research was motivated by the dire need to transition to a more sustainable society. The Systems Science principle of leverage shows that, with understanding of complex system structure, small changes in the system at the right place can create large changes throughout the entire system (Senge, 2006). Individual behavior and value change can have a strong impact on slowing environmental impact and changing societal values from materialism to post-materialism. Not only could this change be good for the environment, but it could also increase individual's own well-being, reinforcing post-materialism lifestyles. This section provides more detail about these concepts, and provides a theoretical lens for this study.

Climate change is a harsh reality. Arctic sea ice is melting, the oceans are rising, and there is already strong evidence of unprecedented droughts, heat waves, monsoons, Introduction Materialism, Food, and Satisfaction 17 
raging winter storms, hurricanes, and massive loss of biodiversity, and natural resource depletion (Meadows, Randers, \& Meadows, 2004). Scientists have warned that carbon dioxide (CO2) levels above 350 parts per million are incompatible with preserving a planet "similar to that on which civilization developed," but current levels are already above 385 CO2 parts per million (Schor, 1999).

There are various ways to change current behaviors to reduce climate change effects, many of which involve global, governmental, economic, and societal-level changes. While individual behavior change by itself may not be big enough to stem the tide of climate change and other impacts of global unsustainable behaviors, the Systems Science concept of Panarchy shows that policies and business practices can be very slow to change (Gunderson \& Holling, 2001). If a system's mechanisms are properly understood, catalysts for large-scale changes can often come through carefully placed and highly driven individual's commitment to sustainability (Senge, 2006). Research has shown that consumers are important drivers for the way material goods and foods are produced and used (Bin \& Dowlatabadi, 2005; Crompton, 2008; de Geus, 2003).

Individuals are powerful change agents, not just by their consumer habits, but in their roles as economic, governmental, and cultural agents, shaping the organizations they are part of, and influencing other individuals in personal, professional, and civic contexts. This research focuses on individual-level experiences, but is not limited to isolated, individual's consumer choices. Rather, it focuses on sustainability at the individual level within the many contexts which individual may be influenced by and 
influence.

At the individual level of sustainability, it is important to focus on individual's relationship with material goods and food, both of which have strong psychological, mental, and emotional components involving need fulfillment.

\subsubsection{Satisfaction}

Humans have basic physical needs (e.g., food, water, and shelter) and psychological needs (e.g., security, self-esteem, connectedness, autonomy) that motivate behavior and, along with other factors, shape individual beliefs, values, heuristics, and life goals or aspirations (Kasser, 2003). Satisfaction or fulfillment of these needs have been shown to increase individuals well-being and quality of life (Kasser, 2003). While fulfillment of needs is a predictor of well-being, and needs motivate behavior, knowing what humans need at a basic level does not help us understand what specific behaviors correspond to fulfill most of these needs, since the method of satisfying needs may vary from individual to individual (Kasser, 2003).

For many individuals in our society now, the search for what behaviors can consistently satisfy their needs and well-being tends to leas people towards high consumption. Consumption in the United States is rampant (Bin \& Dowlatabadi, 2005; Crompton, 2008; de Geus, 2003; Richins \& Rudmin, 1994; Van Boven, 2005); individuals in our society are highly driven to seek satisfaction of needs and higher wellbeing through consumption (Kasser, 2003; Kasser \& Ryan, 1993, 1996; Richins \& Rudmin, 1994; Van Boven, 2005). When many individuals in a society regularly seek 
satisfaction and higher well-being through consumption, two patterns emerge: 1) at an individual level, a lifestyle of consumption, called materialism, is adopted very frequently and with much conviction, along with a set of life goals, values, beliefs, and heuristics for satisfaction and well-being seeking (Bin \& Dowlatabadi, 2005; Crompton, 2008; de Geus, 2003; Richins \& Rudmin, 1994; Van Boven, 2005) through consumption, and 2) at a societal level, a consumer culture is created, encouraging and perpetuating consumerism and materialism as acceptable methods for seeking satisfaction and well-being (Richins \& Rudmin, 1994).

Individuals adopt materialism because they want to satisfy psychological and physical needs, and increase their well-being, and because they think that consumption is the set of behaviors that can help them be happy and satisfied. Study after study shows that individuals who strongly adopt materialism have significantly less well-being and less satisfaction of needs than individuals who have not (or at least have not as strongly) adopted materialism (Kasser \& Ryan, 1993, 1996).

Given the relationship between materialism and satisfaction, individuals with high materialistic qualities cannot simply be told to stop being so materialistic, since these individuals are satisfying many of their psychological needs through their materialistic behaviors. Decreasing these materialistic behaviors would cause highly materialistic individuals to become less satisfied over the short term, which they find very unpleasant and not at all incentivizing.

A deeper dive into needs and well-being may provide some clarity about the Introduction Materialism, Food, and Satisfaction 20 
relationship between materialism, satisfaction, and well-being. There is general consensus about the types of needs that must be satisfied for individual well-being, with each of the four nonhierarchical sets of needs listed below empirically associated with quality of life (Kasser \& Ryan, 1993, 1996): 1) safety, security, and sustenance, 2) competency, efficacy, and self-esteem, 3) connectedness, and 4) autonomy and authenticity.

Literature on measuring materialism is growing (Belk, 1985; Kasser, 2003; Kasser \& Ryan, 1993, 1996; Pierce, 2000; Richins \& Dawson, 1992), and there is some consensus about the characteristics of highly materialistic individuals, and what observable variables can be used to assess the level of materialism for individuals as well as nations or societies (Inglehart, 1981).

Previous research indicates that if an individual is a materialist (if they score high on materialistic belief and assumptions or if they have strong materialistic life goals), then they will not be as happy as if they were less materialistic, i.e., they will be doing a poorer job of satisfying their psychological needs (Kasser, 2003; Kasser \& Ryan, 1993, 1996; Richins \& Dawson, 1992; Van Boven, 2005). But what, broadly speaking, about being a materialist is different regarding the way they seek satisfaction?

Kasser \& Ryan say that the difference is between extrinsic and intrinsic goals (Kasser \& Ryan, 1993, 1996), where extrinsic goals (e.g., financial success, physical appearance, and social recognition) are materialistic and rely on external sources to fulfill psychological needs, through rewards and praises. Intrinsic goals (e.g., self- 
acceptance, affiliation, and community feeling) are non-materialistic and lead to greater satisfaction of psychological needs, since these goals lead to greater satisfaction regardless of external sources (i.e., other people). An additional powerful difference between extrinsic and intrinsic goals is that actions towards intrinsic goals result in feelings of satisfaction, without having to wait for external validation.

So, materialism isn't only a set of specific beliefs and assumptions, it is a different approach to satisfying psychological needs, one that requires individuals to be dependent on sources outside of the individual's control to achieve satisfaction. This is the key to understanding why materialism so often leads to lower satisfaction and lower well-being. This builds a compelling case for abandoning materialism, to increase personal well-being and satisfaction as well as decrease overall consumption.

But it is known that materialists have a whole belief structure built around getting satisfaction through materialism, and it will not be easy to motivate abandonment of that belief structure. As mentioned above, changes in materialistic behavior must lead to more psychological satisfaction than materialists possessed previously in order to motivate genuine behavior, belief, and lifestyle change.

\subsubsection{Post-Materialism}

Literature on specific mechanisms involving changes in materialism is limited, although popular writing abounds about the virtues of abandoning materialism and adopting a simpler life (Andrews \& Urbanska, 2009; Beavan, 2007; Carlomagno, 2005; De Graaf, et al., 2001; Elgin, 2009; New American Dream, 2011; Robin, Dominguez, \& Tilford, 2008; 
Schwartz, 2004), and blogs and support groups are gaining following as well. To understand more about the transition away from materialism, it will be helpful to see what non or post-materialism looks like, to see what the end result of transitioning away from materialism looks like.

One popular movement focusing on shifting away from materialism is called Voluntary Simplicity. A voluntarily simple life is sometimes defined as outwardly simple in terms of material possessions and inwardly rich or complex (Gregg, 1936; Pierce, 2000), indicating a shift from external to internal satisfaction. There are many names for this type of lifestyle: "down shifting," "post-consumerism," "post-materialism," "voluntary simplicity," "simple living," "intentional conscious living," "slow living," and "frugal living," to name a few.

While the voluntary simplicity movement is encouraging in terms of individual's commitments to changing their lifestyles to intrinsic satisfaction and less overall consumption, this movement has been criticized for being too focused on the individual lives and not on cultural, societal, and governmental structures that could be changed to facilitate a broader societal transition to voluntary simplicity (Pierce, 2000). For example, voluntary simplicitarians could work to increase health benefits for part time workers, increase wages for part time work to make them closer to living wages, and organize "work share" programs where two people both work part time in the same position, essentially splitting a full time position between them. Additionally, Voluntary Simplicity as a materialism intervention and sustainable solution is powerful, especially 
when it acknowledges issues of power and privilege; individuals who choose to decrease material possessions to increase their happiness have the privilege and power to have more material possessions than they need. But Voluntary Simplicity is not an appropriate approach to more sustainable behavior for individuals who have lower income and do not have a choice to have more possessions than they need.

Pierce shows that self-reported motivations for adopting Voluntary Simplicity are diverse (Pierce, 2000). Within the diverse motivations of seeking intrinsic satisfaction that Pierce mentions, Pierce finds that transitions to post-materialism often happen after a major life event, such as a death of a family member, a brush with death or serious injuries, divorce, or loss of a job (Pierce, 2000). These major life events often create a space for reflection and review of life priorities, but ideally the transition to post-materialism would be accessible to all consumers.

Another approach is needed to help materialists meet their psychological needs intrinsically so they are positively motivated to decrease their materialism. The ideal approach would not involve converting individuals to support a lifestyle for moral or ethical reasons, or expecting individuals to develop a high level of self awareness. A major change in lifestyle, like Voluntary Simplicity, should be motivating for individuals; it should help them satisfy their psychological needs as well or better than their previous lifestyle, and not make them feel obliged to change their lifestyle.

To avoid negative associations with the process of changing to Post-Materialism, any steps along the way should lead to an increase in satisfaction for individuals. 
Therefore, initial steps in the change process cannot directly focus on sustainability or materialism, but must instead focus on satisfaction-increasing types of thinking and behavior, such as intrinsically satisfying experiences that individuals have already accepted as valuable to their perceived satisfaction.

Behaviors that result in intrinsic satisfaction may vary from individual to individual, but research shows a general consensus about the intuitive difference between purchases that are intended for intrinsic or experiential purposes compared to extrinsic or materialistic purposes (Van Boven, 2005). Van Boven makes the distinction between "acquiring life experiences" (intrinsic) and "acquiring material possessions" (extrinsic). He developed an intention-based survey instrument where participants intuitively categorized their own purchases between "experiential" or "material" based on their intentions for these purchases (i.e., to acquire life experiences vs. material possessions).

The results of this study (Van Boven \& Gilovich, 2003) showed clear distinctions between material and experiential purchases, with experiential purchases defined as things such as beauty spas and products, dining, fees and admissions (to concerts, ski slopes, etc.), and travel, and material purchases as things such as books and compact discs, clothing and jewelry, television, stereo, computer equipment, and vehicles. He also made the connection between experiential purchases and increased subjective wellbeing, which is in agreement with other research on non-materialist behaviors. According to Van Boven, experiential purchases make people happier than materialist purchases for three reasons: 1) experiential purchase are easier to reinterpret as 
positive in retrospect, 2) experiential purchases are harder to compare, so are less prone to lead to regret or to changes in social status, and 3) experiences are more likely to lead to social interactions and cohesion.

There are many different types of intrinsically satisfying experience. Some involve appreciation of material goods more directly, such as enjoying the experience of driving a very nice car, savoring a newly purchased computer, listening to music on a good quality stereo system, or the satisfaction of replacing a worn-out pair of shoes with a brand-new pair. Other intrinsically satisfying experiences are farther removed from material goods, such as biting into a perfectly ripe peach, a summer picnic with friends, playing with one's dog, listening to a beautiful piece of music, going out dancing, watching a great movie, or going to an art gallery. Intrinsically satisfying experiences often engage the senses more deeply, and are often compelling in a visceral way. Some intrinsically satisfying experiences are, or can be, part of everyday life, such as cooking dinner, going for a walk, writing poetry, drinking wine, listening to music, cultivating plants, practicing religion or spirituality, or spending time with friends and family.

\subsubsection{Food: Activities and Projects}

There are many types of intrinsically satisfying experiences. Food experiences are one of the most common types of experiences, and can be intrinsically satisfying. Take, for example, the activity of gardening. For a small percentage of people, this activity could be intended as a material activity (to have a beautiful garden to impress one's neighbors), but for most everyone it is experiential. This dissertation research explored 
the phenomenon of gardening (including production and preparation of food) as an intrinsically satisfying experience by studying individual gardeners and their food activities, with the expectation that a sample of urban gardeners will be low on the spectrum of materialism.

It should be noted, though, that power and privilege may also play a role in the accessibility of gardening as an activity; for individuals with low income, gardening may be less of a leisure activity, and more of a way to provide much needed fresh food for their family that they could not otherwise afford. Additionally, single parents or families with working parents may not have time for leisure activities such as hobby gardening or cooking from scratch or time-consuming meals.

Everyone eats. For some, eating is a bother, something to get out of the way in order to get back to work. For others, each bite is a spiritual experience, full of ponderable, mindful joy. For others, eating is an addiction that cannot be slowed, a sort of mindless shoveling. And for others, food is a delight to all the senses, and is done socially, with much gusto. Food is not a simple thing in our lives, although it may seem so at times a distraction, a necessary chore in the background of life. Food is woven throughout our lives, and creates meaning from experiences, from bodily satisfaction, commensality (the experience of sharing food eating with others), romance, comfort, and excitement. M. F. K. Fisher explains why she writes about food, and explores the complex role of food (Fisher \& Reardon, 2004): 
People ask me: Why do you write about food, and eating and drinking? Why don't you write about the struggle for power and security, and about love, the way others do? They ask it accusingly, as if I were somehow gross, unfaithful to the honor of my craft. The easiest answer is to say that, like most other humans, I am hungry. But there is more than that. It seems to me that our three basic needs, for food and security and love, are so mixed and mingled and entwined that we cannot straightly think of one without the others. So it happens that when I write of hunger, I am really writing about love and the hunger for it, and warmth and the love of it and the hunger for it . . . and then the warmth and richness and fine reality of hunger satisfied ... and it is all one...There is a communion of more than our bodies when bread is broken and wine drunk. And that is my answer, when people ask me: Why do you write about hunger, and not wars or love?

The physical distance, historical changes in food culture and expectations about food quality, and the other cultural factors of reductionism (the economy as a machine and the take-make-waste system) have created a mental and emotional disconnect from authentically engaging in food as an intrinsically satisfying experience (Pirog, 2004; Vileisis, 2008). These disconnects prohibit consumers from being able to use Systems Thinking and other Systems Science tools to understand the impacts of their behaviors on the natural environment, as well as preventing consumers from experiencing and connecting with the sources and sinks of their food system, i.e., the production, preparation, and waste processes of food. Despite these cultural factors driving the disconnect between individuals and authentic food experiences, some individuals have reclaimed satisfying food experiences, and some have reduced their attachment to attaining stuff (material goods) and have created a more intrinsically satisfying lifestyle.

Growing food is one of the most basic human activities. Activities involving food at a personal level, such as personal food production, preparation, and eating, can lead to deeply meaningful and satisfying experiences. Some people may already enjoy food Introduction Materialism, Food, and Satisfaction 
activities, and want to continue or increase their level of activity, while others may be just beginning to do more food activities, and are just realizing that they enjoy food activities sufficiently want to increase it. Sometimes the change can be small, such as spending more time to cook more elaborate dinners, or just taking time to enjoy making dinner. Other times the change can be large, like converting a front yard into a garden space.

There are many opportunities each day to maintain or increase food activities. Each meal can be carefully and thoughtfully prepared, and can be savored. Gardens can be mindfully tended and tinkered with, and food can be processed in different, fun, and "from scratch" ways. Each of these activities can be added to regular, everyday food activities as part of increasing satisfaction. This is the benefit of personal food activities from the context of intrinsic satisfaction and Post-Materialism: there are lots of opportunities to increase intrinsic satisfaction (and also perceived satisfaction) on a daily basis.

Food activities provide many opportunities to practice gratitude, mitigate adaptation, and experience long-term intrinsic satisfaction. There are many types of food activities, and much diversity in experiences of satisfaction from food activities. While there are many kinds of food activities, the most common and approachable food activity is eating. 


\subsubsection{Intrinsically Satisfied Eaters}

Eating fulfills a bodily need for sustenance, but is also the gateway for satisfaction through psychological needs and sensory experiences. Mindful eating is a technique often used by people suffering from eating disorders. It is a way to become more satiated from less food, by using Buddhist techniques of mindfulness while eating to be more present and focused on the experience at hand (Kristeller, 2003). It is similar to a number of diet and health books focused on the psychological aspect of eating, addressing negative reinforcing factors, such as guilt and shame, and encouraging positive reinforcing factors, such as the pleasures of eating through increased awareness of sensations during eating (Roth, 2003, 2010). But eating as an intrinsically satisfying experiences isn't always motivated by health concerns. Sometimes eating is deeply embedded in cultural, social, geographical, and personal identities.

For Americans, healthy eating often means adopting "scientific dieting." That is, diets that are based on the assumption (Levenstein, 2003):

". . that taste is not a true guide to what should be eaten; that one should not simply eat what one enjoys; that the important components of food cannot be seen or tasted, but are discernible only in scientific laboratories; and that experimental science has produced rules of nutrition that will prevent illness and encourage longevity."

The French are near polar-opposite in their foodview: "when you eat or drink, it needs to be a shared experience that incorporates sensory analysis and sensory pleasure. The ability to discern tastes is a cultural imperative" (Trubek, 2008). There is a high level of awareness about eating, so much so that it extends beyond the actual sensory experience, to include awareness and reflection of the role of the natural world to their Introduction Materialism, Food, and Satisfaction 30 
sense of taste: "When the French take a bite of cheese or a sip of wine, they taste the earth: rock, grass, hillside, valley, plateau. They ingest nature, and this taste signifies pleasure, a desirable good" (Trubek, 2008). This French quality of involving nature in their sense of taste is called Terroir.

Terroir is a complex term that does not translate easily. The simplest translation is the "taste of place," but is still difficult to grasp since it implies caring about and being able to discern ingredients, their origins, and their quality. Reflection, awareness of experiences, and enhanced satisfaction all sound very much like Post-Materialistic (or pre-materialistic) intrinsically satisfying experiences. The French have discovered, or maintained, how to make food experiences of eating a powerfully intrinsically satisfying experience, by making it socially satisfying as well as a very satisfying sensory experience through awareness, reflection, and analysis.

Another powerful way to dive deeper into food activities and terroir is by growing and preparing one's own food.

"At the most basic level, gardening shows us what it takes to raise food, from the work of shoveling earth and pulling weeds to the joy of watching seeds grow into plants with frilly leaves. Even more, gardening offers the distinct personal satisfaction of knowing the whole story of food that you raise, gather, cook, and eat."(Trubek, 2008)

Terroir itself is not the ultimate goal, but it is a powerful way to enhance satisfaction from food experiences, and increase engagement in intrinsically satisfying behaviors.

Gardening and other personal food activities can lead to increased perceived satisfaction, increased intrinsic satisfaction, and may also contribute to developing 
awareness and the transition to Post-Materialism. Increased food activities can lead to increases in self-efficacy, a contributor to awareness, and may also help motivate engagement in a wider range of intrinsically satisfying behaviors and a transition to Post-Materialism (Doppelt, 2010).

\subsubsection{Research question}

While the concrete focus of this research is food activities, particularly on growing, preparing, and eating food, the theoretical focus is much more closely related to the relationship between materialism and sustainability. Materialism conflicts with sustainability, and, as a paradigm, is very poor at satisfying the psychological needs of individuals.

To adequately explore this topic, the research question had to be broad and general enough to encompass constructed, subjective meanings of the participants, while also keeping the focus on materialism, perceived satisfaction, intrinsic satisfaction, and food experiences. The study participants were individuals who grow, prepare, and eat their own food, such as long-term serious gardeners, and intermediate/starting gardeners. Qualitative methods were used to explore the meaning-making of food activities, materialism, and awareness.

My larger research question (not fully addressed in this research) is: do intrinsic goal-seeking activities such as gardening, preparing, and eating one's own food help individuals become less materialistic and more satisfied? But for the purpose of this study, the data had to be allowed to emerge. The objective was not to look for answers, 
rather it was to capture "rich descriptions of phenomena and their settings" (Bentz \& Shapiro, 1998; Kensit, 2000). Focusing on the phenomenon, the research question for the research was: "Given that food activities are generally non-materialist, how do gardeners perceive and describe their experiences of food projects, including the aspirations and goal attainment of those projects, and their resulting feelings of satisfaction?"

This research question is embedded in historical and cultural mechanisms that reinforce materialism, as well as personal experiences and meaning-making, both subconscious meaning-making and overt, awareness-level meaning-making. These contexts were useful to be aware of, but were not be explored directly in this phenomenological study. Rather, the lived experiences were explored and described, within these larger contexts. 


\section{Article 1 - "Every day there is a food project": exploring the phenomenon of self-concordance for urban gardeners}

Abstract

Self-concordance, that is, internalized motivation, has been shown to increase satisfaction and increase efficacy of goal attainment. Projects involving gardening and food preparation are often internally motivated and provide observable examples of self-concordant experiences. Although research has categorized and quantified motivations for goal attainment, little is understood about motivations of lived experiences and outcomes of self-concordance. To remedy this gap, the current study explored the phenomenon of self-concordance through first person, lived experiences of urban gardeners. The findings suggest that food projects are often: 1) selfconcordant (motivated by both personally important and pleasurable reasons), such as creativity and curiosity, 2) were affected by factors that enabled such as social relationships and disabled, such as financial, and 3) resulted in feelings of satisfaction and competency. The findings from the study help to build theory and to provide direction for potential future research in understanding self-concordance experiences in a variety of contexts.

Keywords: life satisfaction; self-concordance; intrinsic motivations; internalized motivation; gardening and food projects

\subsection{Introduction}

As an example of internally motivated nonmarket projects, gardening and food projects show great promise for increasing the well-being for a broad range of individuals. Gardening and food related activities are inexpensive, have low physical impact, and can 
be enjoyed across a variety of environmental and socioeconomic conditions. With the existence of community and school gardens, those individuals without their own land are able to grow their own food.

Additionally, insight from individual experiences of self-concordant projects such as gardening can deepen understanding of adoption and positive reinforcement of internally motivated nonmarket home projects. This knowledge could be beneficial in policy and sustainability contexts to encourage individuals to more efficiently utilize urban spaces for food production and community building, and in a therapeutic or clinical context to help individuals become physically, mentally, and emotionally healthier through gardening.

While various authors have looked at self-concordance projects (Burke \& Linley, 2007; Koestner et al., 2006; Koestner, Lekes, Powers, \& Chicoine, 2002; Sheldon \& Elliot, 1999; Sheldon, et al., 2004; Sheldon \& Houser-Marko, 2001; Vasalampi, SalmelaAro, \& Nurmi, 2009), there is a dearth of literature on self-concordance and internally motivated nonmarket activities. The purpose of the present study is to better understand the psychological benefits of self-concordant food projects, through the lenses of subjective well-being, self-determination theory, and self-concordance. Through a phenomenological study of urban gardeners in Oregon, we explored the firstperson, lived experiences of urban gardener's food projects. Our results inform the policy efforts on urban gardens and public well-being and contribute to the literature regarding lived experiences, adoption, and constructed meanings of self-concordance. 


\subsubsection{Background}

Intentions and motivations have been differentiated in terms of autonomy versus coercion, with autonomous or internalized motivation positively correlated with psychological well-being (Deci \& Ryan, 2000, 2008a, 2008b; Moller, Ryan, \& Deci, 2006) as well as sustained behavior change and improved performance and effectiveness (Moller, et al., 2006; Reeve, Jang, Hardre, \& Omura, 2002). Additionally, increases in the fulfillment of the psychological needs of autonomy, relatedness, and competency through internalized motivation have been shown to facilitate further internalization of motivation (Deci \& Ryan, 2008b; Weinstein, Przybylski, \& Ryan, 2009).

Self-concordance is a motivation construct that may help explain differences in motivation and how these differences can lead to higher effectiveness in goal attainment and increased well-being. Coercive or externalized motivation is often associated with emotions such as shame, guilt, or environmental pressure; whereas autonomous or internalized motivation, is often associated with emotions such as pleasure or personal importance. In this context, literature about internalized motivation and behaviors is described as Self-Concordance. Table 2.1 highlights the two types of motivations and their associated goals. 
Table 2.1. Self-Concordance in terms of motivations and goals

\begin{tabular}{|l|l|l|}
\hline & \multicolumn{1}{|c|}{ External } & \multicolumn{1}{c|}{ Self-Concordant } \\
\hline \multirow{3}{*}{ Motivations } & $\begin{array}{l}\text { Introjected (shame and guilt) } \\
\text { Environmental (basic needs) }\end{array}$ & $\begin{array}{l}\text { Pleasure } \\
\text { Competency and autonomy } \\
\text { Relatedness }\end{array}$ \\
\hline \multirow{3}{*}{ Goals } & $\begin{array}{l}\text { Buying a large house } \\
\text { Wearing expensive jewelry } \\
\text { Having cosmetic procedures }\end{array}$ & $\begin{array}{l}\text { Gardening and cooking } \\
\text { Creating art } \\
\text { Learning a new language }\end{array}$ \\
\hline
\end{tabular}

Literature on the benefits of self-concordance in goal attainment and internalized motivations positively increasing life satisfaction is plentiful (Burton, Lydon, D’Alessandro, \& Koestner, 2006; Deci, 1975; Grouzet, et al., 2005; Losier \& Koestner, 1999; Niemiec, et al., 2009; Ryan \& Deci, 2000; Ryan, Frederick, Lepes, Rubio, \& Sheldon, 1997; Sheldon \& Elliot, 1999; Sheldon, et al., 2004; Sheldon \& Houser-Marko, 2001; Sheldon \& Lyubomirsky, 2006). Although the theory of self-concordance has been addressed by many researchers, far less attention has been given to lived experiences and constructed meanings of self-concordance, and experiences of adoption and reinforcing of self-concordance. Greater insight is needed into the experiences of selfconcordance; this kind of information may be useful for informing new processes and contexts to increase life satisfaction and goal attainment.

According to self-determination theory (Ryan \& Deci, 2000), individuals set goals based on aspirations, choose behaviors that move towards those goals, attain the goals, and experience increased satisfaction and self-efficacy because of this process. Individuals who pursue self-concordant goals, rather than being motivated by shame or 
guilt or pressure from other people or situations, tend to attain their goals with greater ease. Also, goal attainment with self-concordance leads to more positive increase in well-being than goal attainment without self-concordance (Sheldon \& Elliot, 1999; Sheldon, et al., 2004), Further, self-concordance increases the effectiveness of goal attainment, which leads to increased self-concordance and intrinsic aspirations (Sheldon \& Houser-Marko, 2001). These relationships are illustrated in Figure 2.1.

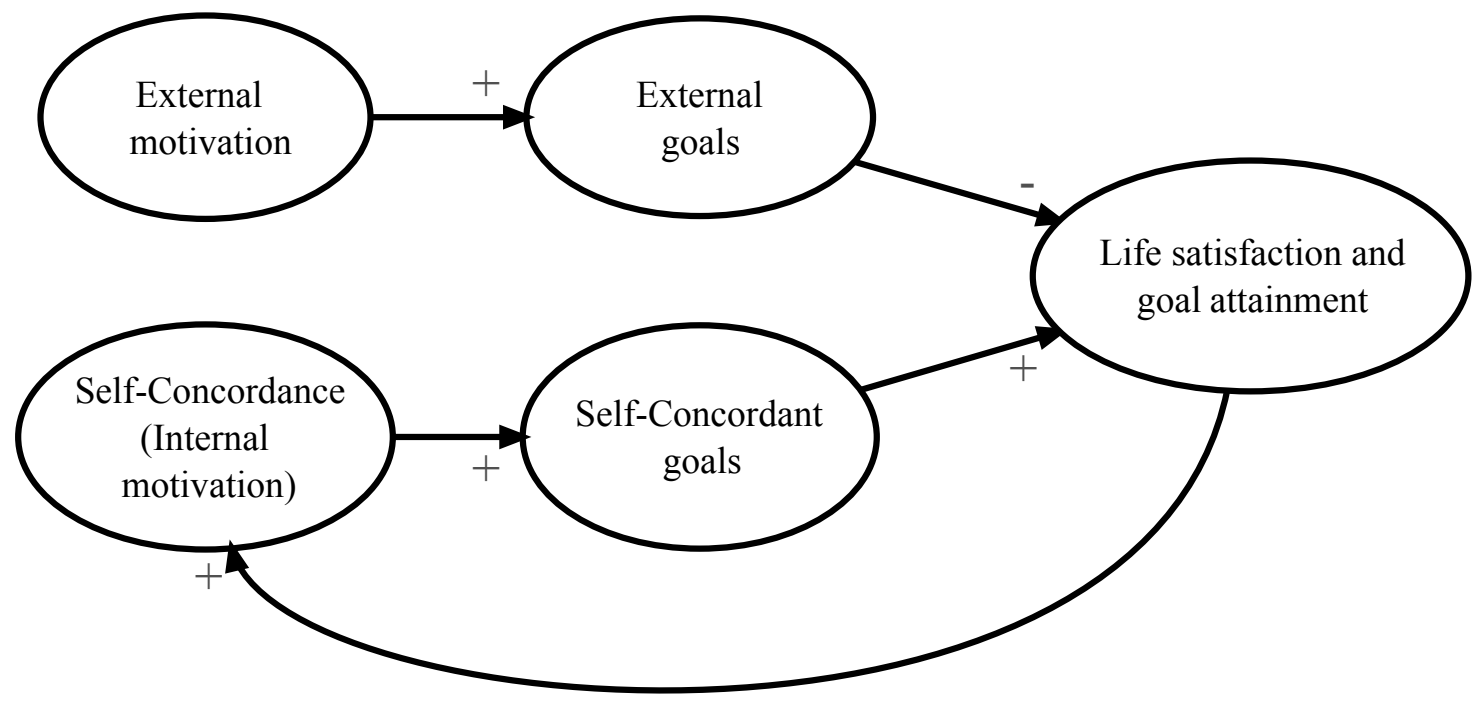

Figure 2.1. Self-concordance in the context of motivations, goals, and life satisfaction

\subsubsection{Gardening and Food}

For many, gardening and food preparation are enjoyable nonmarket activities, but such activities differ from other more passive nonmarket activities such as watching television because gardening is a more participatory and intentional pastime. Gardening may be intrinsically motivated (Cheng, 2010; Hale et al., 2011; Kaplan, 1973), and has also been shown to increase gardener's sense of connection with the natural world, due to the constant and intentional interactions with nature while gardening (Hale, et al., 2011; Kaplan, 1973). 
Garden therapy is sometimes used to help children with behavioral disorders or to gain more environmental awareness (Lautenschlager \& Smith, 2007). Many studies exploring the psychological benefits of gardening focus on mental illness, or connections with nature, or gardening as a catalyst for an ethical awakening (Sumner, 2008; Waliczek, Zajick, \& Lineberger, 2005; Weinstein, et al., 2009). Despite the numerous articles regarding food and gardening experiences, there is a lack of research on gardening as a type of enjoyable nonmarket activity that is internally motivated, and the resulting psychological benefits.

\subsubsection{Self-Determination Theory}

While most research on subjective well-being involves static predictors (Diener, Lucas, \& Scollon, 2009), more recent research is being done on subjective well-being to explore the longevity and sustainability of increases in happiness (Lyubomirsky \& Sheldon, 2005; Schwartz, 2004; Sheldon, Elliot, Kim, \& Kasser, 2001). Subjective wellbeing has been associated with a shift to intrinsically motivated behaviors or actions (Deci \& Ryan, 2000, 2008a, 2008b; King, Hicks, Krull, \& Del Gaiso, 2006; Moller, et al., 2006), increased self-awareness or mindfulness (Bishop et al., 2004), and internally consistent goal-seeking (Deci \& Ryan, 2008a, 2008b; Kasser \& Ryan, 1996; Sheldon \& Elliot, 1999; Sheldon, et al., 2001; Sheldon, et al., 2004). The research explores strategies and processes for sustained increased subjective well-being.

Self-determination theory (SDT) is a psychological, empirically based macro theory involving differentiated types of motivation, psychological needs, goal-attainment, and 
resulting changes in well-being (Deci, Eghrari, Patrick, \& Leone, 1994; Deci \& Ryan, 2008a, 2008b; Moller, et al., 2006; Reeve, et al., 2002; Sheldon, et al., 2001).

Autonomous motivation has been positively correlated with psychological well-being (Deci \& Ryan, 2000, 2008a, 2008b; Moller, et al., 2006), maintained behavior change, and improved performance and effectiveness (Moller, et al., 2006; Reeve, et al., 2002). In turn, increases in the fulfillment of the psychological needs of autonomy, relatedness, and competency have been shown to facilitate further internalization and integration of motivation (Deci \& Ryan, 2008b; Weinstein, et al., 2009).

\subsubsection{Self-concordance and goal attainment}

Self-determination theory has also been applied to goal-seeking processes to explore the role of different types of motivation in the intention-behavior gap. Self-concordance is a motivation construct that may help explain differences in motivation and how these differences in motivation can lead to higher effectiveness in goal attainment and increased well-being (see Figure 2.1). Sheldon states that self-concordance:

Enables individuals to put sustained effort into achieving their goals, helping them to better attain those goals, [and] it makes it more likely that those goals, when attained, will afford the experiences of autonomy, competence, and relatedness that are essential to enhanced well-being (Sheldon \& Elliot, 1999).

Goal-seeking processes appear to be a very promising method to increase subjective well-being because of the implied potential for flexibility and behavioral change. The self-concordance model applies theories from self-determination to longitudinal goal attainment processes, positing that individuals who are internally motivated to seek goals have better subjective well-being, are more effective in their goal attainment, and 
are more likely to engage in more goal attainment processes (Burke \& Linley, 2007;

Burton, et al., 2006; Sheldon \& Elliot, 1999; Sheldon, et al., 2001). Self-concordance has been described as a sense of ownership of goals, and a sense of rightness and fulfillment (Burke \& Linley, 2007; Sheldon, et al., 2004; Sheldon \& Houser-Marko, 2001).

This study used food projects as a context to expand the understanding of the psychological benefits to subjective well-being of self-concordance, as well as explore ways in which self-concordance can be adopted and reinforced. The research question is:

'Given that food activities are generally internally motivated, how do gardeners perceive and describe their experiences of food projects, including the aspirations and goal attainment of those projects, and their resulting feelings of satisfaction?'

To address this question, we interviewed eight urban gardeners, asking them to vividly describe several of their poignant internally motivated food project experiences. The results of this study can inform both policy and clinical therapeutic methods; increasing urban food production is sustainable and fosters community building, and gardening as a therapy is beneficial for mental, physical, and emotional health.

\subsection{Methods}

\subsubsection{Pilot Study}

In October 2009, a pilot study was conducted with four urban farmers. Participants in the pilot study described how gardening and other food activities contribute to their perceived life satisfaction, and how their level of satisfaction from gardening had changed over time. Each participant had a recollection of a specific moment where they noticed a change in their awareness, a moment of awakening, that was often correlated 
with a specific event. The pilot study helped inform the interview procedure for the current study by shifting the focus from changes in awareness to experiences of satisfaction and goal attainment in food projects.

\subsubsection{Primary Study: Recruiting and Participants}

Participants were recruited based on intensity sampling criterion through community gardens in Portland, Oregon. Portland has a strong history of both sustainability initiatives (City of Portland Bureau of Planning and Sustainability, 2006; Grewe, Anderson, \& Butman, 2002) and local food projects \& interest (Bates, 2009; City of Portland Bureau of Planning and Sustainability, 2006, 2011; EcoTrust, 2011), making it an appropriate place to find participants for a study on food projects.

An upper limit of 10 participants is recommended for phenomenological study (Creswell, 2007; Groenwald, 2004), and in this study, saturation was reached at eight participants for the lengthy, semi-structured interviews and in-depth analysis necessary for phenomenology. Primarily, an intensity sampling strategy was employed where participants were sought who had intensely and abundantly experienced internalized motivations so that they could describe their experiences in detail (Bailey, 2007; Patton, 2002). Snowball, or chain sampling was also used, since in a few cases, participants knew of other appropriate participants. See Table 2.2 for demographics of the sample. 
Table 2.2 Demographics of study participants

\begin{tabular}{|l|l|l|l|l|}
\hline $\begin{array}{l}\text { Participant's } \\
\text { Pseudonyms }\end{array}$ & \multicolumn{1}{|c|}{$\begin{array}{c}\text { Work } \\
\text { status }\end{array}$} & $\begin{array}{c}\text { Age } \\
\text { (years) }\end{array}$ & Gender & \multicolumn{1}{|c|}{ Favorite food projects } \\
\hline Sue & Part-time & 56 & Female & $\begin{array}{l}\text { Making pickles, pruning fruit } \\
\text { trees, starting back yard garden }\end{array}$ \\
\hline Annie & Retired & 70 & Male & $\begin{array}{l}\text { Tinkering with bread recipe to } \\
\text { be tasty and whole wheat, } \\
\text { preparing dried chickpeas for } \\
\text { lunch salads, expanding garden } \\
\text { as teenager }\end{array}$ \\
\hline Mike & Retired & 65 & Female & $\begin{array}{l}\text { Finding spice blend for Indian } \\
\text { feast for friends, overly rich } \\
\text { Greek lasagna from food } \\
\text { magazine }\end{array}$ \\
\hline Melissa & Disability & 59 & Male & $\begin{array}{l}\text { Learning to gather wild } \\
\text { mushrooms, buying fresh fish } \\
\text { off the docks, picking } \\
\text { blueberries }\end{array}$ \\
\hline Danielle & Disability & 65 & Female & $\begin{array}{l}\text { Making soup stocks, building } \\
\text { soil using cover crops and layer } \\
\text { method, making bamboo } \\
\text { trellises }\end{array}$ \\
\hline Cathy & Full-time + & 50 & $\begin{array}{l}\text { Planting blueberries in back } \\
\text { yard, cooking pot stickers with } \\
\text { daughter }\end{array}$ \\
\hline Full-time & 44 & Male & $\begin{array}{l}\text { Learning to cook gluten-free, } \\
\text { permaculture garden planning }\end{array}$ \\
\hline
\end{tabular}

Ethical concerns such as prolonged involvement and reflexivity were mitigated as much as possible by the researcher volunteering time and effort at the Learning Gardens Lab and Brentwood Darlington Community Gardens throughout 2012, and continuing more informally at least through Summer 2013. For the purpose of this study, 'food 
projects' were defined as a project involving food, such as preserving, planning and cooking a complex or difficult meal, planning and growing a new type of food, changing diets, or learning a new gardening/gathering skill.

\subsubsection{Interviews and Observations}

Semi-structured interviews were conducted during February and March 2011, and in all cases but one, the interviews took place at the gardener's home. Most interviews lasted between one and just over two hours. The interviews were audio and video recorded, and fully transcribed by the author. Pseudonyms were used for all participants to protect their confidentiality. Interviews with each participant were guided by a question designed to explore the participant's experiences of food projects: 'Tell me about the last time you completed a project involving food and tell me anything you can about the situation, about what you felt, did or said.'

In addition to 104 single-spaced pages of interview transcripts, and audio and video recordings of the interviews, observational data were collected, including 10 pages of field note observations of the participant during and after the interview, 330 photographs, and 20 pages of field note observations of the participant's home and garden spaces.

\subsubsection{Data analysis}

Data analysis began by reading and rereading all the transcripts, to become more sensitized to major themes. Following Moustakas' and Groenwald's recommendations for explication of phenomenological data, (Groenwald, 2004; Moustakas, 1994), each Article 1 Materialism, Food, and Satisfaction 44 
transcript was reviewed and separated into smaller units of meaning, ranging from a few words to a few paragraphs in length, each of which represented an illuminating statement about the phenomenon. Initial coding was inductive, based on particularly poignant statements within the units of meaning. After several transcripts were reviewed, the units of meaning (i.e., data) were iteratively clustered into discrete themes. Other themes were more deductively created, based on the research scope of motivation and goal attainment. A subjective heuristic was used to determine whether or not categories and topics were significant enough to become a discrete theme. Significant themes needed to 1 ) be described by multiple participants, 2) be described as poignant or particularly meaningful, and 3) relate to relevant aspects of the research, such as satisfaction, meaning-making of food experiences, goal attainment, motivations, or challenges.

As more transcripts were reviewed and separated into units of meaning, these data were clustered into existing themes, clustered into new themes, or sometime used to split an existing theme into two or more new themes if the new theme concepts were discrete enough from other themes. As data were grouped into themes, theme hierarchy became evident, with some themes belonging to other themes. Convergence and saturation were reached when many similar units of meaning were found to reflect the same or similar experiences between gardeners.

Calculations such as reliability coefficients are not typically used in phenomenological qualitative research (Groenwald, 2004; Moustakas, 1994). Instead, 
the researcher must rely on their ability to bracket their own presuppositions and integrate the textural and structural descriptions of the essences of the phenomenal experience (Groenwald, 2004), what is sometimes referred to as saturation or convergence. In the context of the participant's experiences of self-concordance and their meaning-making of this phenomenon, a set of themes emerged, representing different aspects of goal-attainment, motivation to start a project, contextual aspects that facilitated or hindered the food projects, motivations to continue working on or complete a project, and the outcomes or effects of completed or failed projects.

\subsection{Results}

Before delving into the motivations behind the participant's goals, a brief description will be given of the scope, types, and durations of the food projects that the participants described (see Table 2.2). Food projects varied in length, from a few hours to build a trellis for the garden, a few days for planning and cooking a special meal, or several months for trying a new gardening technique or growing a new type of food. Also, some projects were primarily gardening projects, such as improving the soil, while other projects were primarily cooking or preserving projects, such as learning a new cooking technique, and still other projects were both gardening and cooking or preserving projects, such as starting tomatoes from seed and then cooking them into a marinara sauce. Learning new skills was also a component of many, but not all food projects. One gardener wanted to acknowledge that they felt that their interest in gardening and cooking were unusually intense: 'I love to cook, I love food, I love to garden...sometimes 
I think about it and I'm like "wow, I'm a bit obsessed." (Annie)

Since the aim of this study was to describe and understand urban gardener's experiences of self-concordance during the goal attainment process, the data are organized by the various stages of this process, from motivations for goal setting and goal setting, achieving or failing to achieve the goal, and the effects of the selfconcordant goal process, shown in Table 2.3.

In addition to the self-concordance aspects of the food projects, many participants described other contextual factors that impacted their ability to complete their food projects successfully. Some of these contextual factors facilitated the success of projects, such as past experiences in growing plants or observing their parents garden, or having friends to do projects with, while other life events and situations hindered the participant's success. 
Table 2.3. Themes: Motives, facilitators, and outcomes of self-concordant food projects

\begin{tabular}{|c|c|}
\hline Phase of food project & Themes \\
\hline \multirow{2}{*}{$\begin{array}{l}\text { Initial Motivations and Goal } \\
\text { Setting }\end{array}$} & Motivated for food projects because of a sense of \\
\hline & $\begin{array}{l}\text { - } \quad \text { Failure or dissatisfaction } \\
\text { - } \text { - Curiosity or adventure } \\
\text { - Self-sufficiency } \\
\text { - Creativity and spiritual connection with nature } \\
\text { - } \quad \text { Sensory and experiential satisfaction } \\
\text { - Past experiences }\end{array}$ \\
\hline \multirow[t]{2}{*}{$\begin{array}{l}\text { Steps Toward Goal } \\
\text { Attainment }\end{array}$} & $\begin{array}{l}\text { Contributing or hindering factors towards goal } \\
\text { attainment }\end{array}$ \\
\hline & $\begin{array}{ll}\text { - } & \text { Learning } \\
\text { - } & \text { Working with friends and family } \\
\text { - } & \text { Being inhibited by health problems, finances } \\
\text { limitations, or time/energy limitations }\end{array}$ \\
\hline \multirow{2}{*}{$\begin{array}{l}\text { Effects of Self-Concordant } \\
\text { Goal Process }\end{array}$} & Outcomes from food projects \\
\hline & $\begin{array}{l}\text { - } \quad \text { Easy and enjoyable } \\
\text { - } \text { Practical and realistic view of available effort } \\
\text { - } \quad \text { Individually tailored goals and actions are } \\
\text { satisfying } \\
\text { - } \quad \text { Feeling strength and confidence } \\
\text { - } \quad \text { Goals make life enjoyable, not burdensome }\end{array}$ \\
\hline
\end{tabular}

\subsubsection{Initial Motivations and Goal Setting}

First, identified motivations were expressed by participants describing their reasons of starting a food project because a) they were dissatisfied with the choices they were making, b) they felt a sense of failure with a past project, or c) they wanted to increase the usefulness or practicality of their food growing, cooking, and preserving efforts. Intrinsic motivations and goal setting were described as a sense of adventure or because of curiosity, a desire to feel competent, a desire to be more creative or to experience a Article 1 Materialism, Food, and Satisfaction 48 
stronger connection with nature, or simply a desire to experience more sensory

pleasure. There were also contextual factors involved in motivation to start a food project, as mentioned above, which were expressed when participants described past experiences they had with gardening, as children and/or with their parents, or with other related activities such as owning and caring for houseplants.

\subsubsection{Learning from past experiences}

After gardening for a few years, several gardeners recognized that they had made choices in the past that they were not happy with, and they saw opportunities to make different choices. Annie described crop rotation mistakes she's made in the past:

Every year it's a new challenge. It's like 'ok, this year, I'm going to do even better,' but sometimes life really does throw you a curve, you know? There's always an opportunity for growth and change and becoming... a better steward of the earth.

Melissa described how she was no longer willing to try to combat garden pests, and has decided to change what she grows:

I'm going to forgo the lettuce this year, that was another thing that I grew, but I'm sick and tired of dealing with slugs. So I'm just going to let it go and do more easy things, and I'll grow more herbs.

Last year, Charles was dissatisfied with letting some of his harvest go to waste: 'You know, it's cool to grow some strange squash, but if I don't ever use it, then what the heck?' And Danielle wanted to make an effort to change her diet for health and sustainability reasons: 'What I'm doing is focusing on cutting back on the amount of meat that I eat.'

Four gardeners had experiences in gardening or caring for plants before starting Article 1 Materialism, Food, and Satisfaction 49 
their own garden. These past experiences were the beginnings of the participant's interest in gardening. As Sue describes: 'Houseplants were the gateway drug to the gardening.' Other gardeners had more extensive childhood gardening experience:

I did a relatively small garden the first year; I was probably 14, that at 15 , the next year, I asked my parents 'Well, can I expand this garden?' (Joe)

And

I went to these garden classes every summer from the time before I was in kindergarten until I was in junior high. (Annie)

These experiences of gardening while they were growing up gave the participants enough of a taste of the experience to want their own garden as adults.

\subsubsection{Practical and Useful}

Similar to Charles' concern about being wasteful, many gardeners focused their efforts on making their gardening and cooking efforts more effective, by increasing the productivity of their garden space, and growing food to store and eat during the winter. Mike explained his gardening strategy: 'I do very intensive gardening. It is very well organized, very well watered, very well planned. I've researched all these varieties over the years.'

Annie enjoys trying to store enough food to last her all winter long: 'I try to grow as many drying beans as I can. Last year I did ok, but you know you can always do more.' And Melissa described how she uses her produce: 'I grow things for the wintertime a lot. So when I'm doing my soup stocks I can get the parsley and I can get the leeks.' She used her stored food in cooking projects. The participants recognized a need for food 
efforts to be practical and/or useful.

\subsubsection{Curiosity and Adventure}

All participants described why they started projects, and increased their efforts towards current projects, out of a desire to be adventurous, exploratory, or because of their curiosity. Joe described his bread-making efforts over the last 10 years:

I think it called for about a 50/50 mix of white flour and whole wheat flour. I've gradually been experimenting with more and more whole wheat and less and less white flour, so now I'm at about, to make three loaves of bread, at about six cups of whole wheat flour and three and a half cups of white flour. And it's the best bread I've ever made. So, I'm going to go farther and farther in that direction.

Charles described his curiosity: 'I like to know why a lot of things. You know, with home brewing I want to know why does this work?' And: 'To me it's just been kind of a fun adventure, seeing what works and what doesn't work.' For him, curiosity fuels some of his other food hobbies, and he enjoys trying out different ideas with gardening and observing the results.

\subsubsection{Competency}

Six of the gardeners described a need for feeling competent as a motivation for food projects. Mike explained that for him, it's a very positive experience to do things for himself, on his own: 'I like doing things with my own hands, making things, taking care of things, and producing things. It feels much more rewarding.' And Annie described competency as follows:

People that I admired most growing up were people that were able to do almost everything for themselves...I think handiness is just a capital positive characteristic. 
Annie thought that being competent is virtuous, and should be encouraged.

\subsubsection{Creativity and Spirituality}

For many gardeners, food activities were a way to experience creativity and spirituality.

Danielle simply said: 'The outdoors is my spiritual practice.' Melissa described a

stronger need to feel at peace: 'I have to have a place where I can just get away from that and put my hands in the earth.' While for Charles, gardening and food projects were exciting because of a sense of wonder, as well as for the creative outlet:

I start with that seed, and look what it produces! The mystery, the spirit, the magic, there is incredible.

And

Brewing is, to me very satisfying, in a lot of ways...it provides that creative outlet for me, which I need, I have a very technical job, I don't have as much flexibility.

Food projects were an important part of Charles' life, and increased his mental health.

Being in their garden and working with food gave participants a sense of peace and tranquillity that some described as spiritual or magical.

\subsubsection{Sensory Pleasure}

All participants had food projects that were described as enjoyable because of the pleasurable sensory aspect. Melissa described making soup, and how enjoyable the activity was for her:

...Then I just let things cook, and it is the best soup stocks I've had...then I get to smell it, and dream about it. I like that, too. I love having my whole place smell; like what I'm cooking. 
And Danielle described another activity: 'I'm excited when I get to dig potatoes; it's like finding little treasures in the ground.' She delighted in harvesting potatoes. Participants found many food experiences enjoyable because of sensory pleasure.

\subsubsection{Steps Toward Goal Attainment}

In addition to goal setting and initial motivations for starting food projects, gardeners also exhibited self-concordance in their descriptions of taking actions to finishing a food project. Participants described actions driven by identified motivations, when they talked about how they sought new information and knowledge, and how they learned from others or through trial and error. The social aspects of food projects were often described as intrinsic. Also, despite internalizing the goals for their food projects, contextual and external events inhibited the gardener's success, which were described as physical injuries and illnesses, financial limitations, work stress, family obligations, and physical energy limitations.

\subsubsection{Learning skills and knowledge}

Learning skills and new information helped gardeners complete their projects.

Gardeners described how they learned more by reading books, learning from others, and trial and error. Mike described how he worked on his project of mushroom gathering, using books and gaining experience in the field:

I already bought a couple of books on mushrooming. They all just looked like brown leaves, autumn leaves, the stuff you'd expect to see under the cottonwoods. Then once you see one, once you find one...then you can start seeing them. 
While Cathy described making copper spheres as garden art:

I graduated, I got bigger and I used a little bigger copper, and then I looked at it, and I went "the copper's too big" So then I got smaller wire and I started over. This wasn't a "I did it right the first time" at all. The garden art actually is something that I very highly prize. And the reason that I can tell you that, and this is very simple, that is, that I made it all myself.

Cathy found this to be a sometimes arduous but necessary experience of trial and error.

\subsubsection{Social relationships}

There was a sensory, simple pleasure to cooking and working with friends, family, and spouses. Sue described an experience she had sharing work with others during harvest: 'One year we had a big garlic harvest festival, where we got all these women to help us clean the garlic, and then we took it down to the barn and hung it.'

Annie was trying to make a recipe, but wasn't sure what one of the spice ingredients was. She described going to a spice shop and working with the owner to try to figure it out: 'I brought in all this stuff from the Internet, and we had a great time discussing herbs. Basically, it's an Indian spice blend.' Charles enjoyed a particularly complicated cooking project with his wife:

One of the most fun things, most rewarding thing I ever made with the wife is soufflé, which is a son of a gun to make.

Food projects with others were described as a facilitator of food projects, when resources such as time, energy, money, and equipment could be shared or borrowed. Projects often involved sharing work with others, either for intense short-term projects like harvesting, or by sharing resources with others. 


\subsubsection{Time, energy, health, and financial limitations}

All participant gardeners experienced challenges or barriers to their food projects, from external sources, or due to unrealistic expectations. Mike explained feeling overwhelmed about taking on too large of a project: 'I had two plots, for a very brief time, for one season, and it was too much work.' For Melissa, the challenge involved wanting to cook food, but not having the right space or equipment:

I moved here and the kitchen is so lousy, it's just like the smallest, dinkiest kitchen, I thought: 'What in the hell am I going to do?'

Danielle broke her leg the summer before she was interviewed, and was worried how her injury might limit her ability to tend her garden:

My first thought when it happened when I woke up from the hospital was that I'd have to give up my garden.

There were many contextual factors that acted as barriers or challenges for the gardeners during participant's food projects.

\subsubsection{Effects of Self-Concordant Goal Process}

Finally, self-concordance was present in the gardener's descriptions of the outcomes of their projects, in both cases that these projects were successfully or unsuccessfully completed. Perhaps because of the internalized nature of self-concordant projects, the gardeners described many of their projects as easy, and were excited about starting more projects as soon as the current ones were complete. They described both the process and the outcome as enjoyable and worthwhile.

The gardeners also described the success or failure of many of their food projects in 
terms of very little stress about the outcome. They were at times unconcerned with planning, and able to quickly recover from a cooking mistake. Also related to selfconcordance, the gardeners described a desire to be realistic about how much time and effort they wanted to commit to their food projects, sometime choosing to eat out at a restaurant when the meal was more effort than they wanted to exert, or choosing to not strictly adhere to dietary restrictions if it became too difficult.

Projects that were successfully completed were described as very rewarding experiences, with increased sense of feeling confident and strong, even when the projects involved dietary limitations because of health concerns.

\subsubsection{Resilience}

Projects were described as easy and enjoyable to complete, with many gardeners excited to start more projects as soon as they complete them. Joe always has some sort of project going, preparing ingredients for future meals, or working in his garden: 'Every day there is a food project.' Annie is relaxed about the amount of work she puts into her garden, and has expectation to match her efforts:

I don't cover anything at the community garden, except for spinach. I don't have time. And there'll just be snow, ice, whatever, it doesn't matter, there'll still be a beautiful head of cauliflower, come May.

She has a similar unashamed attitude about cooking and the occasional bad recipe: 'I'm like "no, I followed the recipe exactly, it's just crap. So...who's going to order a pizza?"' Being realistic about expectations of food projects made them more enjoyable for the participants. 


\subsubsection{Effective}

Gardeners described that they felt that they were able to work on and complete their gardening and food projects effectively; their projects felt easy and were realistic in terms of their time, energy, and financial limitations. For Cathy, she recognizes that she has time and financial limits that her diet changes and cooking projects have to fit into: 'I’m going to be reasonable about eating gluten free.' Projects became more personalized for gardeners as they realized how much they wanted to do their projects, personally. Melissa described how she recognized that other gardeners enjoy different aspects of gardening than she does:

We all like something different when we garden. Some people love to weed. They really love something like that. Some people like to plant, some people like to build. I like to build soil, that's what I like to do.

Danielle described how she is more relaxed when it comes to designing her garden: 'That's what I tend to do with my garden, is I just poke stuff in somebody gives me something, and I say "oh yeah, I'll put it there." I don't do planning as well as some people do.' For both of these gardeners, their projects were satisfying in part because the gardeners could do the projects exactly the way they wanted.

\subsubsection{Strength and Confidence}

As mentioned above, feeling competent, handy and capable was a motivation to start food projects. As described by Sue, competency was a result of completing her favorite food projects, making pickles from cucumbers she had grown:

When you're fermenting, you have to check in with them [your senses] a lot. I like that aspect. I felt very strong. I feel very confident and strong when I'm doing something 
like that. I've been doing pickles for a number of years, and I know when I first started, just like with gardening, I just had so many doubts about everything. It's like 'alright, am I watering too much?' All those things. So I think as I've built confidence, that ... it's like Julia Child: she didn't have really think twice after...she just knew enough to just look at the food, and see the little bubbles and see the little bubbles in the fermenting, I would just slice one open 'alright!' and just that confidence gave me the strength that I knew what I was doing.

Sue enjoyed the feeling of making something herself, and how learning new skills give her more confidence.

\subsubsection{Life Satisfaction}

Food projects that gardeners planned and carried out were described as challenging at times but definitely adding to their quality of life. Joe describes how he feels about his many small food projects to prepare healthy food from scratch for him and his wife, on a daily basis: 'You know, we don't feel hard done by it. We've come to really enjoy what we're eating.' Joe also feels that his efforts growing food are worth it: 'We like the food to be healthful, and we think that what we are getting out of the garden is really optimal.' Melissa described earlier how she enjoys building and enriching her soil:

I know that the quality from the soil we've made is about as good as you're going to get with your produce. And I like doing that.

Melissa enjoyed reaping the rewards of her efforts in the resulting superior vegetables. Table 2.4 shows initial coding efforts and final themes used, listed in the order that the themes appear in the results section. 
Table 2.4. Initial coding and quote topics by theme

\begin{tabular}{|c|c|c|}
\hline \multicolumn{3}{|c|}{ Final Theme: Learning from past experiences } \\
\hline Participant & Type of activity & Initial coding \\
\hline Sue & Keeping houseplants & $\begin{array}{l}\text { Gardening; History with type of experience; } \\
\text { getting more interested; first way to get into } \\
\text { hobby }\end{array}$ \\
\hline Joe & $\begin{array}{l}\text { Expanding garden as } \\
\text { a teenager }\end{array}$ & $\begin{array}{l}\text { Food projects; history of type of experience; } \\
\text { gardening; school projects; rural living }\end{array}$ \\
\hline Annie & $\begin{array}{l}\text { Taking gardening } \\
\text { classes as a child }\end{array}$ & $\begin{array}{l}\text { Food Experiences; History / Getting Started; } \\
\text { Gardening as a child }\end{array}$ \\
\hline Annie & $\begin{array}{l}\text { Always learning } \\
\text { about gardening }\end{array}$ & Challenge; learning/reflecting \\
\hline Melissa & $\begin{array}{l}\text { Deciding to stop } \\
\text { growing lettuce }\end{array}$ & $\begin{array}{l}\text { Food Experiences; Food Projects; } \\
\text { Learning/changing; Trial and Error }\end{array}$ \\
\hline Danielle & $\begin{array}{l}\text { Decreasing the } \\
\text { amount of meat } \\
\text { consumed }\end{array}$ & $\begin{array}{l}\text { Observations; Try to buy less meat and buy no } \\
\text { processed foods }\end{array}$ \\
\hline Charles & $\begin{array}{l}\text { Wanting to use } \\
\text { everything that is } \\
\text { grown }\end{array}$ & $\begin{array}{l}\text { Food Experience; Food Projects; No waste; use } \\
\text { what you grow; fun to experiment, but growing } \\
\text { food to eat; planning what to grow; gardening }\end{array}$ \\
\hline \multicolumn{3}{|c|}{ Final Theme: Practical and Useful } \\
\hline Participant & Type of activity & Initial coding \\
\hline Joe & $\begin{array}{l}\text { Experimenting with } \\
\text { bread recipe }\end{array}$ & $\begin{array}{l}\text { Food projects; food experiences; baking bread; } \\
\text { changing recipes; improving recipe over time; } \\
\text { learning; tinkering; lifelong learning; healthy } \\
\text { baking; whole wheat; thoughtful practice }\end{array}$ \\
\hline Annie & $\begin{array}{l}\text { Preserving bean } \\
\text { harvest }\end{array}$ & Food Projects; Reflecting/goals \\
\hline Mike & $\begin{array}{l}\text { Organized and } \\
\text { efficient gardening }\end{array}$ & $\begin{array}{l}\text { Food Experiences; gardening; Food Projects; } \\
\text { practical; want garden to be productive; ego }\end{array}$ \\
\hline Melissa & $\begin{array}{l}\text { Growing for making } \\
\text { soup stocks }\end{array}$ & $\begin{array}{l}\text { Food Projects; Food Experiences; Gardening; } \\
\text { Preserving Food for winter; Learning different } \\
\text { ways to preserve foods; growing food to } \\
\text { preserve }\end{array}$ \\
\hline
\end{tabular}




\begin{tabular}{|c|c|c|}
\hline \multicolumn{3}{|c|}{ Final Theme: Curiosity and Adventure } \\
\hline Participant & Type of activity & Initial coding \\
\hline Charles & $\begin{array}{l}\text { Trying different } \\
\text { varieties of } \\
\text { vegetables }\end{array}$ & $\begin{array}{l}\text { Food projects; gardening; growing food; trying } \\
\text { different plants; trial and error; fun adventure }\end{array}$ \\
\hline Charles & $\begin{array}{l}\text { Wanting to know } \\
\text { how different home } \\
\text { brewing techniques } \\
\text { work }\end{array}$ & $\begin{array}{l}\text { Food Experiences/Food Projects; enjoying } \\
\text { extra info in cookbooks; curious; want to know } \\
\text { why things work }\end{array}$ \\
\hline \multicolumn{3}{|c|}{ Final Theme: Competency } \\
\hline Participant & Type of activity & Initial coding \\
\hline Annie & $\begin{array}{l}\text { Admiring people who } \\
\text { are handy }\end{array}$ & Being Handy; history \\
\hline Mike & $\begin{array}{l}\text { Enjoying making } \\
\text { things with own } \\
\text { hands }\end{array}$ & Connections; capable; experiential purchase; \\
\hline \multicolumn{3}{|c|}{ Final Theme: Creativity and Spirituality } \\
\hline Participant & Type of activity & Initial coding \\
\hline Melissa & $\begin{array}{l}\text { Need a place to } \\
\text { escape and touch soil }\end{array}$ & $\begin{array}{l}\text { Food Experiences; Gardening as spiritual; } \\
\text { mental health }\end{array}$ \\
\hline Danielle & $\begin{array}{l}\text { The outdoors as a } \\
\text { spiritual practice }\end{array}$ & $\begin{array}{l}\text { Observations; not religious, but spiritual with } \\
\text { outdoors }\end{array}$ \\
\hline Charles & $\begin{array}{l}\text { Home brewing beer } \\
\text { is satisfying }\end{array}$ & Food Projects; Brewing Beer; Satisfaction \\
\hline Charles & $\begin{array}{l}\text { The magic of growing } \\
\text { food from a seed }\end{array}$ & $\begin{array}{l}\text { Food Projects; Gardening; magic of growing a } \\
\text { plant from seed; caring for family with a seed }\end{array}$ \\
\hline \multicolumn{3}{|c|}{ Final Theme: Sensory Pleasure } \\
\hline Participant & Type of activity & Initial coding \\
\hline Melissa & $\begin{array}{l}\text { Enjoying the smell of } \\
\text { soup stock as it cooks }\end{array}$ & $\begin{array}{l}\text { Food Projects; Cooking; making stock; enjoying } \\
\text { the smell of food cooking; sensory experiences; } \\
\text { enjoying anticipating good food as it's cooking }\end{array}$ \\
\hline Danielle & $\begin{array}{l}\text { Enjoying harvesting } \\
\text { potatoes }\end{array}$ & $\begin{array}{l}\text { Food Experiences; Experiential; enjoyable; } \\
\text { harvesting; "finding treasure" }\end{array}$ \\
\hline \multicolumn{3}{|c|}{ Final Theme: Learning skills and knowledge } \\
\hline Participant & Type of activity & Initial coding \\
\hline Mike & $\begin{array}{l}\text { Learning about } \\
\text { mushroom gathering }\end{array}$ & $\begin{array}{l}\text { Food Projects; Learning; Misc. Food projects; } \\
\text { learning from books; learning mushroom } \\
\text { identification; gathering wild food }\end{array}$ \\
\hline
\end{tabular}




\begin{tabular}{|c|c|c|}
\hline Cathy & $\begin{array}{l}\text { Learning how to } \\
\text { make copper spheres }\end{array}$ & $\begin{array}{l}\text { Projects; Learning; Material Possessions; } \\
\text { practicing/trying out a technique, reflecting on } \\
\text { how it worked, trying again }\end{array}$ \\
\hline \multicolumn{3}{|c|}{ Final Theme: Social relationships } \\
\hline Participant & Type of activity & Initial coding \\
\hline Sue & $\begin{array}{l}\text { Community garlic } \\
\text { harvest festival }\end{array}$ & $\begin{array}{l}\text { Food Projects; Growing Garlic; Experience } \\
\text { described }\end{array}$ \\
\hline Annie & $\begin{array}{l}\text { Taking about spices } \\
\text { with shop owner }\end{array}$ & $\begin{array}{l}\text { Food Projects; Challenges; finding ingredients } \\
\text { for recipe; food adventures; Social Food } \\
\text { Projects; talking to shop owner about herbs }\end{array}$ \\
\hline Charles & $\begin{array}{l}\text { Cooking complex } \\
\text { food items with wife }\end{array}$ & $\begin{array}{l}\text { Food Experiences; cooking; cooking with } \\
\text { spouse; challenging recipes; "son of a gun to } \\
\text { make"; Food Project success and failure; } \\
\text { understanding science behind }\end{array}$ \\
\hline \multicolumn{3}{|c|}{ Final Theme: Time, energy, health, and financial limitations } \\
\hline Participant & Type of activity & Initial coding \\
\hline Mike & $\begin{array}{l}\text { Trying to garden two } \\
\text { plots at once }\end{array}$ & $\begin{array}{l}\text { Food Experiences; community gardening; } \\
\text { figuring out right amount of space; how much } \\
\text { work do you want to do }\end{array}$ \\
\hline Melissa & $\begin{array}{l}\text { Realizing that } \\
\text { kitchen in new living } \\
\text { space is too small } \\
\end{array}$ & $\begin{array}{l}\text { Food Experiences; food equipment; renting } \\
\text { house with small kitchen; working with smaller } \\
\text { kitchen that you want; making it work }\end{array}$ \\
\hline Danielle & $\begin{array}{l}\text { Realizing that major } \\
\text { injury impacts ability } \\
\text { to garden }\end{array}$ & $\begin{array}{l}\text { Live Events; gardening is important; challenges } \\
\text { in food projects; injury }\end{array}$ \\
\hline \multicolumn{3}{|c|}{ Final Theme: Resilience } \\
\hline Participant & Type of activity & Initial coding \\
\hline Joe & $\begin{array}{l}\text { Everyday food } \\
\text { projects }\end{array}$ & $\begin{array}{l}\text { Food projects; food experiences; preparing } \\
\text { dinner; left overs }\end{array}$ \\
\hline Annie & $\begin{array}{l}\text { Being practical about } \\
\text { overwintering } \\
\text { vegetables }\end{array}$ & $\begin{array}{l}\text { Food Projects; gardening; Misc. food projects; } \\
\text { overwintering; Practical }\end{array}$ \\
\hline Annie & $\begin{array}{l}\text { Failed recipes, } \\
\text { ordering pizza as a } \\
\text { solution }\end{array}$ & $\begin{array}{l}\text { Food Experiences; Food and life; bad cooking } \\
\text { experiences; practical; not very embarrassed } \\
\text { about mistake; challenges }\end{array}$ \\
\hline \multicolumn{3}{|c|}{ Final Theme: Effective } \\
\hline Participant & Type of activity & Initial coding \\
\hline Melissa & \begin{tabular}{|l} 
Individual \\
preferences for \\
gardening tasks
\end{tabular} & $\begin{array}{l}\text { Food Experiences; Gardening; building soil; } \\
\text { understanding that people have different } \\
\text { gardening styles/interests }\end{array}$ \\
\hline
\end{tabular}

Article 1

Materialism, Food, and Satisfaction 


\begin{tabular}{|c|c|c|}
\hline Danielle & $\begin{array}{l}\text { Gardening without } \\
\text { much planning }\end{array}$ & $\begin{array}{l}\text { Food Projects; not a lot of research or } \\
\text { planning; more trial and error; not a thirst for } \\
\text { knowledge/curiosity driving projects }\end{array}$ \\
\hline Cathy & $\begin{array}{l}\text { Eating gluten free } \\
\text { reasonably }\end{array}$ & $\begin{array}{l}\text { Food Experiences; changing diet with money } \\
\text { concerns; being resourceful about healthy } \\
\text { eating }\end{array}$ \\
\hline \multicolumn{3}{|c|}{ Final Theme: Strength } \\
\hline Participant & Type of activity & Initial coding \\
\hline Sue & $\begin{array}{l}\text { Feeling strong from } \\
\text { making pickles }\end{array}$ & $\begin{array}{l}\text { Food Projects; Pickling Cukes; Growing Cukes; } \\
\text { Feeling strong through experience }\end{array}$ \\
\hline \multicolumn{3}{|c|}{ Final Theme: Life Satisfaction } \\
\hline Participant & Type of activity & Initial coding \\
\hline Joe & $\begin{array}{l}\text { Eating health feels } \\
\text { rewarding, not a } \\
\text { sacrifice }\end{array}$ & $\begin{array}{l}\text { Food experiences; health concerns; being } \\
\text { healthy; exercising; enjoying being healthy; } \\
\text { motivated to enjoy life by staying healthy }\end{array}$ \\
\hline Melissa & $\begin{array}{l}\text { Enjoying high quality } \\
\text { produce from high } \\
\text { quality soil }\end{array}$ & $\begin{array}{l}\text { Produce for People; motivation to get involved; } \\
\text { generosity; community; political; Food } \\
\text { Experiences; Giving best quality produce } \\
\text { because of soil quality; Being extraordinary }\end{array}$ \\
\hline
\end{tabular}

\subsection{Discussion}

Findings indicated that the food project factors and outcomes could be characterized in terms of personally important or practical, pleasurable, and enabling or disabling, and three main themes emerged which describe distinct stages of food projects: motivations and goal setting, actions or step taken toward goal attainment, and the effects or outcomes of food projects. Figure 2.2 shows the factors throughout the food project process. These data suggest that self-concordance in food projects is a multifaceted, complex experience, and food projects, as a nonmarket activity, are strongly intrinsically motivated. 


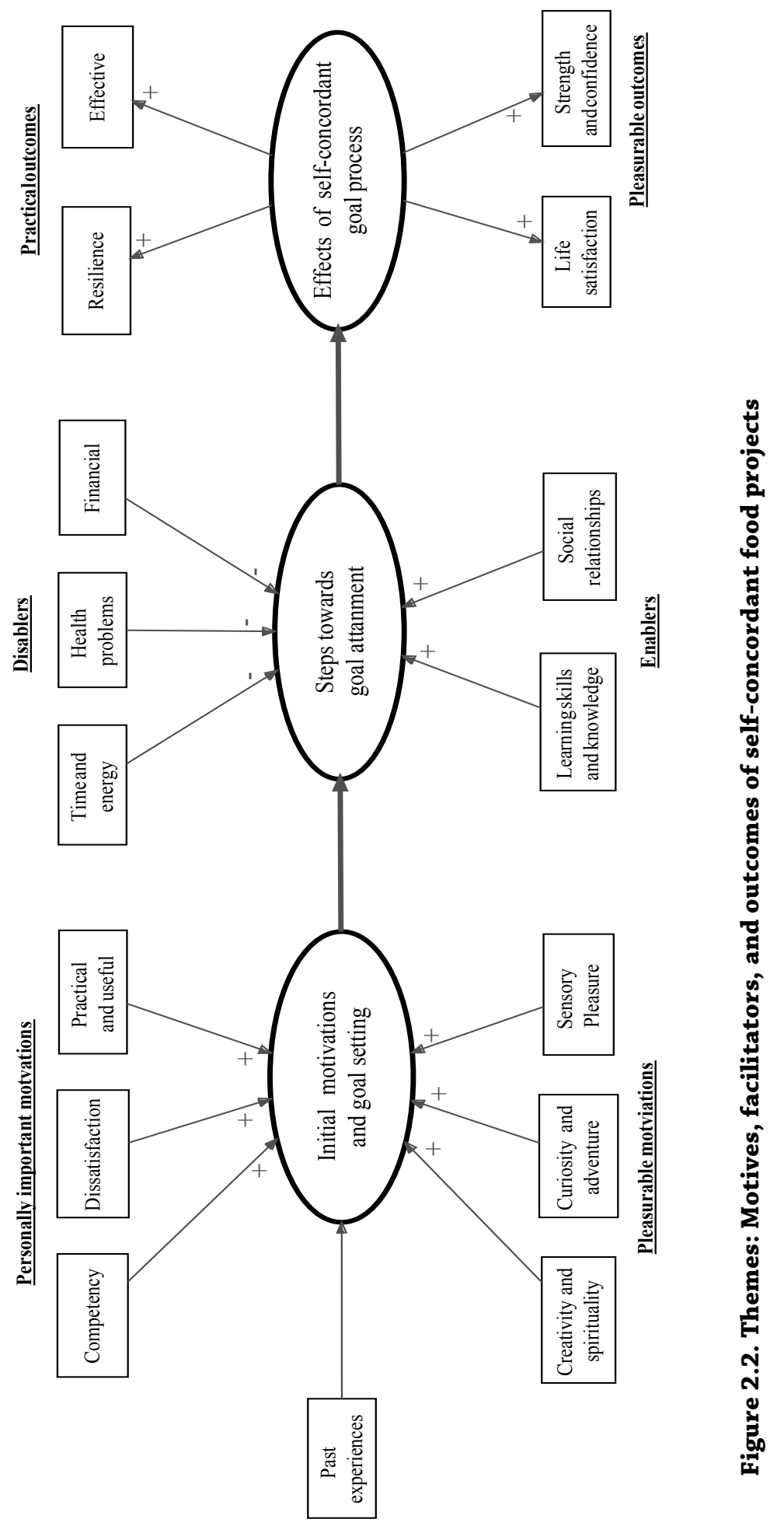

Article 1

Materialism, Food, and Satisfaction 63 
Prior to this study, little was known about self-concordance from a qualitative perspective. This study explored and illuminated urban gardeners experiences of selfconcordance by looking at first-person lived-experiences of food projects. Thick descriptions provided a deeper understanding of the intrinsic, identified, and contextual motivations and outcomes for self-concordance through the process of planning, carrying out, and completing food projects.

The participants in this study were all avid gardeners, but were not necessarily naturally talented at gardening. Rather, their successes in their food projects, and their knowledge and skills about food growing and preparation, came from their natural enjoyment of the tasks associated with gardening and food preparation. Understanding more about the experience of self-concordance in food projects may shed some light on how self-concordance can be encouraged in other hobbies and personal goals, increasing subjective well-being and goal attainment efficiency.

Although self-concordance focuses on motivations for goals and the goal attainment process, in this study it was not always clear in descriptions from the participants that they had completed their projects, or how they felt about completing their projects. Not all projects were structured, discrete, or concrete. Instead, the gardener's foci were more often on the activities and benefits from working on the project. More satisfaction came from working on the project, and enjoying the finished product than on the sense of finishing a project and thus meeting a goal. Ryan \& Kuhl (1997) provide an example of identified (as oppose to intrinsic) motivation: 
A father may perform an activity that aids his child (e.g., changing a diaper) because he clearly sees its importance and necessity for his loved one. In this case, he would be doing the activity autonomously [internally], for self-endorsed reasons, even though he is not intrinsically [hedonically] motivated.

In the present study, descriptions of aspects of the project that used identified motivation to this extreme were rare; food projects described were mainly intrinsically motivated, with minor elements of identified motivations. For example, one motive, a need for food efforts to be practical and/or useful, is identified: activities associated with this motive would not be entirely sensory and experientially satisfying, but the activities are far from being unpleasant. The goal of growing food that will be used results in more food to be enjoyed, and producing the food is generally enjoyable for the gardeners as well.

Although there were several deductive themes, especially involving motivations and goal attainment, one theme, competency, was described by nearly all gardeners, as something that was both a strong motivator and a positive outcome of food projects. Competency is argued to be one of three types of psychological needs within selfdetermination theory (Deci, 1975; Sheldon \& Elliot, 1999), and refers to feeling effective and able in personal activities and behaviors (White, 1959). In terms of their motivations, gardeners described competency as a need for food efforts to be practical and/or useful, and a need to be self-sufficient, and as an outcome of completing projects, gardeners felt stronger and more confident.

Phenomenological studies are not intended to be generalizable, given the small sample size and interpretive process. As recognized by phenomenological research 
guides (Groenwald, 2004; Moustakas, 1994), qualitative research is subject to personal and sample biases, as well as limits associated with self-reporting. This means that: 1 ) when other researchers with a different professional background than the author look at the same data, they may infer different themes; 2) different recruiting methods could have resulted in different themes, and 3) data from participants was limited to the participant's awareness of their own experiences. On the other hand, the qualitative, phenomenological methodology allowed for more complexity and subtlety than a more standard quantitative approach.

Further research is recommended to clarify the intrinsic, identified, and contextual themes that emerged from this study, to more deeply understand the experience of selfconcordance in goal attainment and subjective well-being. Food projects could be explored in more depth, with a larger sample size, using a more deductive research design with the themes that emerged from this study, or another experiential goal attainment context could be chosen, such as woodworking or other artisanal handicraft projects, to confirm these themes, as well as to further explore the relationship between these themes.

\subsection{Conclusion}

This study indicates that gardening and food production are more complex than a series of intrinsically satisfying activities; rather they are often embedded in larger food projects or other goal attainment processes, and are often self-concordant. The motivations and activities that make up these food projects have been shown to be 
mainly hedonic and intrinsic, with identified aspects motivating and facilitating goal attainment. This study also suggests that satisfying a need for competency is a major motivator for gardeners engaging in food projects. The exploratory nature of this study limited the generalizability of these results. Additionally, the demographics of the participants show limited age range and little ethnic diversity. Further research is needed to clarify the relationship between the need for competency and the success of self-concordant goal attainment processes.

The findings support the suggestions that gardening and food activities are more organized and active than other nonmarket activities such as watching TV (Cheng, 2010; Hale, et al., 2011; Kaplan, 1973), and that individual's relationships with food are partially governed by past experiences and other contextual factors (Bisogni, Conners, Devine, \& Sobal, 2002; Bisogni, Jastran, Shen, \& Devine, 2005; Devine, 2003). The findings also expand upon suggestions that motivations for gardening are entirely experiential (e.g., connection with nature) (Kaplan, 1973), by exploring gardening as a set of projects and goals, not just a series of events or activities. This study also built upon previous work done on self-concordance (Deci \& Ryan, 2008a; Kasser \& Ryan, 1996; Sheldon \& Elliot, 1999; Sheldon, et al., 2004; Sheldon \& Houser-Marko, 2001) and self-determination theory (Deci, et al., 1994; Deci \& Ryan, 2008a, 2008b; Moller, et al., 2006), to provide a more in-depth, rich description of how these theories and processes are experienced by individuals.

The results of this study can inform urban food production policy and garden 
therapy methods by more clearly understanding motivations behind gardening and the satisfaction felt by gardening. Gardening is rewarding and satisfying in and of itself as an experience, not just as a means to an end. Gardening and cooking could be promoted as intrinsically satisfying experiences, in addition to encouraging sustainability, community building and mental, emotional, and physical health. 


\section{Article 2 - Mitigating the negative psychological effects of materialism through experiential hobbies: A phenomenological exploration of material possessions of urban gardeners}

\section{Abstract}

We propose that experiential hobbies such as urban gardening may help individuals feel more satisfied, adopt more intrinsic life aspirations, and be less materialistic. Where previous research focused on defining and assessing materialism from a life goals level, this study begins to explore how intrinsic life goals translate into concrete, lived experiences. Phenomenological interviews centered on food activities and material possessions revealed that experiential long term hobbies are highly valued and a source of great life satisfaction for a variety of psychological needs. Results indicated that urban gardeners are not all low materialists, but rather represent a range of low materialists to moderate materialists. Additionally, food activities were found to be mostly intrinsically motivated, as hypothesized, but were also sometimes extrinsic. Exploring urban gardener's richly complex and multi-layered experiences of material possessions and food activities illuminates the continuum of materialism. The data reveal that the need for adopting extrinsic life aspirations is not strongly expressed when other experiential activities, such as gardening and food preparation, are a part of regular life.

Keywords: Materialism, Intrinsic Aspirations, Experiential Activities, Sustainability, Voluntary Simplicity, Urban Gardening 
I take care of what I own. I may not own a lot, but I take care of it. And so it lasts, and it takes care of me. That's a part that I'm very grateful for. I always know that those pair of pliers are going to be there, because every year I sand them down and I oil them. (Cathy)

She's my materialistic girl. 'Diamonds? Diamonds!' That's fine, I knew that [when I married her]. I have a canoe, a pair of hiking boots, that's fine [for me]. (Charles)

\subsection{Introduction}

Consumer culture offers the promise of happiness through acquisition of materials goods. Increasingly researchers and individuals acknowledge that this idea has not only been shown to not live up to the promise but additionally encourages the depletion of natural resources, reduction in biodiversity, excessive waste, and many other negative sustainability outcomes (Burroughs \& Rindfleisch, 2002; Crompton, 2008).

Along those lines, activities related to food production and preparation have gained national attention with increasing focus on healthy food, food production and preparation and diet-related health issues. People's experiences around food activities are another potential source of satisfaction and at the same time can counter the negative effects of materialism. Thus, looking at the relationship between these activities and different perspectives on materialism is an important area for research. The present study was motivated by the desire to understand satisfying experiences of low materialism such as with Cathy, who described how she enjoyed using and caring for her gardening tools, versus Charles' wife who wants precious gems.

Why and how do people become less materialistic? How similar are intrinsically 
satisfying experiences across individuals and across different types of experiences? Research to date does not address these questions adequately, but instead focuses on quantifying the effects of materialism and developing measures for materialism.

Materialism has been shown to be negatively correlated with life satisfaction and psychological well-being (Belk, 1985; Grouzet, et al., 2005; Kasser \& Ryan, 1993, 1996; Richins \& Dawson, 1992; Richins \& Rudmin, 1994). But what, broadly speaking, about being a materialist is different in the way they seek satisfaction? Kasser \& Ryan (Kasser \& Ryan, 1993, 1996) posit that the difference is between extrinsic and intrinsic goals, where extrinsic goals (e.g., financial success, physical appearance, and social recognition) are materialistic and rely on external sources to fulfill psychological needs, through rewards and praises. Intrinsic goals (e.g., self-acceptance, affiliation, and community feeling) are non-materialistic and lead to greater satisfaction of psychological needs, since these goals lead to greater satisfaction regardless of external sources, i.e., other people or events, (see Figure 3.1).

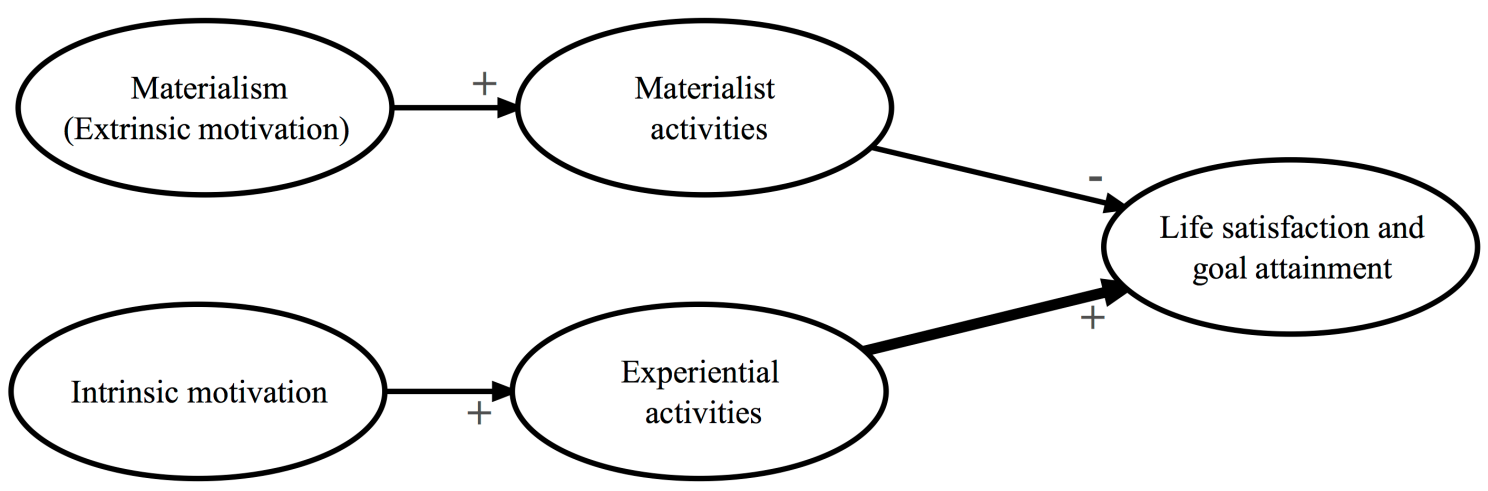

\section{Figure 3.1. Materialism framework}

Behaviors that result in intrinsic satisfaction may vary from individual from 
individual, but research shows a general consensus about the intuitive difference between purchases that are intended for intrinsic or experiential purposes compared to extrinsic or materialistic purposes (Van Boven, 2005). Both may involve purchasing material possessions, but may involve different experiences; intrinsic purchases involve buying a material possession in order to have a life experience, while extrinsic purchase involve buying a material possession as the terminal experience. Intrinsically motivated activities may not always be more sustainable than extrinsically motivated activities; for example, air travel may be highly satisfying, but may not be more sustainable than a more extrinsically motivated activity such as buying luxury clothes. But intrinsically motivated activities show potential in decreasing overall materialist life aspirations and behaviors in favor of more intrinsically motivated and, in general, more sustainable activities.

This investigation sought to find out how intrinsically motivated experiences such as gardening are satisfying, and to understand the continuum of materialistic experiences with possessions. To begin to explore these questions, phenomenological interviews were conducted, comparing and contrasting gardening experiences and experiences of their material possessions. Informed by psychological research on life satisfaction, materialism, gardening, and food experiences, the analysis of these narratives reveals a surprising diversity of descriptions of how and why gardening and food activities are satisfying, as well as a spectrum of types of experiences involving material possessions, from minimalism, distain or indifference, to unabashed desire for 
more acquisition.

\subsection{Literature Review}

In this section, research on materialism and well-being will be synthesized. Two distinct areas of research will also be reviewed, as they relate to the phenomenon of lowmaterialist experiences of possessions and gardening: the barriers to decreasing materialist values and mitigate negative psychological effects, and other methods of researching experiences of materialism.

\subsubsection{Effects of Materialism on Well-Being}

Although desires to consume material goods for non-utilitarian purposes have been present for most of human civilization, it is a recent development that seeking happiness and psychological well-being through consumption has been made available to and has been readily adopted by the masses (Belk, 1985; Crompton, 2008; Kasser \& Ryan, 1993, 1996; Richins \& Dawson, 1992).

Materialistic values and aspirations have been found to be negatively correlated with psychological well-being, happiness, and satisfaction (Kasser \& Kanner, 2004; Kasser \& Ryan, 1993, 1996; Richins \& Dawson, 1992; Richins \& Rudmin, 1994; Sheldon, et al., 2001; Sheldon \& Houser-Marko, 2001). Materialists pursue happiness through acquisition of material goods, but these behaviors typically do not lead to long term increased happiness (Fromm, 1976; Kasser, 2003; Kasser \& Kanner, 2004; Kasser \& Ryan, 1993, 1996; Maslow, 1954; Sheldon, et al., 2001; Sheldon \& Houser-Marko, 
2001; Van Boven, 2005). Unmet psychological needs both motivate materialism and are a result of materialistic endeavors, in a reinforcing cycle of high consumption (Fromm, 1976; Kasser, 2003; Maslow, 1954). Materialism is chosen as a short term, quick fix for unmet psychological needs for a number of reasons, but, as mentioned above, and explored partially below, tends not to be helpful in meeting psychological needs long term, and may actually harm an individual's psychological well-being.

There have been many studies exploring aspects of materialism such as measures or components of materialism (Belk, 1985; Inglehart, 1981; Kasser, 2003; Kasser \& Ryan, 1993, 1996; Richins \& Dawson, 1992; Richins \& Rudmin, 1994; Van Boven, 2005), causes or contributing factors to adoption of materialism and consequences or negative qualities correlated with materialism (Burroughs \& Rindfleisch, 2002; Inglehart, 1981; Kasser, 2003; Kasser \& Ryan, 1993, 1996; Richins \& Dawson, 1992; Richins \& Rudmin, 1994; Schwartz, 2004; Van Boven, 2005; Van Boven \& Gilovich, 2003). There are far fewer studies about ways to limit the effects and adoption of materialism, and little is known about this process (Doppelt, 2010; Pierce, 2000; Schwartz, 2004; Sheldon \& Houser-Marko, 2001).

\subsubsection{Barriers and opportunities to mitigating the effects of materialism}

Literature on interventions to limit negative psychological effects of materialism is limited, although popular writing abounds about the virtues of abandoning materialism and adopting a simpler life (Andrews \& Urbanska, 2009; Beavan, 2007; Carlomagno, 2005; De Graaf, et al., 2001; Elgin, 2009; New American Dream, 2011; Robin, et al., 
2008; Schwartz, 2004). Other qualitative studies have explored experiences of consuming, but mostly focus on why people purchase certain items, or their relationships with the producers or suppliers, and do not ask what else people are doing to pursue happiness as an alternative to consuming (Cotte, Rathenshwar, \& Mick, 2004; Holt, 1995; Maclaran \& Brown, 2005; Zepeda \& Leviten-Reid, 2004).

There are several psychological barriers to people shifting their aspirations and purchase behaviors away from materialism including: 1) a culture of defined needs that far exceeds what is necessary, 2) materialism blindness or unawareness, and 3) hedonic adaptation (Sheldon \& Lyubomirsky, 2006; Sundie et al., 2010; Van Boven, 2005). The prolific nature of advertising feeds expectations that material acquisitions will lead to psychological well-being and reinforces the luxurious definitions of what is needed to fulfill basic needs (Crompton, 2008; de Geus, 2003; Elgin, 2009; Huneke, 2005; Kasser, 2003; Maniates, 2002; Schwartz, 2004). While well-being and set points or baselines can be correlated with circumstances such as geographical locations, genetics, or level of income, some changes in set points are correlated with individual's intentional activities (Sheldon \& Lyubomirsky, 2006). Positive changes in intentional activities are less susceptible to hedonic adaptation, and changes in intentional activities have been shown to increase well-being (Sheldon \& Lyubomirsky, 2006).

Physical distances, historical changes in food culture and expectations about food quality, and other cultural factors have created a mental and emotional disconnect from food (Clayton, 2007; Emmons \& Crumpler, 2000; Emmons \& McCullough, 2003; 
Kristeller, 2003; Petrini \& Padovani, 2006; Pirog, 2004; Trubek, 2008, 2009; Vileisis, 2008; Wakefield, et al., 2007; Waliczek, et al., 2005). These factors inhibit authentically engaging in food as an intrinsically satisfying experience, but gardening may be a way to overcome this disconnect between food production and food consumption experiences.

\subsubsection{Materialism as a phenomenological, lived experience}

There are few studies about ways to limit the effects and adoption of materialism, and little is known about this process (Doppelt, 2010; Pierce, 2000; Schwartz, 2004; Sheldon \& Houser-Marko, 2001). One strength of intrinsic aspirations compared to extrinsic aspirations is that they support self-expression and meeting each individual's psychological needs uniquely, though a vast range of experiences, and are not limited to the amount and type of products available for purchase (Huneke, 2005; Pierce, 2000; Shaw \& Newholm, 2002).

A methodology called existential-phenomenology provides a framework for exploring first-person lived experiences such as materialism, voluntary simplicity, mindfulness, gratitude, and satisfaction (Groenwald, 2004; Maniates, 2002). Phenomenology is a qualitative research method, following the social constructivist worldview in the assumption that individuals create meaning from individuals and objects in their lived experiences, that these meanings are highly subjective, and are embedded in personal, social, and historical contexts (Bailey, 2007; Giorgi, 2006; Groenwald, 2004; Moustakas, 1994; Ragin, Nagel, \& White, 2004; Seamon, 2000). Phenomenological research focuses on thickly described first-person lived experiences, 
to explicate the essence of the structure and meaning of a phenomenon (Giorgi, 2006;

Groenwald, 2004; Moustakas, 1994; Thompson, Locander, \& Pollio, 1989).

Phenomenology can provide some much needed insight into this process by starting with first-person lived experiences of phenomena related to materialism such as happiness, experiential purchasing, and meeting needs. There are a few phenomenological studies exploring the experience of deciding to make a purchase (Thompson, et al., 1989). Others address home, sense of place, and relationships between the environment, people, and their behavior (Russell \& Levy, 2012; Seamon, 1982, 2000). Other qualitative studies have explored experiences of consuming, but mostly focus on why people purchase certain items, or their relationships with the producers or suppliers, not what else they are doing to pursue happiness besides consuming (Cotte, et al., 2004; Holt, 1995; Maclaran \& Brown, 2005; Zepeda \& LevitenReid, 2004).

\subsection{Research Objectives}

The literature review suggests that although there is a relationship between extrinsic life aspirations and materialistic activities and behaviors, there is a lack of in depth understanding of how individuals experience materialistic or non-materialistic activities, and the changes in well-being associated with these activities. This study contributes to filling the gap in literature about materialism topics by exploring phenomenological topics such as satisfaction of psychological needs, experiential activities, and experiential purchasing. Our research aims to explore how gardeners 
perceive and describe both non-materialist and materialist experiences within the context of food activities and material possessions. The goal is to gain a deeper understanding of experiential and materialist experiences, and how intrinsic and extrinsic life aspirations are experienced as activities.

\subsection{Methods}

To illuminate the phenomenon of materialism, the author conducted a series of one-totwo hour interviews where participants were asked about their food experiences as examples of intrinsically motivated satisfying experiences (Kaplan, 1973; Rozin, 2005;

Van Boven, 2005; Waliczek, et al., 2005), their experiences of using existing material possessions, and their experiences of purchasing new material possessions (Holt, 1995; Huneke, 2005). Interviews were conducted in the phenomenological tradition (Thompson, et al., 1989), exploring first-person lived experiences of phenomena related to materialism such as happiness, experiential purchasing, and meeting psychological needs.

\subsubsection{Participants}

Participants were recruited based on intensity sampling criterion (Bailey, 2007; Patton, 2002), through community gardens in Portland, Oregon. An upper limit of 10 participants is recommended for phenomenological study (Creswell, 2007; Groenwald, 2004), and in this study, eight was adequate for saturation for the lengthy, semistructured interviews and in-depth analysis necessary for phenomenology. The sample of eight included a broad cross-section across ages and genders (see Table 3.1). 
Table 3.1. Demographics of participants

\begin{tabular}{|l|l|l|l|l|}
\hline $\begin{array}{l}\text { Participant's } \\
\text { Pseudonyms }\end{array}$ & \multicolumn{1}{|c|}{$\begin{array}{c}\text { Work } \\
\text { status }\end{array}$} & $\begin{array}{c}\text { Age } \\
\text { (years) }\end{array}$ & Gender & \multicolumn{1}{|c|}{ Favorite Material Item } \\
\hline Minimalists & & & & \\
\hline Mike & Retired & 65 & Male & $\begin{array}{l}\text { Framed sketch, made by } \\
\text { participant }\end{array}$ \\
\hline Hedissa & Disability & 59 & Female & Triple steamer from Finland \\
\hline Charles & Full-time & 44 & Male & Xbox, bought for Sons \\
\hline Joe & Retired & 70 & Male & Luxury car \\
\hline Cathy & Full-time + & 50 & Female & $\begin{array}{l}\text { Copper spheres made by } \\
\text { participant }\end{array}$ \\
\hline Sue & Part-time & 56 & Female & Ukulele \\
\hline Materialists & & & & \\
\hline Danielle & Disability & 65 & Female & Bread knife from grandmother \\
\hline Annie & Part-time & 44 & Female & Renovated house \\
\hline
\end{tabular}

\subsubsection{Procedures}

Semi-structured interviews were conducted during February and March 2012, and in all cases but one, the interviews took place at the gardener's home. Most interviews lasted around one hour, while one lasted just over two hours. The interviews were audio and video recorded, and fully transcribed by the author. Pseudonyms were used for all participants to protect their confidentiality. The interviews with each participant were guided by three questions, which were first-person versions of the research question, as is suggested for phenomenological research (Groenwald, 2004; Kvale, 1996), designed to explore the participant's experiences of food and material possessions, to explore both materialist and experiential activities: 'Tell me about the last time you purchased a material possession and tell me anything you can about the situation, about what you felt, did or said,' 'Tell me about the last time you completed a project involving food and 
tell me anything you can about the situation, about what you felt, did or said,' and 'Tell me about the last time you purchased food and ate it, and tell me anything you can about the situation, about what you felt, did or said.'

In addition to interview transcripts, and audio and video recordings of the interviews, observational data were collected, including field note observations of the participants during and after the interview, and photographic and field note observations of the participant's home and garden spaces. At the time of the interviews, observations were made of the participant's living space, including 200 photographs of relevant materialism indicators and 20 pages of field notes. The 104 single-spaced pages of transcripts served as the raw data for interpretation.

\subsubsection{Analytic Strategy}

Following Moustakas' and Groenwald's recommendations for explication of phenomenological data, (Groenwald, 2004; Maniates, 2002), each transcript was read and reread, then reviewed and separated in to smaller units of meaning, ranging from a few words to a few paragraphs in length, each of which represented an illuminating statement about the phenomenon. Initial coding was inductive, based on particularly poignant statements within the units of meaning. After several transcripts were reviewed, the units of meaning (i.e., data) were iteratively clustered into discrete themes. A subjective heuristic was used to determine whether or not categories and topics were significant enough to become a discrete theme. Significant themes needed to 1 ) be described by multiple participants, 2) be described as poignant or particularly 
meaningful, and 3) relate to relevant aspects of the research, such as satisfaction and meaning-making of food experiences or experiences of material possessions.

As more transcripts were reviewed and separated into units of meaning, these data were clustered into existing themes, clustered into new themes, or sometime used to split an existing theme into two or more new themes if the new theme concepts were discrete enough from other themes.

Calculations such as reliability coefficients are not typically used in phenomenological qualitative research (Groenwald, 2004; Maniates, 2002). Instead, the researcher must rely on their ability to bracket their own presuppositions and integrate the textural and structural descriptions of the essences of the phenomenal experience (Groenwald, 2004), what is sometimes referred to as saturation or convergence. Through the theme exploration process, units of meaning were occasionally reassigned to a different theme, to increase the saturation of themes, and to aid in settling on a parsimonious set of themes.

\subsection{Results}

Research findings contrast how urban gardeners experienced materialist and nonmaterialist aspects in their lives. Food experiences were explored, as well as other intrinsically motivated nonmarket activities. When describing experiences of material possessions, some urban gardeners described strong minimalist, anti-materialist sentiment, while others described hedonic, intrinsically satisfying experiences with material possessions, and still others described materialist tendencies. Given this 
continuum, study participants were characterized as either minimalists, hedonists, or materialists. Minimalists were characterized by their avoidance of owning many possessions. Hedonists were characterized as living a good life and enjoying using material possessions and other physical pleasures. Materialists were characterized by their need for, and attachment to, material possessions to create meaning in their lives. For example, although Cathy lived in a small space with few possessions, she enjoyed her possessions immensely, and wanted to have as many sensory experiences as possible, which indicated that she was more of a hedonist than a minimalist. This spectrum of materialist and non-materialist experiences will be explored in more depth below.

\subsubsection{Mike (Minimalist): retired artist, enjoys the simple life}

Mike is a Jewish 65-year-old retired nurse from New York. He started gardening when he retired nine years ago, although he had been harvesting berries and fruit in the wild and at pick-your-own farms for many years, as well as buying fish fresh from the fishermen on the Oregon coast, and going mushroom gathering. Since retiring from nursing, he had become an artist and has had his drawings and paintings shown in galleries. For him, art was about expressing anything about which he felt strongly.

\subsubsection{Food Experiences}

Mike enjoys gardening, and he enjoys eating the food that he's grown, but he is also concerned with his efforts being efficient and practical: 
I like to have things that are very, very, very productive. I like to pick a lot of my own stuff, because it's delicious. So it has to be...I do very intensive gardening, it's very well organized, very well watered, very well planned. I've researched all these varieties over the years.

Even with very pleasurable activities like gathering and cooking wild mushrooms, he likes to keep things simple and have just enough food, not too much:

Get the butter hot, and cooked, and then we ate them, just like that. We didn't have to pick massive quantities, but we had a good meal.

And

I had never canned, so I got the help of a woman friend, and told her I was petrified, and she said 'I'm going to hold your hand.' We made a couple of batches of dilly beans and they were delicious, but it was miserable. I gave up canning. The whole thing, I never did it enough to get over my fear of it.

More than keeping things simple, Mike found it stressful when food activities got more complex, and when responsibilities became a burden.

\subsubsection{Material Possessions Experiences}

Mike proudly presented his favorite material possession: a framed, abstract charcoal sketch of his partner, represented by jagged, frenetically drawn dark lines. He described his experience of deciding to take up art:

I went to nursing school, and became a nurse, and then I got disenchanted with that. I had always liked drawing well, and I had some money saved up, so I just decided that I would draw. I had one memorable teacher who told me, he said 'draw things that you absolutely love, or you absolutely hate. Just forget about trying to draw the rest.'

He was also overtly scornful for non-practical or impersonal material possessions:

I don't have a car, [my partner] does. I obviously use it sometimes. I bike. I don't care much about material things. I like doing things with my own hands, making things,

Article 2

Materialism, Food, and Satisfaction 
taking care of things, and producing things. It feels much more rewarding.

He also had intense dreams about being homeless:

My relationship with material things...I have nightmares about being homeless, an unstable existence. I have continuing nightmares, not the same one all the time, about being homeless for one reason or another. That...is a fear that is...below the conscious. I'm sort of aware of it, but if I dream about it so often it must be deeply.

While he was scornful of being burdened by too many possessions, he also has strong feelings of insecurity, which manifested in his frequent dreams of becoming homeless.

\subsubsection{Melissa (Minimalist): renter with a digestive condition, enjoys sparse comfort}

Melissa is a 59-year-old single woman who lives alone and had had a digestive condition that greatly restricted what she could eat; she also has to stop using manures in her gardening to avoid blood infections. She has gardened for over 20 years, but only at community gardens since she has always rented her living space. She is on disability because of her medical condition, although in the past she had worked in food preparation. Also, her mother was dying, and she was responsible for her mother's hospice care as well as clearing out her house and sorting through all of her mother's possessions.

\subsubsection{Food Experiences}

Because of her medical condition, Melissa often donates what she grows. For Melissa, gardening is satisfying not just for the food she could eat, it fulfills her needs to be outside, get physical exercise, and connect with nature: 
A lot of times I just give [the vegetables that I grow] away. I have to do it. It's just communing, communing with nature. I like to be around the bees and birds. I like when they are happy. They are just ignoring you. They are just doing what they are doing.

Gardening serves as stress relief, and the experience of gardening is much more important to Melissa than the vegetables, berries, and flowers that she got out of her garden:

I have to have a place where I can just get away from that and put my hands in the earth. It's basically like doing Qi Gong, or meditation, when you're working.

Although Melissa gives away most of what she grows, she does enjoy cooking soup stocks and other foods that she can eat:

I've learned, I'm a slow cooker, I have the slow cooking mentality. Part of what I do is a feeding line, and I get a lot of my nutrition from the feeding line. I don't need a lot of what I grow, but it has to have really good flavor.

Quality is very important to her, and she is very thoughtful and methodical about her cooking projects.

\subsubsection{Material Possessions Experiences}

When asked what her favorite material possession was, Melissa described how she is very attached to a special distilling pot that she used to make soup stocks and concentrated berry juice:

I think my cooking pans, I have to have that stuff. [I love my distiller], that's how I do the raspberries, that's how I do a lot of things. You can distill it down to a concentrate, and then you can freeze that, then you can bag that. 
While Melissa sees her pots and pans as essential, she sees many of her other possessions as a burden:

Stuff, yeah...the fun stuff is anything that's grown. The not so fun stuff is having all these inanimates. Some people just love to decorate it all up. But it gets messy for me, so less is better. I'm not even there yet. I've pared down a lot already. I think on this last move I got rid of a third, and I'd like to get rid of a third more.

Material possessions are a burden for Melissa, especially because of her somewhat frequent moving, and because of the additional time needed to keep things tidy and maintained.

\subsubsection{Charles (Hedonist): beer home brewer, enjoys providing for his family and savoring food}

Charles is a married 44 year old engineer and father of two. Although his parents were avid gardeners when he was growing up, he was entirely ambivalent to gardening and cooking. He started brewing beer when he was living in Texas to save money and have access to high quality beer, and then picked up gardening. He is eager to teach his children how to be self-sufficient, appreciate good food, and to understand where their food comes from. His wife doesn't always share his enthusiasm for food production and the occasional mess that comes with it.

\subsubsection{Food Experiences}

Savoring an experience and sensory pleasure were both very important to Charles in his food experiences:

I find things enjoyable in life really are sensual. That, what you feel, what you taste, what you touch. That, to me, is it. It really is. So food to me is so important, because 
it's such a sensual thing.

Charles brews beer and enjoys gardening. He described how important it is to him to feel creative and feel a sense of wonder:

When I brew, I don't use any automation, it's all just me brewing, and kind of that mystery of it. I guess I call it the magic of it. But I just want to be... as bare bones, as down to earth, as old school as possible. [With gardening], I start with that seed, and look what it produces! The mystery, the spirit, the magic, there is incredible.

Charles has had a few surprising gardening projects:

The first project of my own is that I over-planted tomatoes, and didn't realize how big they would be here, there were so many tomatoes! And the wife, she has some input, she likes to see more orderly type of layout in the garden. And what happens with tomatoes is that they get kinda gangly on you and go kinda crazy. And she did not, doesn't like it when they go crazy.

Sometimes Charles' enthusiasm for gardening and providing good food for his family is in conflict with his wife's desire to keep their house and yard looking tidy.

\subsubsection{Material Possessions Experiences}

Charles' favorite material possession is the Xbox video game console that he bought for his sons as a holiday present. At times, his game playing was a source of conflict between him and his wife because of poor time management and his engagement in the game experience:

Well, it's the kids', but, you know, I get to use it, it's Dad's time. Playing Xbox video games, head to head, especially with another person, that's something I really enjoy, I really do. That's a fun thing to do. I can get sucked in for hours. It has been an issue between me and the wife, for a period of time, it's gotten a lot better, because I don't do it as often. 
Charles and his wife have vastly different experiences of their material possessions:

She's my materialistic girl. 'Diamonds? Diamonds!' That's fine, I knew that [when I married her]. I have a canoe, a pair of hiking boots, that's fine [for me].

Charles is quite aware of these differences between him and his spouse, and accepts that they must make compromises about how to spend their money.

\subsubsection{Joe (Hedonist): Jet setting retiree, enjoys a tidy home and driving his luxury} car

Joe is a Canadian-born retired professor, who moved to Portland to retire a few years ago. Since retiring, he and his wife have been going on many 'once-in-a-lifetime' international tours and cruises, and spend much of their time when they are not traveling skiing, cooking, gardening, and going to the gym. He has also bought a new sports car that he enjoyed taking out for drives. He is wealthy enough to have bought his house, vacations, and car outright.

\subsubsection{Food Experiences}

Between his wife and him, Joe is much more involved in growing and preparing food. When they got married, Joe had more cooking experience, so he became the family cook. But he didn't mind, he likes spending his time gardening and cooking:

I do most of the cooking in our family. I really like to cook. Even when I was working, I found time to prepare stuff. For me, the time I spend in the kitchen is not a drag. Obviously I enjoy cooking, otherwise we'd eat out more, or make lighter fare than I prepare.

As he's gotten older, Joe has become more concerned about preparing healthy foods for him and his wife: 
To sum up our attitude about food, we like the food to be healthful, and we think that what we are getting out of the garden is really optimal, because the garden produce is organic, for one reason, the community gardens don't let you use commercial fertilizers or pesticides. So you know it's organic. And even the flavor is better.

While he enjoys gardening as an activity, he also values the high quality of food that he can get out of his garden plot.

\subsubsection{Material Possessions Experiences.}

Joe's prized possession was his Porsche that he bought new five years prior. He kept his car in his garage, under a protective cover:

You can see how I love it, because its covered up. I thought about it for three or four years, and, in fact, here's a quote, Sarah said to me 'Well, for heaven's sake, if you're not going to buy it now, when are you going to buy it?' And I was 65, and I understood.

Joe and his wife have realized that they really enjoyed traveling, and that even though international trips are costly, it is worth it for them to have such enjoyable experiences:

Well we've always traveled, but now we're doing, what some people might consider a once-in-a-lifetime trip, but we tend to do these each year, because we've got the time, and we can afford it, and we're getting older, so we don't want to procrastinate.

Since he is getting older, Joe has shifted his ideas about money from a more conservative approach to more of a seize-the-day approach.

\subsubsection{Cathy (Hedonist): Spiritual garden artist, enjoys eating seasonally and gluten- free}

Cathy is a 50-year-old single woman, who lives by herself in a 400 square foot studio apartment. She has recently moved and was excited to have an entire apartment for herself. She works more than full-time at two different jobs, and has recently started to 
eat gluten free on a modest budget. She enjoys having her own space, and worked to maintain physical and mental space in her life for the things she really enjoys, such as gardening, arts and crafts, and writing. It is also very important to Cathy to incorporate metaphysical symbols and themes into her projects and her life in general.

\subsubsection{Food Experiences}

Cathy described how intense and positive her experiences were of eating her garden produce, especially after she started getting most of her vegetables from her garden, eating more in season vegetables, and using more organic soil amendments:

I notice that my peas are very sweet. All the produce is sweet. It's not that it's sweet, it's sweet because it's sweet and because I can taste all the nutrients in the produce. And then, then I'm just exceedingly grateful, because what comes out of the soil is all this fabulous produce. Because I eat seasonally, by the time something comes into harvest, I'm like 'I'm so ready! I'm so ready for this food!'

She enjoys feeling a strong connection with the food she prepared and ate. She described a particular time when she prepared zucchini bread for a friend's holiday party:

They didn't realize that it took a year of planning to make that zucchini bread...It's not just, you know, let me go buy some zucchini. The gardening plan, to make sure that it's there, all the things that go into that, revolve around what a good experience that's going to be.

Cathy felt mindful about all the work that went into that food item, and she also felt somewhat disconnected from other people who were not as engaged in food as her.

\subsubsection{Material Possessions Experiences}

Cathy immediately knew her favorite material possession; she had made two spheres 
out of copper wire, that were in metaphysically important shapes:

So this one is a Heliosphere, that's what it's called. They come from the solar winds, and the solar...the solar things. So, here's how you make the Heliosphere. [Showing a diagram from the garden book] this is the Genesa crystals, and that's how you make it. And let me tell ya, they're hard to create. There's some crimps that I didn't get quite right, you can see those too.

She treasures her material possessions:

I may not own a lot, but I take care of it. And so it lasts, and it takes care of me. I always know that that pair of pliers are going to be there, because every year I sand them down and I oil them.

She takes care of what she owns so they will last longer and she can continue enjoying using them, like her garden pliers that she maintains at the end of the summer garden season.

\subsubsection{Sue (Hedonist): former farmer, enjoys feeling connection to her food and making music}

Sue is a semi-retired, 56 year old woman living with her female partner and is a garden manager at her community garden. She had a large garden in her back yard as well as a plot at the community garden. In the past, she had lived with a women's farming collective and tried unsuccessfully to start a Community Supported Agriculture cooperative. She has a high level of awareness about her food, and tries her best to eat local, organic, and ethically raised foods.

\subsubsection{Food Experiences}

Sue has recently started growing cucumbers so that she could pickle them. She enjoys pickles, and was hoping to pickle enough of them to replace the pickles she would buy 
from the store. The process was very satisfying to her, to feel more connected with her food and feel capable of large food production projects:

I just love that, I love that feeling 'ooo, I GREW all of these! I grew all of this, I put it all up.' So it's a big process, and it just makes me feel good. When you're fermenting, you have to check in with them [your senses] a lot. I feel very confident and strong when I'm doing something like that.

Sue took a trip to Italy many years ago, and she had fond memories of the food culture during her time there:

I'm waiting, and then all of a sudden, the waiter came towards me with this basket, and I thought 'Oh, they're bringing me bread.' The waiter is putting the basket in front of me, and I'm looking, and it was the mushrooms, and I got to choose my mushrooms for my dinner. It was a fantastic dinner. I think it was because they were just so proud and so connected to their food.

Sue appreciated the focus on connection and relationship with food, and the slower pace taken to savor food.

\subsubsection{Material Possessions Experiences}

Sue's favorite material possession was her Ukulele. She bought a cheap one first, to see if she enjoyed playing it, before buying her current more expensive instrument. She described how she loved playing music with friends:

My friend started us all on Ukuleles; we used to get together, on a number of nights. We could just play for hours, and sing, it's just very fun.

Besides her Ukulele and a new food processor she had gotten recently for her birthday, Sue wasn't eager to talk about her material possessions:

Gardening is definitely a part of my life. I love it. If you look around the house, you can 
see a lot of houseplants. And I thought, 'Houseplants were the gateway drug to the gardening.' I would have every window filled if I could.

Sue had a collection of houseplants that she was proud of, and her house had many personal belongings in it, but was not particularly luxurious or cluttered.

\subsubsection{Danielle (Materialist): broke her leg, enjoys feeling a connection to the past}

Danielle is a married 65-year-old gardener whose husband was a hoarder. She broke her leg the spring before the interview, had to leave her job as a cook, and had to get help from her friends to plant and tend her garden. She was not sure if she would return to her job after her leg heals. Danielle's parents were working class; her father hunted and fished, and they often went camping for vacations.

\subsubsection{Food Experiences}

Despite her leg injury, Danielle spent time and energy in her garden, and enjoyed her time gardening and cooking. She especially enjoyed harvesting potatoes:

I love growing potatoes, so I'm excited when I get to dig potatoes, it's like finding little treasures in the ground. Then everywhere you've planted them around the garden you have volunteers forever after.

But she didn't always spend the time she needed to keep up with her endeavors. She tried composting at her home once, and it didn't go very well, she thought it was a good idea, but didn't follow through with maintenance:

I got one of those rotating compost bins that somebody had and decided that they didn't like, and I just found it an awful lot of trouble to get it to work. Because you have to have just the right mix of brown and green. So that's sitting in my back yard with blackberries vines growing over it. It's hard to keep that up. 
It was important for Danielle to feel like she has enough food:

I do a lot of grocery shopping. That's the shopping that I do. Grocery shopping. Oh, I always have a house full of food.

Danielle enjoys shopping for food, and she tries to make sure she buys high quality, tasty food.

\subsubsection{Material Possessions Experiences}

Danielle carefully unwrapped her favorite material possession; a knife that belonged to her grandmother:

It's very useful. We don't buy our bread pre-sliced. I have this and one other knife, and this is my go-to knife. It's something that my grandmother gave me.

Similar to the kitchen equipment inherited from her grandmother, Danielle felt very sentimental about her first bicycle:

I had a bicycle that I got for my eighth birthday. I had that bike until I went to college, same bike. While I was at college, my parents had a garage sale and sold it. And I was just really devastated, you know 'How could you even think of selling my bike?!'

Danielle's husband hoards things, and she sometimes daydreams about living in a space with less clutter:

I've often fantasized...there's so much clutter everywhere. [My husband] buys books, he's got a ton of books. I do have a lot of books that are mine as well. My fantasy is to get rid of everything, and he's trying to hold onto everything.

Although Danielle felt strong sentimentality about items, she also feels overwhelmed by the amount of possessions that are in her house. 


\subsubsection{Annie (Materialist): Survivalist with a big heart and a big house}

Annie is a married 44 year old part-time hospice grief counselor. She started gardening classes when she was four, and has had her own garden in various ways since then. She is a garden manager at her community garden. She and her husband are both concerned about food security and disaster preparedness, which motivates them to continue to become more self-sufficient.

\subsubsection{Food Experiences}

As a garden manager, Annie wanted to take care of everyone. She wanted to inspire other gardeners, teach them skills, and share her extra produce with her neighbors, friends, and those less fortunate than her:

I grow a lot of stuff and then put as much aside as I can. And I share our garden. I have this, I don't know if it's a disorder, it's like 'I need to grow more stuff and then I have too much. We don't have any children, and one needs to nurture. It's my mission to try and help people to feel excited about this stuff, however they choose to be excited about it.

As part of her desire to nurture, she enjoyed cooking for others:

We made Indian food for a couple of friends who came over a few weeks ago. It was colossal. Rick and I did it all. The whole shootin' match from scratch. And we had these friends over. The one gal, she cooks a lot, and she's a real foodie, so I was really trying to impress her. It worked.

Annie seemed motivated to cook for others and nurture others to strengthen social relationships, and also to be admired and for status. 


\subsubsection{Material Possessions Experiences}

Annie's favorite possession was her house:

I fell in love with this house for a bunch of reasons. It was for sale, it was something we could afford, because it was almost a teardown. It was a wreck! We've redone every single floor in this house, tore it down to the studs almost. It's not just the building, it reflects my husband and I as people, and how we express ourselves artistically.

And:

We lived in a tiny little house. There's this adorable little yellow house with an adorable little yellow garage. That was my house that I had when I met [my husband]. That house was really small. I wanted a bigger house. I grew up in a great big house. I like lots of rooms that I don't even go in most of the time. I'm weird that way. It's like I covet space.

Although Annie values her house as a manifestation of personal expression, she also bought her house because wanted a larger house; a house with lots of space that felt spacious beyond being practical. Table 3.2 shows initial coding efforts, listed in the order that the quotes appear in the results section. 
Table 3.2. Initial coding and short description of quotes, sorted by materialism spectrum and participant

\begin{tabular}{|c|c|}
\hline \multicolumn{2}{|l|}{ Mike-Minimalist } \\
\hline Short description & Initial Coding \\
\hline $\begin{array}{l}\text { Organized and efficient } \\
\text { gardening }\end{array}$ & $\begin{array}{l}\text { Food Experiences; gardening; Food Projects; practical; } \\
\text { want garden to be productive; ego }\end{array}$ \\
\hline Cooking fresh mushrooms & $\begin{array}{l}\text { Food Experiences; savoring; eating a lot; gathering } \\
\text { mushrooms; eating what you've gathered; quality over } \\
\text { quantity }\end{array}$ \\
\hline $\begin{array}{l}\text { Trying to learn to can green } \\
\text { beans }\end{array}$ & $\begin{array}{l}\text { Food Projects; learning from others; scared to learn, but } \\
\text { interested }\end{array}$ \\
\hline $\begin{array}{l}\text { Using savings to spend time } \\
\text { drawing }\end{array}$ & $\begin{array}{l}\text { Not Materialistic; devoting time to experiential } \\
\text { activities; financial security; drawing }\end{array}$ \\
\hline $\begin{array}{l}\text { Enjoying making things } \\
\text { with own hands }\end{array}$ & Connections; capable; experiential purchase \\
\hline $\begin{array}{l}\text { Nightmares about being } \\
\text { homeless }\end{array}$ & Stress; fear of financial insecurity \\
\hline \multicolumn{2}{|l|}{ Melissa-Minimalists } \\
\hline $\begin{array}{l}\text { Communing with nature } \\
\text { while gardening }\end{array}$ & $\begin{array}{l}\text { Food Experiencing; gardening; being outside; spiritual; } \\
\text { communing with nature }\end{array}$ \\
\hline $\begin{array}{l}\text { Need a place to escape and } \\
\text { touch soil }\end{array}$ & Food Experiences; Gardening as spiritual; mental health \\
\hline Growing flavorful food & $\begin{array}{l}\text { Food Experiences; Cook/grow food for high flavor; } \\
\text { don't eat a lot so must be high value with good flavor }\end{array}$ \\
\hline $\begin{array}{l}\text { Attachment to cooking pots } \\
\text { and pans }\end{array}$ & Material Possessions; favorite stuff; food equipment \\
\hline $\begin{array}{l}\text { Wanting to get rid of more } \\
\text { stuff }\end{array}$ & $\begin{array}{l}\text { Materialism; Less is better; want to get rid of third of } \\
\text { stuff; pairing down }\end{array}$ \\
\hline \multicolumn{2}{|l|}{ Charles - Hedonist } \\
\hline Short description & Initial Coding \\
\hline Food is sensual & $\begin{array}{l}\text { Food Experiences; Things enjoyable in life are sensual; } \\
\text { Food is a sensual thing; value sensual/experiential } \\
\text { aspects to life; }\end{array}$ \\
\hline $\begin{array}{l}\text { The magic of home brewing } \\
\text { beer }\end{array}$ & Food Projects; Magic; Down to Earth \\
\hline Overplanting tomatoes & $\begin{array}{l}\text { Food Projects; Gardening; orderliness; visually } \\
\text { appealing garden; not messy }\end{array}$ \\
\hline
\end{tabular}




\begin{tabular}{|l|l|}
\hline \multicolumn{1}{|c|}{ Short description } & \multicolumn{1}{c|}{ Initial Coding } \\
\hline $\begin{array}{l}\text { Getting sucked into playing } \\
\text { video games }\end{array}$ & $\begin{array}{l}\text { Hobbies/Activities; Materialism; Enjoying video games; } \\
\text { being absorbed/sucked into activity; losing track of } \\
\text { time }\end{array}$ \\
\hline $\begin{array}{l}\text { Using children's video game } \\
\text { console }\end{array}$ & $\begin{array}{l}\text { Hobbies/Activities; Materialism; Favorite Possession; } \\
\text { Xbox; using/enjoying your kid's toys/stuff }\end{array}$ \\
\hline $\begin{array}{l}\text { Wife is materialistic, enjoys } \\
\text { diamonds }\end{array}$ & $\begin{array}{l}\text { Materialism; different values than spouse; (gender bias? } \\
\text { thinks women are highly materialistic and that's ok); } \\
\text { values difference; materialism is feminine? }\end{array}$ \\
\hline Joe - Hedonists & $\begin{array}{l}\text { Food experiences; cooking; making time to cook; being } \\
\text { busy; enjoying spending time in the kitchen }\end{array}$ \\
\hline $\begin{array}{l}\text { Enjoying spending time in } \\
\text { the kitchen }\end{array}$ & $\begin{array}{l}\text { Food experiences; cooking; eating; healthful food; } \\
\text { garden food is better in quality and flavor }\end{array}$ \\
\hline $\begin{array}{l}\text { Grown food is healthful and } \\
\text { optimal }\end{array}$ & $\begin{array}{l}\text { Material possessions; taking good care of favorite items; } \\
\text { loving material possession }\end{array}$ \\
\hline Love car, well cared for & $\begin{array}{l}\text { Experiences; experiential purchases; traveling; } \\
\text { retirement; seizing the day; having enough money; } \\
\text { extraordinary experiences }\end{array}$ \\
\hline Going on many vacations \\
\hline Cathy - Hedonist & \multicolumn{2}{|c|}{ Initial Coding } \\
\hline \multicolumn{1}{|c|}{ Short description } & $\begin{array}{l}\text { Food Experiences; Gardening; taste difference in food } \\
\text { after adding earth nutrients; replenishing the soil; }\end{array}$ \\
\hline $\begin{array}{l}\text { Garden produce tastes } \\
\text { sweet with soil } \\
\text { amendments }\end{array}$ & $\begin{array}{l}\text { Food Experiences/Food Projects; sense of time; year of } \\
\text { work for zucchini bread; meaningful }\end{array}$ \\
\hline $\begin{array}{l}\text { Experience and connection } \\
\text { with zucchini bread }\end{array}$ & $\begin{array}{l}\text { Project; Material Possessions; Learning; Mistakes; } \\
\text { Trying }\end{array}$ \\
\hline $\begin{array}{l}\text { Learning to make copper } \\
\text { spheres for garden art }\end{array}$ \\
\hline $\begin{array}{l}\text { Taking care of belongings, } \\
\text { garden pliers }\end{array}$ & $\begin{array}{l}\text { Material Possessions; Taking care of possessions; value } \\
\text { possessions }\end{array}$ \\
\hline
\end{tabular}




\begin{tabular}{|c|c|}
\hline \multicolumn{2}{|l|}{ Sue-Hedonist } \\
\hline Short description & Initial Coding \\
\hline $\begin{array}{l}\text { Feeling connection to using } \\
\text { cucumbers for making } \\
\text { pickles }\end{array}$ & $\begin{array}{l}\text { Food Projects; Pickling Cucumbers; Growing all of the } \\
\text { ingredients }\end{array}$ \\
\hline $\begin{array}{l}\text { Choosing which mushroom } \\
\text { will be prepared for dinner } \\
\text { in Italy }\end{array}$ & Food experiences; Eating out; connection to food \\
\hline Playing ukulele with friends & Material Possessions; experience description; social use \\
\hline Keeping houseplants & $\begin{array}{l}\text { Gardening; History with type of experience; getting } \\
\text { more interested; first way to get into hobby }\end{array}$ \\
\hline \multicolumn{2}{|l|}{ Danielle - Materialist } \\
\hline Short description & Initial Coding \\
\hline $\begin{array}{l}\text { Enjoying harvesting } \\
\text { potatoes }\end{array}$ & $\begin{array}{l}\text { Food Experiences; Experiential; enjoyable; harvesting; } \\
\text { "finding treasure" }\end{array}$ \\
\hline $\begin{array}{l}\text { Recycling and curb side } \\
\text { composing }\end{array}$ & $\begin{array}{l}\text { Observations; have composted at home in past without } \\
\text { much success; curbside compost; recycles; advocate for } \\
\text { recycling at work }\end{array}$ \\
\hline House full of food & $\begin{array}{l}\text { Observations; Food Experiences; Materialism; Grocery } \\
\text { Shopping; enjoys buying food from local stands; enjoys } \\
\text { buying food }\end{array}$ \\
\hline $\begin{array}{l}\text { Buying whole loaves of } \\
\text { bread and using } \\
\text { grandmother's bread knife }\end{array}$ & $\begin{array}{l}\text { Materialism; Favorite Possession; Use a lot \& } \\
\text { frequently; enjoy less processed, not sliced bread }\end{array}$ \\
\hline $\begin{array}{l}\text { Dismay over parents selling } \\
\text { childhood bicycle }\end{array}$ & $\begin{array}{l}\text { Material Possessions; Sentimental; wants to keep } \\
\text { possessions for sentimental reasons }\end{array}$ \\
\hline $\begin{array}{l}\text { Fantasizes living in clutter- } \\
\text { free home }\end{array}$ & $\begin{array}{l}\text { Observations; Materialism; clutter conflict with spouse; } \\
\text { fantasy/grandiose plan }\end{array}$ \\
\hline \multicolumn{2}{|l|}{ Annie-Materialist } \\
\hline Short description & Initial Coding \\
\hline $\begin{array}{l}\text { Want to grow too much } \\
\text { produce to give to others }\end{array}$ & Abundance; generosity; no waste \\
\hline $\begin{array}{l}\text { Making complex Indian } \\
\text { meal to impress foodie } \\
\text { friend }\end{array}$ & Food Projects; Challenges \\
\hline Deciding to buy large house & Misc. Food Projects; Challenges; Knowledge/Awareness \\
\hline $\begin{array}{l}\text { Wanting bigger house, } \\
\text { coveting space }\end{array}$ & $\begin{array}{l}\text { Sentimental; Material Possessions; Deciding to } \\
\text { purchase; experiential; history; want big house; } \\
\text { want/need }\end{array}$ \\
\hline
\end{tabular}




\subsection{Discussion}

This inquiry was motivated by a desire to understand how urban gardeners experience material possessions. Research to date on materialism experiences has been informed by the quantitative consumer psychology perspectives that shifting consumer behavior allows for more ethical and sustainable purchasing experiences (Burroughs \& Rindfleisch, 2002; Crompton, 2008), and that negative psychological effects of materialist lifestyles can be mitigated by adopting more intrinsic life aspirations (Belk, 1985; Grouzet, et al., 2005; Kasser \& Ryan, 1993, 1996; Richins \& Dawson, 1992;

Richins \& Rudmin, 1994). The results from this current study offer a different perspective of the materialism phenomenon.

\subsubsection{Current Findings}

The experiences of materialism and material possessions in the context of urban gardening documented in this inquiry were richly complex in the meaning making. More than mitigating negative psychological effects of materialism, urban gardening provided a source for increased life satisfaction.

Intrinsic life aspirations were evident in rich descriptions of food experiences and material possessions that included sensory pleasure, mindfulness, connection with production sources, creative and personal expression, spirituality, generosity, security, and learning. The data also revealed multilayered experiences of material possessions 
that included elements of materialism, as well as minimalist, anti-materialist elements.

Mike and Melissa showed the most pronounced tendencies towards minimalism; they both wanted to be efficient in their gardening, and were unattached to most of their material possessions to the point of feeling overburdened. Mike was adverse to more complex food processing activities such as canning, and Melissa enjoyed preparing and cooking her food very slowly and thoughtfully. Their experiences with food and material possessions satisfied psychological needs for comfort and sensory pleasure, while avoiding dissatisfying experiences of becoming overwhelmed by overly complex food preparation, and too many, cluttered or messy material possessions. These results indicate that for other minimalists, gardening and food activities can be highly satisfying nonmarket activities since they can be tailored to be comforting, simple, and sensory.

Charles, Joe, Cathy and Sue showed strong aspects of hedonism; in their experiences of food and material possessions they described sensory pleasure, feeling connection, and personal expression. Charles valued most his possessions he used to have sensory and social experiences, and enjoyed feeling a connection to his food. Joe enjoyed being creative in the kitchen, and had bought himself a luxury car because he enjoyed the experience of going for long drives. Cathy took pride in buying possessions thoughtfully and maintaining them, and delighted in savoring the first harvest of the year. Sue enjoyed feeling a connection to the wood that her Ukulele was made out of, and enjoyed eating her pickles that she had made with cucumbers she had grown. For 
hedonists, gardening, food, and material possessions may provide ample opportunities to have complex, creative, involved, time-consuming sensory-rich experiences.

Danielle and Annie were the most materialistic of all of the participants; they had strong attachments to their material possessions beyond the experiences of using them, and both had food security concerns that caused them to stockpile food and focus on self-sufficiency. Danielle felt strongly sentimental about many of her possessions but ironically had difficulty with clutter; while she enjoyed gardening, she was not always realistic about planning or following through with maintaining her garden. Annie felt that having a large house was very important to her even though she did not plan on using all of the space, and felt the need grow more food than she needed so that she could nurture and feed her neighbors, friends, and family.

For these materialists, food experiences were satisfying; Annie and Danielle did enjoy savoring freshly prepared meals, and gardening tasks. But Annie and Danielle were also quite materialistic in their food and material possessions experiences compared to the other participants. Many of their experiences focused on external motivations, and reinforcing social relationships, such as impressing people with their cooking and holding onto excessive material possessions because of sentimentality.

The exploration of food experiences in this study revealed that experiential, nonmaterialistic activities such as gardening, preparing food, and eating food are at least partially effective at supporting intrinsic life aspiration and satisfying a diverse set of psychological needs. This study reveals that material possessions can be highly 
experiential, if that is the intention for them. Because of the ability to uniquely and intrinsically satisfy individual's psychological needs, urban gardening and food activities presents a promising example of non-materialist long term activities. Participants expressed richly complex psychological needs, many of which were satisfied through their experiential activities involving food.

\subsubsection{Limitations of current research and opportunities for further research}

The present study was limited by the sampling strategy; since participants were recruited from two community gardens, they lived in the same area, were of limited age range, lacked ethnic diversity, and had shared experiences about the same garden area. Additionally, the intensity sampling criterion was chosen to yield only low-materialists to delve deeply into the nature of intrinsically motivated experiences but instead, to the surprise of this researcher, there were several participants who were somewhat materialistic.

The themes that emerged in the this study suggest many avenues for further research: expanding to experiential activities besides gardening, exploring choice and motivation when contrasting experiential and materialistic endeavors, and focusing on the roles that time, wealth, and self-awareness play in becoming less materialistic. Further research could involve additional phenomenological studies on groups of participants who self-identify as actively and frequently engaging in specific experiential activities, such as people who frequently travel for leisure, artists, woodworkers, knitters, concert goers, rock climbers, yoga enthusiasts, or cyclists. 
A large component of materialism research focuses on individuals choosing to work less and earn less money in favor of increasing leisure time (Huneke, 2005; LeonardBarton, 1981; Schor, 1999; Shaw \& Newholm, 2002), but time use and time commitment was beyond the scope of this study. A few participants in this study expressed interest in spending less time maintaining material possessions. Time wealth prioritization could be an avenue of future research. A possible research question from an intention-behavior gap perspective (King, et al., 2006; Sheldon, Kasser, Smith, \& Share, 2002) could include 'under what circumstances do intrinsically aspiring individuals succeed in increasing their free time?'

\subsection{Conclusion}

This study revealed that individuals who engage in nonmarket activities such as gardening and cooking can be motivated in their experiences of food and their material possessions by a combination of intrinsic and extrinsic aspirations. It is not clear from this exploratory study whether or not gardening and cooking, or other potentially intrinsically motivated nonmarket activities, encourage or discourage materialism. Rather, this research topic should be explored in more detail in future studies. The current study provided groundwork for future studies to develop measures for satisfaction from food activities by characterizing and synthesizing thick descriptions of satisfaction.

Participants were characterized in terms of their relationships with material possessions as minimalist, hedonist, or materialist. But even within the 
characterizations of materialists, experiential activities and intrinsic aspirations were evident, indicating intrinsic elements within each individual. Also, while these experiential activities can be characterized as similar in action or behavior, the specific experience and meaning taken from these actions is unique to each individual and satisfies different psychological needs for different individuals. By understanding more about individual's experiences and behaviors within different levels of materialism, theories can be further developed about how to facilitate individual's increasing wellbeing, more efficiently satisfying psychological needs, and decreasing materialism. 


\section{Article 3 - "I grow for flavor": A phenomenological study of urban gardening and satisfying food experiences}

\section{Abstract}

As nonmarket activities, gardening and cooking are often associated with increased well-being and happiness. To understand this relationship more thoroughly, food production and preparation experiences were explored through in-depth semi-structured phenomenological interviews with eight urban gardeners. Gardening and cooking are often motivated by intrinsic life aspirations such as competency, autonomy, and relatedness, which have been positively related to life satisfaction. Additionally, activities motivated by intrinsic aspirations tend to be more unique and diverse than extrinsically motivated activities, although little is known about what specific food experiences lead to increase feelings of well-being and satisfaction. This article explores the highly individualized food related activities and how these experiences facilitated the urban gardener's happiness. Qualitative analysis of interview transcripts revealed seven shared meaning themes of intrinsic food experiences: relatedness, connection with food, sensory pleasure, raised expectations, competency, and work-life balance. These results indicate that, although food experiences were highly personalized, the interpretations of these experiences and the resulting feelings of happiness, feelings of community and responsibility, and hedonic pleasure were shared across participants' experiences. The rich descriptions of food experiences provided in this study facilitate greater understanding of happiness and how it is experienced in intrinsically motivated nonmarket activities. 
Keywords: Nonmarket activities; food experiences; gardening and cooking; intrinsic life aspirations; phenomenology

\subsection{Introduction}

Eating is one of the most common human experiences, and some people, such as urban gardeners, chose to be very involved in producing and preparing their food as a nonmarket activity. These urban gardeners make their experiences with food highly individualized, and in turn, these food experiences contribute to their happiness. Observing urban gardeners' food activities can provide greater understanding of what kinds of activities provide happiness, as well as a richer understanding of what aspects of food experiences facilitate happiness. The results of this study could be beneficial in understanding how gardening and cooking, and other individualized, intrinsically motivated nonmarket activities can be used therapeutically to increase happiness, as well as in farm-to-school and other educational programs with children to introduce food experiences in a way that facilitates positive associations.

While various researchers have sought to understand happiness through gratitude, meaningful life, flow, happiness strategies, hedonic treadmills, and positive and negative affect (Csikszentmihalyi, 1999, 2000; Diener, Emmons, Larsen, \& Griffin, 1985; Emmons \& McCullough, 2003; King, et al., 2006; Tkach \& Lyubomirsky, 2006; Watson, Clark, \& Tellegen, 1988), few have looked at the relationship between gardening and happiness using phenomenology, particularly gardening for food production, and food preparation activities. This study aims to better understand 
experiences of gardening and how these experiences may increase an individual's happiness. Through phenomenology, in the context of intrinsically motivated activities, the author's goal was to learn the constructed meanings of satisfaction and happiness from gardening.

While the results may not be generalizable to non-gardeners, or for individuals who do not engage in intrinsically motivated activities, they can inform future research on happiness by providing potential variables involving food experiences such as gardening that may correlate positively with happiness. In addition, the results contribute to the literature on phenomenology, gardening and food experiences, intrinsic and extrinsic motivations, and psychological well-being.

\subsubsection{Background}

An exploration of relevant literature provides a background on the psychological effects of food experiences, previous methodologies used to explore food experiences, and the current gaps in literature that the current study will address.

\subsubsection{Psychology of food activities}

People's relationship with food is vastly complex. Research shows that food provides us with nutrition (Bisogni, et al., 2002; Bisogni, et al., 2005; Devine, 2003), connection with nature (Kaplan, 1973), sensory exploration and satisfaction (Hale, et al., 2011; Macht, Meininger, \& Roth, 2005; Sumner, 2008; Trubek, 2009), cultural identity and consumer choices (Alkon, 2007; d'Astous \& Mathieu, 2008; Essoussi \& Zahaf, 2008; Hinrichs, 2000; Lockie, 2002; Morris \& Buller, 2003; Murdoch, Marsden, \& Banks, 
2000; Penker, 2006), social connection (Lyson, 2005; Morris \& Buller, 2003), self-image (Bisogni, et al., 2002), and sense of place (Hale, et al., 2011; Trubek, 2008). While people's relationship with food was previously thought to be too banal to be worth studying, now there is recognition that food choices and experiences are emotionally rich, and often involve creativity, pleasure, emotional satisfaction, and social connection (Kemmer, 2000; Macht, et al., 2005; Trubek, 2009).

Within the seemingly simple experience of eating food exist layers of constructed meaning from social pressures and personal history that often leads to unhealthy physical and psychological well-being (Bisogni, et al., 2002; Devine, 2003; Kristeller, 2003). Eating experiences can meet both physiological and psychological needs, but foods are often chosen and consumed in unhealthy and unaware ways (Kristeller, 2003). Studies on eating disorders and obesity have found that eating in excess, binging, self-induced vomiting, or self-starving are often emotionally charged, and are motivated by unmet psychological needs (Kristeller, 2003; Rozin, 1996, 2005; Rozin, Kabnick, Pete, Fischler, \& Shields, 2003; Weingarten \& Elston, 1990).

Research has found that people who eat food that they have grown are more psychologically satisfied than non-gardeners, as measured by the Life Satisfaction Inventory (Waliczek, et al., 2005), and that there are some examples of individuals having strong cultural sense of place from the foods they prepare (Herman, 2009; Trubek, 2008; Vileisis, 2008), but a deeper understanding is needed of the sources and types of satisfaction experienced from gardening and eating personally grown foods. 


\subsubsection{Psychology of gardening}

Research on gardening indicates that growing personal food is a popular pastime for Americans, with up to $78 \%$ of U.S. Households participating in lawn and garden activities, and that gardening can be a source of satisfaction and increased well-being (Clayton, 2007; Gross \& Lane, 2007; Waliczek, et al., 2005) for a variety of reasons, including connection with nature (Clayton, 2007; Gross \& Lane, 2007; Hale, et al., 2011; Jackson, 2002; Kaplan, 1973), increased physical health from exercise while gardening and from consumption of fresh produce (Hale, et al., 2011; Lautenschlager \& Smith, 2007; Rivera-Caudill \& Brander, 2008; Twiss et al., 2003; Wakefield, et al., 2007), increased social connection (Clayton, 2007; Kaplan, 1973), and increased sense of place and identity (Clayton, 2007; Gordon, 2006; Kiesling \& Manning, 2010).

As described above, gardening, cooking, and eating are vastly complex emotional and psychological experiences, that are often satisfying and tend to increase psychological well-being (Bhatti, Church, Claremont, \& Stenner, 2009; Hale, et al., 2011; Kaplan, 1973; Kim \& Ohara, 2009; Waliczek, et al., 2005). These food activities may be more satisfying because individuals are investing their time, and sometimes money, in life experiences instead of investing their time and money in acquiring material possessions, and to the extent that most food activities are motivated for intrinsic reasons, not for social recognition, financial success, and physical appearance, they are more satisfying in both the short and long term (Grouzet, et al., 2005; Kasser, 2003; Kasser \& Kanner, 2004; Kasser \& Ryan, 1993, 1996; Van Boven, 2005). An indepth, individual level methodology was used to explore food activities and feelings of 
satisfaction.

\subsubsection{Phenomenology and food experiences}

Existential-phenomenology methodology provides a framework for exploring first-

person lived experiences such as flow, as well as experiences related to food and

intrinsic aspirations, such as satisfaction, and engagement (Bailey, 2007;

Csikszentmihalyi, 1999, 2000; Giorgi, 2006; Groenwald, 2004; Moustakas, 1994; Ragin, et al., 2004; Seamon, 2000). This research approach focuses on thickly described firstperson lived experiences to explicate the essence of the structure and meaning of a phenomenon (Giorgi, 2006; Groenwald, 2004; Moustakas, 1994; Thompson, et al., 1989).

Phenomenology can provide much needed insight into food activities and satisfaction by starting with first-person lived experiences of phenomena related to food activities such as gardening, cooking, and eating. There are a few phenomenological studies exploring the experiences of food activities, such as food cravings (Weingarten \& Elston, 1990), sense of place and relationships between the environment, people, and their behavior (Seamon, 1982, 2000), and health issues of low-income women (Dibsdall, Lambert, \& Frewer, 2002). Other qualitative studies have explored food experiences, but mostly focus on marketing strategies, producer/consumer relationships, gender roles, and health/nutritional issues (Alkon, 2007; Bisogni, et al., 2002; Bisogni, et al., 2005; Devine, 2003; Essoussi \& Zahaf, 2008; Goodman \& DuPuis, 2002; Kemmer, 2000; Rozin, 1996, 2005; Rozin, et al., 2003; 
Zepeda \& Leviten-Reid, 2004). Thus there is a research opportunity to explore happiness from food experiences using phenomenology.

\subsubsection{Psychological satisfaction of food activities and addressing the literature gap}

Research shows that activities that are motivated by intrinsic aspirations, rather than extrinsic aspirations support self-expression and meeting each individual's psychological needs uniquely, offer a vast range of experiences, and are not limited to the amount and type of products available for purchase (Huneke, 2005; Pierce, 2000; Shaw \& Newholm, 2002). This indicates that gardening and other food activities may be a great source of satisfaction, and although there is some research about the psychological experiences of food activities, it is not clear how these psychological experiences impact gardener's experiences of satisfaction and psychological well-being.

Food activities have been shown to increase psychological well-being (Bhatti, et al., 2009; Hale, et al., 2011; Kaplan, 1973; Kim \& Ohara, 2009; Waliczek, et al., 2005), and are known to be complex emotional and psychological experiences (Kristeller, 2003; Petrini \& Padovani, 2006; Trubek, 2008, 2009; Wakefield, et al., 2007), but less is known about the experiences and qualities of satisfaction, and of how psychological well-being is increased from food activities. For example, in one study, gardeners described their motivations as a need to "get their hands dirty," "reduce stress," and "connect with nature," (Clayton, 2007). In another study, gardeners were found to have quantitatively higher life satisfaction than non-gardeners, although specific reasons and descriptions of increased satisfaction were not explored (Waliczek, et al., 2005). 
This article explores these topics further, and attempt to address the gaps in literature involving the phenomenological, first-person lived experiences of food activities that are intrinsically motivated, and how these experiences are related to increases in happiness and satisfaction of psychological needs. The research question was: "Given that food activities are generally intrinsically motivated, how do gardeners perceive and describe their food activity experiences and their resulting feelings of wellbeing?"

\subsection{Methods}

\subsubsection{Participants}

Participants were recruited from community gardens in Portland, Oregon in Winter 2012, using intensity criterion. Intensity sampling required that participants were sought who considered themselves enthusiastic about gardening and preparing food, but did not consider themselves "gourmets" or expert gardeners. There were eight participants for the study, ranging in age from 44 to 70 , with five females and three males. All participants were Caucasian. See Table 4.1 for additional participant demographics. 
Table 4.1 Demographics of study participants

\begin{tabular}{|l|l|l|l|l|l|l|}
\hline $\begin{array}{l}\text { Participant's } \\
\text { Pseudonyms }\end{array}$ & Age & Gender & $\begin{array}{l}\text { Married/ } \\
\text { Partnered }\end{array}$ & $\begin{array}{l}\text { Work } \\
\text { status }\end{array}$ & $\begin{array}{l}\text { Home } \\
\text { Garden }\end{array}$ & $\begin{array}{l}\text { Gardening } \\
\text { (years })\end{array}$ \\
\hline Sue & 56 & Female & Yes & Part-time & Yes & 32 \\
\hline Joe & 70 & Male & Yes & Retired & No & 10 \\
\hline Annie & 44 & Female & Yes & Part-time & Yes & 40 \\
\hline Mike & 65 & Male & Yes & Retired & No & 9 \\
\hline Melissa & 59 & Female & No & Disability & No & 46 \\
\hline Danielle & 65 & Female & Yes & Disability & No & 15 \\
\hline Cathy & 50 & Female & No & Full-time & No & 8 \\
\hline Charles & 44 & Male & Yes & Full-time & Yes & 16 \\
\hline
\end{tabular}

\subsubsection{Interviews}

The author collected data by conducting semi-structured interviews at the participants' home with the exception of one participant, who requested to be interviewed at the author's home. All participants provided their informed consent to participate in the study, to have photos taken of them, their home, and their garden space, and to have their interviews audio and video recorded. Pseudonyms were used for all participants to protect their confidentiality.

Interviews lasted between one to three hours; one shorter interview was followed up on by a second interview to increase saturation. The interviews were guided by a firstperson version of the research question: "Tell me about the last time you completed a project involving food and tell me anything you can about the situation, about what you felt, did or said" and "Tell me about the last time you purchased food and ate it, and tell me anything you can about the situation, about what you felt, did or said."

The interviews were fully transcribed by the author. In addition to 104 single-spaced pages of interview transcripts, and audio and video recordings of the interviews, 
observational data were collected, including a total of 10 pages of field note observations of the participants during and after the interview, 330 photographs, and 20 pages of field note observations of the participants' home and garden spaces.

\subsubsection{Analysis}

Data analysis began by reading and rereading all the transcripts, to become more sensitized to major themes. Following Moustakas' and Groenwald's recommendations for explication of phenomenological data, (Groenwald, 2004; Moustakas, 1994), each transcript was reviewed and separated in to smaller units of meaning, ranging from a few words to a few paragraphs in length, each of which represented an illuminating statement about the phenomenon. Initial coding was inductive, based on particularly poignant statements within the units of meaning. After several transcripts were reviewed, the units of meaning (i.e., data) were iteratively clustered into discrete themes.

Other themes were more deductively created, based on the research scope of food activities and life satisfaction. A subjective heuristic was used to determine whether or not categories and topics were significant enough to become a discrete theme.

Significant themes needed to 1) be described by multiple participants, 2) be described as poignant or particularly meaningful, and 3) relate to relevant aspects of the research, such as satisfaction, happiness, well-being, and meaning-making of food experiences.

As more transcripts were reviewed and separated into units of meaning, these data were clustered into existing themes, clustered into new themes, or sometime used to 
split an existing theme into two or more new themes if the new theme concepts were discrete enough from other themes. Convergence and saturation were reached when many similar units of meaning were found to reflect the same or similar experiences between gardeners.

Calculations such as reliability coefficients are not typically used in phenomenological qualitative research (Groenwald, 2004; Moustakas, 1994). Instead, the researcher must rely on their ability to bracket their own presuppositions and integrate the textural and structural descriptions of the essences of the phenomenal experience (Groenwald, 2004), what is sometimes referred to as saturation or convergence. For example, after the units of meaning of transcripts had been clustered into discrete themes, these themes were explored in-depth through writing, further grouping into micro-themes, and selecting representative units of meaning.

During this theme exploration process, the diversity and similarity of the data was explored, in terms of representation among the participants, and in terms of the specific meaning-making with regards to self-concordance, goal attainment, and motivation. Through the theme exploration process, units of meaning were occasionally reassigned to a different theme, to increase the saturation of themes, and to aid in settling on a parsimonious set of themes. 


\subsection{Results}

Qualitative analysis of the interview data lead to seven distinct themes regarding urban gardeners lived experiences of food and gardening as satisfying activities: 1)

Relatedness: spending time being social, 2) Connection: direct relationship with food, 3)

Sensations: eating with awareness and pleasure, 4) Expectations: getting used to good food, 5) Competency: pride in abilities and self-sufficiency, 6) Work-life balance: food as part of regular life, and 7) Abundance: feeling wealth and gratitude.

\subsubsection{Relatedness}

Many participants described how much they looked forward to and enjoyed spending time being social during food activities. Sharing food experience with others made the experiences more enjoyable, strengthened social relationships, and helped lessen the amount of work. Mike described a special meal that he shared, a Jewish family Christmas at a Chinese Restaurant, with a few friends:

We had a really great time, we joked, and there was a lot of " $\mathrm{Mmm}$ ! Mmm! Oh, this is really good! What did you call this again? Mmm! Mmm!" and "Oh my god! Did you taste this one?" We didn't want it to end, so a couple of us went into the bar and had an after dinner drink. And then my friend and I and my partner came back here and opened our belts and shot the breeze a bit.

While social food experiences can be focused on sharing sensory pleasure, food can also play a major role in social capital. Danielle lived near her daughter, and they often cooked together. She felt very nurtured and was very grateful to her daughter when she broke her leg and her daughter brought her fresh produce and cooked meals for her: 
My daughter is very interested in cooking with me; we do some cooking together. When I broke my leg, she really came through and brought food to me, and as I was being able to get up and cook, we cooked together.

Similarly, when Cathy started gardening, she relied heavily on other gardeners to help her with her garden:

Everybody helped me. So the first year it was really a sense of the community had to help me, because I couldn't do it alone. Everybody took pride in showing me, and I would go and ask everybody questions, and everyone took the time to talk to me, to help me answer the questions.

Feeling grateful to others, and learning from them, was part of Cathy's positive experience gardening.

\subsubsection{Connection}

Knowing where their food came from, and having a relationship with their food as it was growing, was very important to the participants. For some participants, this meant having a social relationship with the people who grow their food, and having an active role in harvesting the food. Mike enjoyed harvesting his own berries, and was consistent about going to the same U-pick place:

I go to a blueberry place, and formed a relationship with a farmer there. I always look forward to the season; I look forward to seeing her, 3 or 4 times during the growing season.

For Charles, having a connection with his food was more about growing his own food in his garden plot and making an effort to use everything that he grew in meals he and his family prepared. He seemed to relish the idea that the meals that he prepared were determined by the food he had decided to grow, and that was ready to harvest: 
Kale, onions, we'd pick those, or I'd pick those. And then I'd work those into our meals during the week. Potatoes in the same way, in the fall we got all of those out, and we found different ways to make those. Really a fake French fry is what I did with most of those. The kids really like [them], with olive oil in the oven. Tomatoes here, picking those the kids would eat the cherries, well, my oldest would eat the cherries just raw with dinner. We'd have a bowl on the counter for tomatoes, and normally we'd work those into a salad, or on a sandwich, or cook them in.

Sue described an experience she had eating chicken soup at a restaurant where she was not sure of the quality or origins of food:

Even though the taste was ok, there was something about it. I could feel that my digestion was not happy. I think that the connection between your stomach and your head, they are connected. So, I'm thinking "oh uh, there's gristle in here, oh the chicken, they are probably not using organic." That all starts to effect how my body reacts. I didn't get nauseous, but my stomach wasn't settled because my mind wasn't settled about it.

Sometimes a desire for awareness and connection lead participants to unpleasant food experiences, when they couldn't enjoy a meal because they were aware of poor quality.

\subsubsection{Sensations}

Sensory pleasure was one of the most common experiences described by the participants. Often these experiences focused on the sensations of simply prepared foods. Almost everyone had a "fresh produce straight from the garden" story. Cathy excitedly anticipated her harvest of peas every year, and rarely waits to get home before eating them:

Half the time I don't cook the peas, I just love them. By god if they even get home I'm amazed.

Melissa described how she savored her cooking experience, and focused on flavor and 
quality over quantity during her gardening experiences:

I've learned, I'm a slow cooker; I have the slow cooking mentality. I love to grow leeks, because you can put the leeks in the soup stock. I grow for flavor. I do it for fun, too. I grow for flavor, so I don't need a lot of what I grow, but it has to have really good flavor.

Mike usually preserved half of his harvest from the blueberry fields by freezing them, and the rest he ate fresh. He described how he chose to eat his berries simply prepared:

The blueberries...I'm not a big cook, I don't make muffins or pancakes, I just eat them as...I have a horrible sweet tooth, so I use them like I would cookies or candy. I eat them frozen during the winter, and I just love it. I eat cups of blueberries.

Mike's attention and mindfulness to his experience allowed him to experience the berries most fully.

\subsubsection{Expectations of quality}

Participants were aware of a change in their expectations about the quality of food that they prepare and eat. Joe tends his garden year round, and harvests some produce during the winter, but not as much as he and his wife would like to eat. He describes how he supplemented his garden produce with bought produce, as well as his interest in buying high quality, healthy foods:

So the garden is a big part of that for about half the year. When we don't have the garden produce... we buy more produce than anything else when we go to New Seasons. We like chocolate, which is another health food we indulge in. Every day we have a small amount of chocolate at lunch. We also eat some almonds at lunch. Almonds are supposed to be very good for us. We buy the medium salted almonds from Trader Joe's, not the normally salted ones; these are $50 \%$ as much salt.

Melissa worked to increase the quality of her soil by adding organic amendments, 
composting, planting cover crops, and layering mulches. She felt that the produce she grows in her garden and donates to others are the highest quality possible, and she now expects to maintain very high quality in her produce:

I know that the quality from the soil we've made is about as good as you're going to get with your produce. And I like doing that. I just love the fact that everything I've done is completely, I guess it's organic. And so I'm giving them something that is good.

Annie kept chickens in her back yard, and she was very fond of them. She described preparing a Greek lasagna recipe using some of her chicken's eggs:

But it was wonderful, because I got to use our tomatoes, and the lamb, and our eggs. Our eggs are, you know, the sauce in the picture was white, like béchamel sauce, but ours isn't like that, it's yellow! They are just great little girls! "Braack!"

She noticed that when she cooked with her chicken's eggs, the food tasted richer. Since becoming more involved in food production, participants described how their food quality has increased, and how they have become accustomed to this higher quality.

\subsubsection{Competency}

Feeling competent was important for participants. Danielle didn't shop for material possessions very much, but she did go grocery shopping frequently, and wanted to have ample food available to her:

What have I bought lately? Mostly groceries. I do a lot of grocery shopping. That's the shopping that I do. Grocery shopping. I always have a house full of food. I go to Bob's Red Mill and buy grain, and beans. I go to the...I guess I do shop pretty local. I go to a fruit market; I sometimes buy fruit and vegetables there.

Sue grew cucumbers and made pickles for herself. She derived satisfaction from making 
a processed food item for herself, from produce she had grown:

I just love that, I love that feeling "Ooo, I GREW all of these!" And not just the pickles. Alright, so then there was the garlic, I grew all the garlic. I like that aspect of it: "I grew all of this, I put it all up." I ferment them first, so I don't just make a brine and put the pickles in jar. I actually brine the pickles first, and that takes about two weeks, and then you can 'em. So it's a big process, and it just makes me feel good.

For Joe and Charles, competency was focused more on caring for others. Joe had an extra plot where he grew food to donate, and enjoyed dropping off the produce at a community soup kitchen and feeling gratitude from the donation recipients:

Usually, at least at the height of the growing season, the car is just full of produce of one kind or another. So I go into the dining hall, and meet with the co-managers if they are there, or the cook, and they usually come out and give me a dolly or a cart to bring the stuff in. There are always volunteers from the dining hall, they greet me, and it's very nice, "Thank you! Thank you for this wonderful produce." Talking to the cook, of course, they have a lot of canned goods, and packaged goods, but... I know I'm not the only donor of fresh produce, but it is very appreciated and it makes me feel very good.

Charles was the one who prepared most of the meals for his household, and was proud of his role in providing high quality nutrition:

She doesn't like to cook as much as me. She'll do it out of necessity, and that's about it. When I go out of town for work, Mom is making dinner, it's "where are we going, Mom?" If it wasn't for me, our family would not eat that healthy, to put that bluntly.

He saw this responsibility as solely his, and was not confident that his family was competent without him. For participants, competency was expressed as a need for food security; for others, it was being able to make processed foods for themselves (e.g., pickles), provide good nutrition for their family, or share their abundance with their community. 


\subsubsection{Work-Life Balance}

As participants grew food and prepared their food, they formed routines about harvesting, processing and eating their foods, in balance with the rest of their regular activities. These routines were intentionally made by the participants, and helped make food activities a regular part of participant's lives. Working participants, such as Danielle, described how they would tend the garden and harvest after work or on weekends:

I'd go to the garden in the morning, or after work, and then get home, clean stuff up, and try to figure out right away what I can cook.

Charles described his work-life balance involving food in terms of his regular dinners that he prepared for his family. He had specific meals that he regularly prepared:

Uh, you know, we're probably down to 8 or 10 dinners we rotate. I'll make tomato sauce 2 gallon or gallon and a half at a time. Again, it's time management, with 2 working spouse... 2 working parents, and kids. So, what I do is spaghetti I guess I'll just...The red sauce I make, I'll work some home grown tomatoes into that. But that's again, a gallon and a half at a time; I'll freeze in gallon, plastic bags, quart bag sized. And I'll pull that out, warm it up in warm water, or whatever heat it up. Serve it up with pasta. That's probably one of my best staples, and I'll occasionally turn that into a lasagna or a pizza sauce.

Charles worked full time, and had to balance his work obligations with his desire to spend time on food activities and nonmarket time with his family. 


\subsubsection{Abundance}

Gardening and other food activities often resulted in periods of heavy production and large harvests for the participants. These periods of large harvests were highly enjoyable for the participants; they revelled in the abundance. Cathy had been using soil amendments, and her production had increased beyond her expectations. She described what she did with her large squash harvest during a visit from her mother:

I made pie filling. I didn't just make the pie level filling. I tripled it. So you don't need to eat a lot, but it was exceptional. [My mother] was here for days, and we ate on it the whole time. Then we cooked it the way she told me about, so we cooked it a.... Turkish way. That is, you cut up a little of it, then you add cinnamon, and maple syrup on top. Then you bake it. So we had that for dessert. So we were eating on this squash as the starch in the meal, or as the dessert. And then I made soup with another part of it. So there were all these different ways we were eating this.

Charles moved from Texas to the Pacific Northwest with his family a few years ago, and one of the biggest changes he had noticed was the abundance and cheapness of berries. Ever year he felt fortunate to be living in a climate that offered such high production:

Up here, compared to Texas, your plethora of fresh berries and fruit, I mean, come on! The blackberries that are such a nuisance are so darn sweet, and down there, they are as tart as all could be. My God, there's so much fruit. I'll pay these kids, go find me a gallon of berries, ok, here's $\$ 5$, awesome.

Similarly, Melissa had raspberry plants in her garden plot, and when they were ripe, there were many more berries than she could eat at once, so she used a distiller to boil her berries down into a thick juice that she froze and ate throughout the year:

So that's one way to work with some things that you have in over abundance. You can 
steam them down. Then you can work with it that way. Or you can just serve it as juice, what the heck! Oh, you can get concord grapes and do that. Oh, God, it's really, really good.

While these results are grouped by how the personal meanings of the food experiences are shared across participants, there is still an amount of individuality to these experiences. The results are summarized in Table 4.2, which lists the results in the same order they have been presented in this section, and provides the theme, a short description for each of the general type of activity, the specific activity, and the personal meaning. 
Table 4.2. Personal meanings of specific food experiences, by theme

\begin{tabular}{|c|c|c|c|c|}
\hline Participant & Theme & $\begin{array}{l}\text { Type of } \\
\text { activity }\end{array}$ & $\begin{array}{l}\text { Specific } \\
\text { experience }\end{array}$ & Personal meaning \\
\hline Mike & Relatedness & $\begin{array}{l}\text { Enjoying } \\
\text { meal with } \\
\text { friends }\end{array}$ & $\begin{array}{l}\text { Jewish Chinese } \\
\text { holiday feast }\end{array}$ & $\begin{array}{l}\text { Companionship } \\
\text { and shared } \\
\text { sensory pleasure }\end{array}$ \\
\hline Danielle & Relatedness & $\begin{array}{l}\text { Cooking with } \\
\text { family }\end{array}$ & $\begin{array}{l}\text { Sharing resources } \\
\text { and quality time } \\
\text { with family }\end{array}$ & $\begin{array}{l}\text { Easing burden } \\
\text { and being } \\
\text { nurtured }\end{array}$ \\
\hline Cathy & Relatedness & $\begin{array}{l}\text { Learning } \\
\text { skills from } \\
\text { community }\end{array}$ & $\begin{array}{l}\text { Being taught how } \\
\text { to garden }\end{array}$ & $\begin{array}{l}\text { Feeling grateful } \\
\text { to others }\end{array}$ \\
\hline Mike & Connection & $\begin{array}{l}\text { Harvesting } \\
\text { fresh berries }\end{array}$ & $\begin{array}{l}\text { Knowing where } \\
\text { food comes from }\end{array}$ & $\begin{array}{l}\text { Connection with } \\
\text { farmer }\end{array}$ \\
\hline Charles & Connection & $\begin{array}{l}\text { Harvesting } \\
\text { and } \\
\text { preparing } \\
\text { foods }\end{array}$ & $\begin{array}{l}\text { Cooking based on } \\
\text { what is fresh and } \\
\text { ready for harvest }\end{array}$ & $\begin{array}{l}\text { Providing } \\
\text { connection with } \\
\text { food and good } \\
\text { nutrition for } \\
\text { family }\end{array}$ \\
\hline Sue & Connection & Eating out & $\begin{array}{l}\text { Awareness of food } \\
\text { quality }\end{array}$ & $\begin{array}{l}\text { Feeling sick and } \\
\text { being aware of } \\
\text { disconnection } \\
\text { with food }\end{array}$ \\
\hline Melissa & Sensations & $\begin{array}{l}\text { Growing } \\
\text { flavorful } \\
\text { food }\end{array}$ & $\begin{array}{l}\text { Building high soil } \\
\text { quality }\end{array}$ & $\begin{array}{l}\text { Enjoying flavorful } \\
\text { foods }\end{array}$ \\
\hline Mike & Sensations & $\begin{array}{l}\text { Eating } \\
\text { Berries }\end{array}$ & $\begin{array}{l}\text { Eating blueberries } \\
\text { raw like candy }\end{array}$ & $\begin{array}{l}\text { Enjoying good } \\
\text { food }\end{array}$ \\
\hline Joe & Expectations & $\begin{array}{l}\text { Buying and } \\
\text { eating } \\
\text { produce }\end{array}$ & $\begin{array}{l}\text { Buying organic } \\
\text { when garden } \\
\text { produce is not } \\
\text { enough }\end{array}$ & Eating healthy \\
\hline Melissa & Expectations & $\begin{array}{l}\text { Growing and } \\
\text { donating } \\
\text { food }\end{array}$ & $\begin{array}{l}\text { Building high soil } \\
\text { quality }\end{array}$ & $\begin{array}{l}\text { Making the world } \\
\text { a better place }\end{array}$ \\
\hline Annie & Expectations & $\begin{array}{l}\text { Eating fresh } \\
\text { eggs }\end{array}$ & $\begin{array}{l}\text { Yolks are richer } \\
\text { than store bought } \\
\text { eggs }\end{array}$ & $\begin{array}{l}\text { Enjoying good } \\
\text { food }\end{array}$ \\
\hline Danielle & Competency & $\begin{array}{l}\text { Buying } \\
\text { groceries }\end{array}$ & Shopping local & Food Security \\
\hline
\end{tabular}

Article 3 


\begin{tabular}{|c|c|c|c|c|}
\hline Participant & Theme & $\begin{array}{l}\text { Type of } \\
\text { activity }\end{array}$ & $\begin{array}{l}\text { Specific } \\
\text { experience }\end{array}$ & Personal meaning \\
\hline Sue & Competency & $\begin{array}{l}\text { Growing and } \\
\text { preserving } \\
\text { food }\end{array}$ & Making pickles & Feeling strong \\
\hline Joe & Competency & $\begin{array}{l}\text { Growing and } \\
\text { donating } \\
\text { food }\end{array}$ & $\begin{array}{l}\text { Being generous } \\
\text { with food }\end{array}$ & $\begin{array}{l}\text { Receiving } \\
\text { gratitude }\end{array}$ \\
\hline Charles & Competency & $\begin{array}{l}\text { Cooking for } \\
\text { family }\end{array}$ & $\begin{array}{l}\text { Providing good } \\
\text { nutrition }\end{array}$ & $\begin{array}{l}\text { Important role as } \\
\text { caregiver }\end{array}$ \\
\hline Danielle & $\begin{array}{l}\text { Work-life } \\
\text { balance }\end{array}$ & $\begin{array}{l}\text { Harvesting } \\
\text { and } \\
\text { preparing } \\
\text { foods }\end{array}$ & $\begin{array}{l}\text { Cooking based on } \\
\text { what is fresh and } \\
\text { ready for harvest }\end{array}$ & $\begin{array}{l}\text { Practical time } \\
\text { management }\end{array}$ \\
\hline Charles & $\begin{array}{l}\text { Work-life } \\
\text { balance }\end{array}$ & $\begin{array}{l}\text { Cooking for } \\
\text { family }\end{array}$ & $\begin{array}{l}\text { Preparing efficient } \\
\text { dinners }\end{array}$ & $\begin{array}{l}\text { Time } \\
\text { management and } \\
\text { efficiency }\end{array}$ \\
\hline Cathy & Abundance & $\begin{array}{l}\text { Preparing } \\
\text { and eating } \\
\text { harvested } \\
\text { food }\end{array}$ & $\begin{array}{l}\text { Abundant harvest, } \\
\text { prepared in many } \\
\text { ways }\end{array}$ & $\begin{array}{l}\text { Feeling } \\
\text { personally } \\
\text { wealthy }\end{array}$ \\
\hline Charles & Abundance & $\begin{array}{l}\text { Harvesting } \\
\text { and eating } \\
\text { fresh berries } \\
\end{array}$ & $\begin{array}{l}\text { Abundant fresh } \\
\text { berries available }\end{array}$ & $\begin{array}{l}\text { Excited about } \\
\text { availability of } \\
\text { good food }\end{array}$ \\
\hline Melissa & Abundance & $\begin{array}{l}\text { Preserving } \\
\text { food }\end{array}$ & $\begin{array}{l}\text { Preserving } \\
\text { abundant harvest } \\
\text { with no waste }\end{array}$ & $\begin{array}{l}\text { Feeling thrifty } \\
\text { and conservative }\end{array}$ \\
\hline
\end{tabular}

\subsection{Discussion}

Although the experiences can be described in terms of similar personal meanings, as in the results section, the uniqueness and complex, multi-layered nature of human experiences are also important in understanding intrinsically motivated nonmarket activities such as gardening and cooking, and the resulting happiness. Additionally, the shared meanings presented in the results section can be further synthesized to reveal 
three meta-themes that describe psychological needs being met by the participants' food experiences. Both the uniqueness of the experiences and the shared meanings of the experiences will be explored more in the sections below.

\subsubsection{Individualized Food Experiences}

As summarized in Table 4.2, each participant's specific food experience and their personal meaning taken from that experience were unique. Although this study's scope was small in terms of sample size and the strong interests of the participants in gardening and food activities, participant's experiences were as unique and diverse as the participants themselves, taking into account their differences in lifestyles, personalities, family structures, and financial, physical, and time resources. Specific gardening, harvesting, preserving, cooking, and eating activities varied by participant. For example, some participants wanted to spend time and energy improving their garden soil, while others were not concerned with soil quality.

Additionally, the same type of food activity often had different personal meanings for different participants. For example, some participants like Cathy described an abundant harvest as an opportunity to prepare and experience her squash in as many different ways as possible, with a feeling of personal wealth and exploration, while other participants like Melissa described a similar experience as an opportunity to preserve food with a feeling of thriftiness and conservation.

The highly individualized experiences described by participants aids in deepening understanding of the relationship between intrinsic life aspirations and happiness. 
Activities motivated by intrinsic aspirations have been shown to be more satisfying than those extrinsically motivated (Deci, 1975; Kasser \& Ryan, 1996; Niemiec, et al., 2009; Ryan \& Deci, 2000; Sheldon, et al., 2001; Sheldon \& Lyubomirsky, 2006), and it is theorized that part of the increased satisfaction is from the tailored activities; if an individual is doing an activity for themselves, they are more likely to do it the way they want to without considering external pressures. Participants described many diverse food experiences, but regardless of the diversity of experiences and interpretations, and the apparent individuality of the participants, there were many common aspects to the food experiences explored in this study.

\subsubsection{Synthesis of shared meanings of food experiences}

These highly individualized food activities were ascribed similar, shared meanings by participants, as described in terms of the themes: 1) Relatedness: spending time being social, 2) Connection: direct relationship with food, 3) Sensations: eating with awareness and pleasure, 4) Expectations: getting used to high quality food, 5) Competency: pride in abilities and self-sufficiency, 6) Work-life balance: food as part of regular life, and 7) Abundance: feeling wealth and gratitude. These shared meanings increased the participant's happiness in similar ways and satisfied common psychological needs, and can be described in terms of three overarching happiness concepts: responsibility, community, and hedonism.

While the themes presented in the results section provide accurate thick descriptions of the participant's food experiences from a phenomenological perspective, 
the seven inductively created themes presented in the results section can be synthesized deductively into three meta-themes: responsibility, community, and hedonism. These meta-themes provide additional conceptual framework to describe the happiness and satisfaction felt from the food activities, and are potentially more useful in understanding how the constructed meanings of food experiences relate to satisfaction of psychological needs, increased well-being, and happiness. Table 4.3 shows how the quotes from the results section were also grouped into the meta-themes.

Table 4.3. Shared meanings themes and feelings of satisfaction meta-themes

\begin{tabular}{|l|l|l|l|}
\hline Participant & Specific experience & Theme & Meta-themes \\
\hline Mike & Jewish Chinese holiday feast & Relatedness & $\begin{array}{l}\text { Community, } \\
\text { Hedonism }\end{array}$ \\
\hline Danielle & $\begin{array}{l}\text { Sharing resources and } \\
\text { quality time with family }\end{array}$ & Relatedness & $\begin{array}{l}\text { Community, } \\
\text { Hedonism }\end{array}$ \\
\hline Cathy & Being taught how to garden & Relatedness & $\begin{array}{l}\text { Community, } \\
\text { Hedonism }\end{array}$ \\
\hline Mike & $\begin{array}{l}\text { Knowing where food comes } \\
\text { from }\end{array}$ & Connection & Community \\
\hline Charles & $\begin{array}{l}\text { Cooking based on what is } \\
\text { fresh and ready for harvest }\end{array}$ & Connection & Community \\
\hline Sue & Awareness of food quality & Connection & Community \\
\hline Melissa & Building high soil quality & Sensations & Hedonism \\
\hline Mike & $\begin{array}{l}\text { Eating blueberries raw like } \\
\text { candy }\end{array}$ & Sensations & Hedonism \\
\hline Joe & $\begin{array}{l}\text { Buying organic when garden } \\
\text { produce is not enough }\end{array}$ & Expectations & Hedonism \\
\hline Melissa & Building high soil quality & Expectations & $\begin{array}{l}\text { Responsibility, } \\
\text { Hedonism }\end{array}$ \\
\hline Annie & $\begin{array}{l}\text { Yolks are richer than store } \\
\text { bought eggs }\end{array}$ & Expectations & Hedonism \\
\hline Danielle & Shopping local & Competency & $\begin{array}{l}\text { Hedonism, } \\
\text { Responsibility }\end{array}$ \\
\hline Sue & Making pickles & Competency & Responsibility \\
\hline
\end{tabular}




\begin{tabular}{|l|l|l|l|}
\hline Participant & Specific experience & Theme & Meta-themes \\
\hline Charles & Being generous with food & Competency & $\begin{array}{l}\text { Community, } \\
\text { Responsibility }\end{array}$ \\
\hline Danielle & $\begin{array}{l}\text { Cooking based on what is } \\
\text { fresh and ready for harvest }\end{array}$ & $\begin{array}{l}\text { Work-life } \\
\text { balance }\end{array}$ & $\begin{array}{l}\text { Community, } \\
\text { Responsibility }\end{array}$ \\
\hline Charles & Preparing efficient dinners & $\begin{array}{l}\text { Work-life } \\
\text { balance }\end{array}$ & Responsibility \\
\hline Cathy & $\begin{array}{l}\text { Abundant harvest, prepared } \\
\text { in many ways }\end{array}$ & Abundance & $\begin{array}{l}\text { Hedonism, } \\
\text { Community, } \\
\text { Responsibility }\end{array}$ \\
\hline Charles & $\begin{array}{l}\text { Abundant fresh berries } \\
\text { available }\end{array}$ & Abundance & $\begin{array}{l}\text { Hedonism, } \\
\text { Responsibility }\end{array}$ \\
\hline Melissa & $\begin{array}{l}\text { Preserving abundant harvest } \\
\text { with no waste }\end{array}$ & Abundance & $\begin{array}{l}\text { Responsibility, } \\
\text { Hedonism, } \\
\text { Community }\end{array}$ \\
\hline
\end{tabular}

\subsubsection{Hedonism}

Food activities were a source of hedonic pleasure and joy for participants. Hedonic eating has been shown to be a significant source of pleasure and happiness (Berenbaum, 2002; Csikszentmihalyi \& Wong, 1991; Macht, Haupt, \& Salewsky, 2004; Macht, et al., 2005). In this current study, the food experiences described as relatedness, sensations, expectations, and abundance were found to be associated with feelings of hedonic pleasure and happiness.

The data from this study add thick description and greater understanding of hedonic pleasure and what types of experiences may lead to hedonic pleasure; participants in this study described feeling hedonic pleasure from food experiences that had to do with 1) relatedness, such as cooking with family, learning how to garden from friends, and eating good food together, 2) sensory, such as eating fresh blueberries and 
working soil, 3) raised expectations about the quality of food, such as buying organic food, making nutrient rich soil, and enjoying rich egg yolks from backyard chickens, and 4) abundance, such as cooking foods in many different ways, buying and eating large amounts of berries, and preserving large quantities of food to enjoy later. Figure 4.1 shows how the descriptions of food experiences and shared meanings relate to the meta-themes.

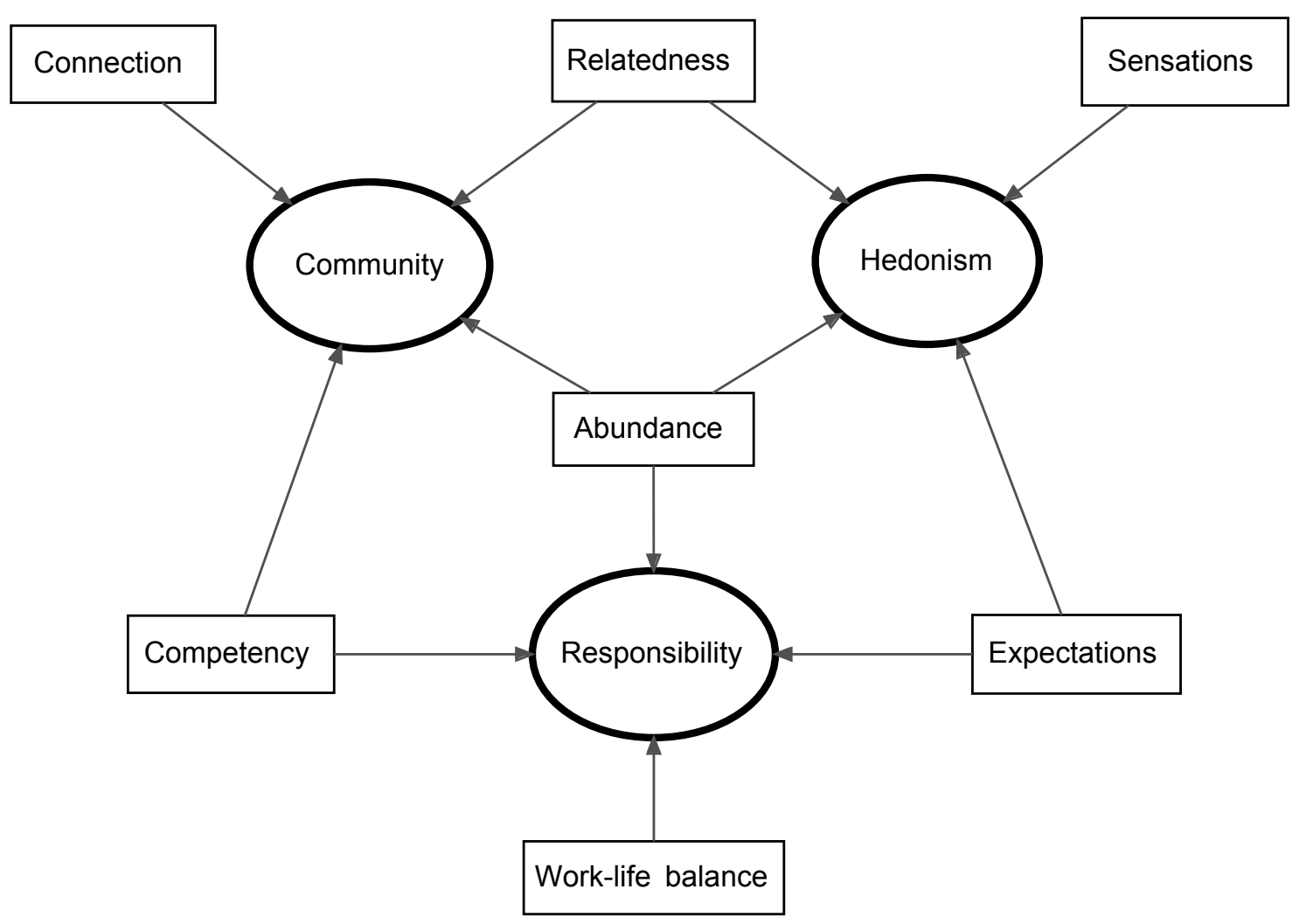

Figure 4.1. Shared meaning themes mapped onto feelings of satisfaction meta-themes

\subsubsection{Community}

Participants also described a variety of food experiences that were associated with the feeling of community. While gardening and cooking can sometime be solo activities, participants still felt a sense of community with other community gardeners, while 
cooking and eating food with friends and family, and through getting to know other food producers that they relied on. Some experiences that resulted in strengthened sense of community for participants overlapped with hedonic experiences; relatedness and abundance themed experiences involved both feelings of community and feelings of hedonic pleasure.

Other food experiences that involved a strengthened sense of community were described with the connection and competency themes: having a relationship with a blueberry farmer, cooking meals with newly harvests food from garden, being generous with food, and providing good nutrition to family and friends. These data provide insight into the relationship between happiness and belonging to a community, especially in the context of food. Part of the participant's joy in food activities involved a sense of being part of a community or communities so that the food experiences could be shared. Participants' happiness from food experiences also involved belonging to a greater community of food production and consumption.

\subsubsection{Responsibility}

Lastly, some food experiences were associated with feelings of responsibility. While some food experiences made participants happy because of sensory pleasure, others were satisfying because participants had identified them as being personally important, felt responsible to follow through with tasks, and felt happy when they had fulfilled their responsibility. Experiences associated with responsibility also elicited both hedonic pleasure and sense of community; food experiences described with the higher 
expectations of food quality theme were associated with both feelings of responsibility and hedonic pleasure, while experiences described with competency theme were associated with both feelings of responsibility and of community.

Food activities described with the Work-life balance theme were solely associated with feelings of responsibility; often participants describe how they were the one responsible in their family for planning the garden, harvesting, and planning and cooking meals. Food experiences described with the abundance theme were associated with feelings of responsibility, community, and hedonic pleasure. Participants took pleasure in sharing their abundance with their community, and felt a sense of responsibility to manage the abundant harvests efficiently to limit waste and increase future happiness by preserving the harvest.

\subsubsection{Limitations and Opportunities for future research}

Phenomenological research of food experiences and satisfaction is a relatively new research area, and there are many different subject areas that could be explored, as well as larger sample sizes, and participants with different demographics. This present study was limited by the sampling strategy; since participants were recruited from two community gardens, they lived in the same area, were of limited age range, lacked ethic diversity, and had shared experiences about the same garden area. Phenomenological research is not intended to be generalizable, but is exploratory, and meant to serve as inspiration or catalyst for future qualitative and quantitative research.

The exploratory findings from this current study have catalogued the types of 
activities and shared social constructs and meaning-making of the participant's food experiences. From this catalogue, quantitative hypotheses could be designed to test and refine these potential variables, to deepen understand of the relationships between these concepts, and to develop theories regarding the mechanisms or processes in which engaging in food experiences increases satisfaction and happiness. Quantitative methods could also be used to test and explore the generalizability of these concepts in relation to food experiences and satisfaction, by expanding the sample size and diversity of sample and developing an instrument to measure the extent of the shared meanings of food experiences. Similarly, a phenomenology study could be done on another sample of urban gardeners with different demographics, or in another geographic area, to compare and contrast to this current study.

To explore similar types of experiences, additional activities that were motivated by intrinsic aspirations could be identified and used to design a new phenomenological study expanding on the present study to explore the happiness and satisfaction felt from intrinsically motivated activities and the associated meaning-making. This may also help increase the generalizability of the shared meanings concepts and the associated psychological needs being met. Other intrinsically motivated nonmarket activities may include knitting or other creative hobbies such as woodworking, playing and writing music, and physical or outdoor activities such as sports or bird watching. 


\subsection{Conclusion}

Although the scope of this study was focused on gardening and food activities, a specific food activity, such as gardening, could not necessarily be generalized and applied to large groups of individuals to increase their happiness. Rather, it is the individually tailored and internally motivated aspects of the activities that were often a source of intense happiness. The shared meanings of these experiences can be used to illuminate a deeper understanding of what happiness means and how it can be felt through intrinsically motivated nonmarket activities. The diversity of food experiences and personal meanings taken from the experiences in this study suggest that intrinsically motivated, individually tailored nonmarket activities seem to increase participants' happiness.

This deeper understanding of the relationship between happiness and intrinsically motivated nonmarket activities can be used in school garden programs, other urban food production programs such as community orchards and community gardens, and clinical or therapeutic settings by allowing for flexibility and diversity of specific activities that can be individually tailored to be most enjoyable for each gardener. For example, school children could be encouraged to choose what type of gardening project that they were most interested in (i.e., carefully planning a garden, growing food to donate or prepare for their family, building healthy soil, savoring eating fresh berries, or learning a new skill), and would therefore be more intrinsically motivated and gain more satisfaction. 


\section{Synthesis}

\subsection{Introduction}

Materialistic lifestyles promise happiness and satisfaction through continuous acquisition of material goods. But research has shown that psychological satisfaction and well-being are higher for individuals with non-materialist, intrinsic life aspirations compared to individuals with materialist, extrinsic life aspirations. Additionally, materialist lifestyles and behaviors tend to use excessive natural resources and are less sustainable, while non-materialist, intrinsically motivated behaviors are potentially more sustainable since these experiential activities tend not to involve a never-ending desire to purchase material possessions.

While individual behavior change by itself may not be big enough to stem the tide of climate change and other impacts of global unsustainable behaviors, research has shown that consumers are important drivers for the way material goods and foods are produced and used, indicating that changes at an individual level can result in larger sustainable changes in cultural, economic, and governmental systems (Bin \& Dowlatabadi, 2005; Crompton, 2008; de Geus, 2003). The current study was motivated by a desire to understand in what way intrinsically motivated activities were satisfying for individuals, and to use this understanding to help individuals become more satisfied and less materialistic by developing food related materialism interventions. The current study explored first-person lived experiences of food activities of urban gardeners as a source of intrinsic satisfaction. Intrinsically motivated activities may not always be 
more sustainable than extrinsically motivated activities; for example, air travel may be highly satisfying, but may not be more sustainable than a more extrinsically motivated activity such as buying luxury clothes. But intrinsically motivated activities show potential in decreasing overall materialist life aspirations and behaviors in favor of more intrinsically motivated and, in general, more sustainable activities.

\subsection{Methods}

Phenomenology was used to explore the food experiences and the constructed meanings of the experiences of eight urban gardeners in Portland, Oregon. One-to-two hour semi-structured interviews and participant observations provided experiential data of urban gardeners who grow and prepare their own food. Participants were recruited using an intensity sampling criterion; participants were all members of one of two neighboring community gardens in South East Portland, had significant experience with personal food activities, and were willing to be interviewed and observed.

Interviews were audio and video recorded, and fully transcribed by the author.

Observational photographs and field notes were taken of the participant's living space and gardening space(s). In total, there were 104 single-spaced pages of transcripts, 330 photographic observations, and 30 pages of field notes, in addition to the audio and video recordings of the interviews.

Adhering to standard qualitative data explication methods, transcripts were separated into smaller units of meaning based on discrete sections of text ranging from a few words to a paragraph or more. Themes were developed iteratively, and were either 
deductively based on relevant concepts such as goal attainment, or inductively based, such as the distinct types of satisfaction felt from food activities. A subjective heuristic was used to determine whether or not categories and topics were significant enough to become a discrete theme. Significant themes needed to 1) be described by multiple participants, 2) be described as poignant or particularly meaningful, and 3) relate to relevant aspects of the research, such as satisfaction and meaning-making of food experiences or experiences of material possessions, and food project goal attainment, barriers, or outcomes.

Systems Science concepts and perspectives aided in data explication by providing multilevel pattern-seeking perspectives to form themes: 1) across participants' data, 2) within participants' data, 3) hierarchically within themes to form meta- and subthemes, and 4) iteratively, building on and modifying themes as necessary as more transcripts were explicated and added to the richness and complexity of the data (Hall, 1969; Linstone, 1999; Senge, 2006).

\subsection{Results}

Findings from the current study suggest that food projects can be: 1) self-concordant (motivated by both personally important and pleasurable reasons), such as creativity, curiosity, competency, and sensory pleasure; 2) were affected by enabling factors such as social relationships and inhibiting factors, such as money, time, energy, and health; and 3) resulted in feelings of life satisfaction, and strength and confidence.

Additionally, when describing experiences of material possessions, some urban 
gardeners described strong minimalist, anti-materialist sentiment, while others described hedonic, intrinsically satisfying experiences with material possessions, and still others described materialist tendencies. Intrinsic life aspirations were evident in rich descriptions of food experiences and material possessions that included sensory pleasure, mindfulness, connection with production sources, creative and personal expression, spirituality, generosity, security, and learning. Minimalists' experiences with food and material possessions satisfied psychological needs for comfort and sensory pleasure, while avoiding dissatisfying experiences of becoming overwhelmed by overly complex food preparation, and too many, cluttered or messy material possessions. For hedonists, gardening, food, and material possessions provide ample opportunities to have complex, creative, involved, time-consuming sensory-rich experiences. For materialists, food experiences were satisfying, but this subset of study participants were noticeably more materialistic in their food and material possessionrelated experiences compared to the other participants. Many of their experiences focused on external motivations, and reinforcing social relationships, such as impressing people with their cooking and holding onto excessive material possessions because of sentimentality.

The data also indicate that the experiences can be described both in terms of similar personal meanings and as unique and highly individual. Each participant's specific food experience and their personal meaning taken from that experience were unique. For example, some participants wanted to spend time and energy improving their garden 
soil, while others were not concerned with soil quality. Additionally, the same type of food activity often had different personal meanings for different participants. The highly individualized experiences described by participants aids in deepening understanding of the relationship between intrinsic life aspirations and happiness.

These highly individualized food activities were ascribed similar, shared meanings by participants, as described in terms of the themes: 1) Relatedness: spending time being social, 2) Connection: direct relationship with food, 3) Sensations: eating with awareness and pleasure, 4) Expectations: getting used to good food, 5) Competency: pride in abilities and self-sufficiency, 6) Work-life balance: food as part of regular life, and 7) Abundance: feeling wealth and gratitude. These shared meanings increased the participants happiness in similar ways and satisfied common psychological needs, and can be described in terms of three overarching happiness concepts: responsibility, community, and hedonism.

\subsection{Discussion and Conclusion}

This study shows that 1 ) when asked about food projects, participants were intrinsically motivated, experienced strong competency, and were very satisfied in many different ways by their food projects; that 2) there is a spectrum of anti-materialist to materialist experiences among individuals who engage in nonmarket gardening and food activities, ranging from minimalist to somewhat materialist; and that 3) the food experiences were both highly individualized for each participant, and could also be described in terms of shared meanings and similar types of satisfaction. 
Findings indicate that gardening and food production are more complex than a series of intrinsically satisfying activities; rather they are often embedded in larger food projects or other goal attainment processes, and are often self-concordant. The motivations and activities that make up these food projects have been shown to be mainly hedonic and intrinsic, with identified aspects motivating and facilitating goal attainment. This study also suggests that satisfying a need for competency is a major motivator for gardeners engaging in food projects.

This study also revealed that individuals who engage in nonmarket activities such as gardening and cooking may be motivated in their experiences of food and their material possessions by a combination of intrinsic and extrinsic aspirations. Participants were characterized in terms of their relationships with material possessions as minimalist, hedonist, or materialist. But even within the characterizations of materialists, experiential activities and intrinsic aspirations were evident, indicating intrinsic elements within each individual. Also, while these experiential activities can be characterized as similar in action or behavior, the specific experience and meaning taken from these actions is unique to each individual and satisfies different psychological needs for different individuals.

Although the scope of this study was focused on gardening and food activities, a specific food activity, such as gardening, could not necessarily be generalized and applied to large groups of individuals to increase their happiness. Rather, it is the individually tailored and internally motivated aspects of the activities that were often a 
source of intense happiness. The shared meanings of these experiences can be used in further research to illuminate a deeper understanding of what happiness means and how it can be felt through intrinsically motivated nonmarket activities, by expanding the sample size and/or exploring other activities. The diversity of food experiences and personal meanings taken from the experiences in this study suggest that intrinsically motivated, individually tailored nonmarket activities may be positively associated with participants happiness, and may be useful in materialism interventions.

\subsubsection{Limitations of Current Study and Contributions to Literature}

Phenomenological research of food experiences and satisfaction is a relatively new research area, and there are many different subject areas that could be explored, as well as larger sample sizes, and participants with different demographics.

\subsubsection{Limitations}

The present study was limited by the sample size and sampling strategy; since participants were recruited from two community gardens, they lived in the same area, were of limited age range, lacked ethnic diversity, and had shared experiences about the same garden area. Additionally, the intensity sampling criterion was supposed to yield only low-materialists to delve deeply into the nature of intrinsically motivated experiences but instead, much to the surprise of this researcher, there were several participants who were somewhat materialistic. The small sample size means that the results from this study are not generalizable, and that the current study is more preexploratory than exploratory, offering potential avenues of future research based on a 
small group of individuals' experiences.

The theoretical lens of this research topic included a hypothesis that intrinsically motivated nonmarket activities such as gardening and cooking may be so satisfying and positively reinforcing that they would be an effective intervention against materialism and extrinsic life aspirations. Although this current study did find that participants could be characterized along a spectrum of materialism (minimalist, hedonist, and materialist), it was beyond the scope of this exploratory qualitative study to draw conclusions about the effectiveness of using gardening as an intervention to decrease materialism. Rather, this study provided a deeper understanding of experiential and materialist experiences, and how intrinsic and extrinsic life aspirations are experienced as activities.

\subsubsection{Significance}

The findings from this study build theory and provide direction for potential future research in: 1) developing measures for types of satisfaction from food activities and testing correlations with materialism and life satisfaction, 2) exploring satisfaction felt from a wider range of intrinsically motivated nonmarket activities, and 3) exploring the role that work-life balance and time-wealth play in facilitating adoption of intrinsically motivated nonmarket activities.

Setting aside the unconfirmed relationships between food activities, intrinsic life aspirations, and materialism, this current study provided a deeper understanding of a small sample of individuals' experiences of food activities and projects, including the 
motivations for starting activities, enablers and inhibitors of activities, and resulting feelings of satisfaction from the activities. The findings expanded upon suggestions that motivations for gardening are entirely experiential (e.g., connection with nature) (Kaplan, 1973), by exploring gardening as a set of projects and goals, not just a series of events or activities. This study also built upon previous work done on self-concordance (Deci \& Ryan, 2008a; Kasser \& Ryan, 1996; Sheldon \& Elliot, 1999; Sheldon, et al., 2004; Sheldon \& Houser-Marko, 2001) and self-determination theory (Deci, et al., 1994; Deci \& Ryan, 2008a, 2008b; Moller, et al., 2006), to provide a more in-depth, rich description of how these theories and processes are experienced by individuals.

Additionally, this current study began to address the gaps in literature involving the phenomenological, first-person lived experiences of food activities that may be intrinsically motivated, and how these experiences are related to increases in happiness and satisfaction of psychological needs, by providing a broader understanding of happiness and satisfaction from food activities. The shared meanings and positive feelings from food experiences expand the current understanding of happiness and satisfaction.

\subsubsection{Recommendations for Future Research}

Despite the limitations stated above, the current study laid initial groundwork for exploring the correlation between intrinsically motivated activities and decreases in materialism by providing experiential thick descriptions of gardening and cooking. While there is considerable research on quantitative measures for materialism in terms 
of extrinsic versus intrinsic life aspirations, there is very little current literature on measuring changes in life aspirations from extrinsic to intrinsic, or correlations between changes in life aspirations and nonmarket activities or lifestyle changes. Future research questions may include: 1) How can various types of satisfaction from food activities be measured (i.e., competency, personal expression and creativity, spirituality and connection with nature)? 2) do these measures correlate positively with standard life satisfaction measures? and 3) Are the various types of satisfaction from food activities and materialism negatively correlated?

The findings from this current study have catalogued the types of activities and shared social constructs and meaning-making of the participant's food experiences. From this catalogue, quantitative hypotheses could be designed to test and refine these potential variables. Additional tests and refinement would deepen understanding of the relationships between these concepts and facilitate development of theories regarding the mechanisms or processes in which engaging in food experiences increases satisfaction and happiness. Quantitative methods could also be used to test and explore the generalizability of these concepts in relation to food experiences and satisfaction, by expanding the sample size and diversity of the sample, by developing an instrument to measure the extent of the shared meanings of food experiences. Similarly, a phenomenology study could be done on another sample of urban gardeners with different demographics, or in another geographic area, to compare and contrast to this current study. 
To explore similar types of experiences, additional activities that were motivated by intrinsic aspirations could be identified and used to design a new phenomenological study expanding on the present study to explore the happiness and satisfaction felt from intrinsically motivated activities, and the associated meaning-making. This may also help increase the generalizability of the shared meanings concepts and the associated psychological needs being met. Other intrinsically motivated nonmarket activities may include knitting or other creative hobbies such as woodworking, performing and writing music, and physical or outdoor activities such as sports or bird watching.

Also, a large component of materialism research focuses on individuals choosing to work less and earn less money in favor of increasing leisure time (Huneke, 2005; Leonard-Barton, 1981; Shaw \& Newholm, 2002), but time use and time commitments were beyond the scope of the current study. Studies show that materialists have high stress and feel compelled to commit more time to work in order to keep up with their materialistic lifestyles (Kasser, 2003; Kasser \& Ryan, 1993, 1996; Richins \& Dawson, 1992; Richins \& Rudmin, 1994; Schwartz, 2004). A few participants in this study expressed interest in spending less time maintaining material possessions. The data also revealed that time spent gardening was limited by the amount that gardeners were working or had family obligations. Finding from this study indicate that many individuals do make time for experiential activities, even those who have not yet retired, but that it can be a struggle to maintain time commitments for nonmarket 
activities, in the face of social, family, and other personal responsibilities. Time wealth prioritization could be an avenue of future research. A possible research question from an intention-behavior gap perspective (King, et al., 2006; Sheldon, et al., 2002) could include: Under what circumstances do intrinsically aspiring individuals succeed in increasing their free time?

Another area of future research for studying decreases in materialistic lifestyles involves Sustainable Thinking (Doppelt, 2010; Ehrenfeld, 2008; Senge, 2006;

Shellenberger \& Nordhaus, 2004). Doppelt suggests that for our society to become more sustainable individuals must embrace their connection with their natural environment and with humanity at large (2010). The process of adopting Sustainable Thinking has many parallels to Systems Science ideas, including cognitive reframing (identifying unsustainable thoughts and behaviors and creating new patterns of thoughts and behaviors that are more sustainable), downplaying costs, making perceived benefits loom larger, increasing sustainability-reinforcing social relationships, and redesigning social and physical structures to elicit more sustainable behaviors (Crompton, 2008; Doppelt, 2010; Ehrenfeld, 2008; Shellenberger \& Nordhaus, 2004). Future research could include developing and testing materialism interventions that teach individuals about Systems Thinking and Sustainable Thinking concepts. 


\subsubsection{Recommendations for Policy and Existing Practice}

As one example of internally motivated nonmarket projects, gardening and food projects show great promise for increasing the well-being for a broad range of individuals. Gardening and food related hobbies are inexpensive, have low physical and environmental impact, and can be enjoyed across a variety of geographies. With the existence of community and school gardens, individuals without their own land are able to grow their own food.

Additionally, insight from individuals' experiences of self-concordant projects such as gardening can deepen understanding of adoption and positive reinforcement of internally motivated nonmarket projects. With additional research to further explore the effects of food activities, the findings from this current study may be beneficial in policy and sustainability context to explore how to encourage individuals to more efficiently utilize urban spaces for food production and community building, and in a therapeutic or clinical contexts to explore how to help individuals become physically, mentally, and emotionally healthier through gardening.

The results of this study can inform future research on urban food production policy and garden therapy methods by more clearly understanding motivations behind gardening and the satisfaction felt by gardening. Gardening is potentially rewarding and satisfying in and of itself as an experience, not just as a means to an end. Gardening and cooking interventions could be planned to test how intrinsically satisfying experiences they may be, in addition to potentially encouraging sustainability, community building 
and mental, emotional, and physical health. 


\section{References}

Alkon, A. (2007). From value to values: sustainable consumption at farmers markets. Agriculture and Human Values. doi: 10.1007/s10460-008-9136-y

Andrews, C., \& Urbanska, W. (2009). Less is More. Gabriola Island, BC, Canada: New Society Publishers.

Bailey, C. A. (2007). A guide to qualitative field research. Newbury Park, CA: Pine Forge Press.

Bates, R. (Writer). (2009). Ingredients: a documentary film. United States.

Beavan, C. (2007, October 28). The No Impact Experiment. Retrieved from http://noimpactman.typepad.com/

Belk, R. W. (1985). Materialism: Trait Aspects of Living in the Material World. The Journal of Consumer Research, 12(3), 265-280.

Bentz, V. M., \& Shapiro, J. J. (1998). Mindful inquiry in social research. Thousand Oaks, CA: Sage.

Berenbaum, H. (2002). Varieties of joy-related pleasurable activities and feelings. Cognition and Emotion, 16(4), 473-494. doi: 10.1080/0269993014000383

Berry, W. (1990). What are people for?: essays. New York: North Point Press.

Bhatti, M., Church, A., Claremont, A., \& Stenner, P. (2009). 'I love being in the garden': enchanting encounters in everyday life. Social \& Cultural Geography, 10(1), 61-76. doi: 10.1080/14649360802553202

Bin, S., \& Dowlatabadi, H. (2005). Consumer lifestyle approach to US enery use and the related CO2 emissions. Energy Policy, 33, 197-208. doi: 10.1016/S03014215(03)00210-6

Bishop, S., Lau, M., Shapiro, S., Carlson, L., Anderson, N. D., Carmody, J., . . Devins, G. (2004). Mindfulness: A Proposed Operation Definition. Clinical Psychology: Science and Practice, 11(3). doi: 10.1093/clipsy/bph077

Bisogni, C. A., Conners, M., Devine, C. M., \& Sobal, J. (2002). Who We Are and How We Eat: A Qualitative Study of Identities in Food Choice. Journal of Nutrition Education and Behavior, 34(3), 128-139.

Bisogni, C. A., Jastran, M., Shen, L., \& Devine, C. M. (2005). A Biographical Study of 
Food Choice Capacity: Standards, Circumstances, and Food Management Skills. Journal of Nutrition Education and Behavior, 37(6), 384-291.

Burke, D., \& Linley, P. A. (2007). Enhancing goal self-concordance through coaching. International Journal of Coaching Psychology Review, 2(1).

Burroughs, J. E., \& Rindfleisch, A. (2002). Materialism and Well-Being: A Conflicting Values Perspective. Journal of Consumer Behaviour, 29.

Burton, K. D., Lydon, J. E., D’Alessandro, D. U., \& Koestner, R. (2006). The Differential Effects of Intrinsic and Identified Motivation on Well-Being and Performance: Prospective, Experimental, and Implicit Approaches to Self-Determination Theory. Journal of Personality and Social Psychology, 91(4), 750-762. doi: 10.1037/00223514.91.4.750

Carlomagno, M. (2005). Give It Up!: My Year of Learning to Live Better with Less. New York: HarperCollins Publishers, Inc.

Cheng, H.-p. (2010). Serious Leisure, Leisure Satisfaction and Gardening by Older Adults. The University of Queensland, Queensland, Australia.

City of Portland Bureau of Planning and Sustainability. (2006). Comprehensive Plan Goals and Policies. Portland, Oregon.

City of Portland Bureau of Planning and Sustainability. (2011). Portland Multnomah Food Policy Council Retrieved 8/30/2011, 2011

Clayton, S. (2007). Domesticated nature: Motivations for gardening and perceptions of environmental impact. Journal of Environmental Psychology, 27, 215-224.

Cotte, J., Rathenshwar, S. R., \& Mick, D. G. (2004). The Times of Their Lives: Phenomenological and Metaphorical Characteristics of Consumer Timestyles. Journal of Consumer Research, 31.

Creswell, J. W. (2007). Qualitative inquiry \& research design: choosing among five approaches. Thousand Oaks, CA: Sage Publishers.

Crompton, T. (2008). Weathercocks \& Signposts: The environmental movement at a crossroads: World Wildlife Fund UK.

Csikszentmihalyi, M. (1999). If We Are So Rich, Why Aren't We Happy? American Psychologist, 54(10), 821-827.

Csikszentmihalyi, M. (2000). Happiness, Flow, and Econmoic Equality. American 
Psychologist, 55(10), 1163-1164. doi: 10.1037//0003-066X.55.10.1163

Csikszentmihalyi, M., \& Wong, M. M.-H. (1991). The situational and personal correlates of happiness: a cross-national comparison. In F. Strack, M. Aryle \& N. Schwarz (Eds.), Subjective Well-being: an interdisciplinary perspective (pp. 193-212). Oxford: Pergamon.

d'Astous, A., \& Mathieu, S. (2008). Inciting consumers to buy fairly-traded products: a field experiment. Journal of Consumer Marketing, 25(3), 149-157. doi: 10.1108/07363760810870644

de Geus, M. (2003). The End of Over-consumption: Towards a Lifestyle of Moderation and Self-restraint. Utrecht, the Netherlands: International Books.

De Graaf, J., Wann, D., \& Naylor, T. (2001). Affluenza: The All-consuming Epidemic. McGraw-Hill Publishing Co.

Deci, E. L. (1975). Intrinsic Motivation. New York, NY: Plenum Press.

Deci, E. L., Eghrari, H., Patrick, B. C., \& Leone, D. R. (1994). Facilitating Internalization: The Self-Determination Theory Perspective. Journal of Personality, 62(1).

Deci, E. L., \& Ryan, R. M. (2000). The "What" and "Why" of Goal Pursuits: Human Needs and the Self-Determination of Behavior. Psychological Inquiry, 11(4), 227-268. doi: 10.1207/S15327965PLI1104_01

Deci, E. L., \& Ryan, R. M. (2008a). Facilitating Optimal Motivation and Psychological Well-Being Across Life's Domains Canadian Psychology, 49(1), 14-23. doi: 10.1037/0708-5591.49.1.14

Deci, E. L., \& Ryan, R. M. (2008b). Self-Determination Theory: A Macrotheory of Human Motivation, Development, and Health. Canadian Psychology, 49(3), 182-185. doi: $10.1037 / \mathrm{a} 0012801$

Devine, C. M. (2003). A Life Course Perspective: Understanding Food Choices in Time, Social Location, and History. Journal of Nutrition Education and Behavior, 37, 121128.

Dibsdall, L. A., Lambert, N., \& Frewer, L. J. (2002). Using Interpretative Phenomenology to Understand the Food-Related Experiences and Beliefs of a Select Group of Low-Income UK Women. Journal of Nutrition Education and Behavior, 34, 298-309.

Diener, E., Emmons, R. A., Larsen, R. J., \& Griffin, S. (1985). The Satisfaction with Life References Materialism, Food, and Satisfaction 153 
Scale. Journal of Personality Assessment, 49(1).

Diener, E., Lucas, R. E., \& Scollon, C. N. (2009). Beyond the Hedonic Treadmill: Revising the Adaptation Theory of Well-Being. In E. Diener (Ed.), The Science of Well-Being: The Collected Works of Ed Diener (pp. 237). New York, NY: Springer.

Doppelt, B. (2010). The Power of Sustainable Thinking: How to Create a Positive Future for the Climate, the Planet, Your Organization and Your Life. Abingdon, Oxford, UK: Earthscan Publications Ltd.

EcoTrust. (2011). FoodHub Retrieved 8/30/2011, 2011, from http://www.ecotrust.org/foodhub/

Editorial. (2007). Studying the ethical consumer: A review of research. Journal of Consumer Behaviour, 6, 253-270. doi: 10.1002/cb.225

Ehrenfeld, J. R. (2008). Sustainability by Design: A Subversive Strategy for Transforming Our Consumer Culture. New Haven and London: Yale University Press.

Elgin, D. (2009). Voluntary Simplicity: Toward a Way of Life That Is Outwardly Simple, Inwardly Rich. New York: HarperCollins Publishers, Inc.

Emmons, R. A., \& Crumpler, C. A. (2000). Gratitude as a Human Strength: Appraising the Evidence. Journal of Social and Clinical Psychology, 19(1), 56-69.

Emmons, R. A., \& McCullough, M. E. (2003). Counting Blessings Versus Burdens: An Experimental Investigation of Gratitude and Subjective Well-Being in Daily Life. Journal of Personality and Social Psychology, 84(2), 377-389. doi: 10.1037/00223514.84.2.377

Essoussi, L. H., \& Zahaf, M. (2008). Decision making process of community organic food consumers: an exploratory study. Journal of Consumer Marketing, 25(2), 95-104. doi: 10.1108/07363760810858837

Fisher, M. F. K., \& Reardon, J. (2004). The Art of Eating. Hoboken, NJ: Wiley Publishing.

Fromm, E. (1976). To Have or To Be? (1st ed.). New York, NY: Harper \& Row.

Giorgi, A. (2006). Difficulties encountered in the application of the phenomenological method in the social sciences. Análise Psicologica, 3(XXIV), 353-361.

Goodman, D., \& DuPuis, E. M. (2002). Knowing Food and Growing Food: Beyond the Production-Consumption Debate in the Sociology of Agriculture Sociologia ruralis, 42(1), 5-22. 
Gordon, E. (2006). Growing a Garden of Access, Opportunity and Healing: The Voices of Eugene's Community Gardens. Eugene: University of Oregon, Environmental Leadership Program.

Gregg, R. (1936). The Value of Voluntary Simplicity (Vol. 3). Wallingford, PA: Pendle Hill Publications.

Grewe, T., Anderson, S., \& Butman, L. (2002). Portland, Oregon: A Case Study in Sustainability. Government Finances Review.

Groenwald, T. (2004). A Phenomenological Research Design Illustrated. International Journal of Qualitative Methods, 3(1).

Gross, H., \& Lane, N. (2007). Landscapes of the lifespan: Exploring accounts of own gardens and gardening. Journal of Environmental Psychology, 27, 225-241.

Grouzet, F. M. E., Kasser, T., Ahuvia, A., Dols, J. M. F. n., Kim, Y., Lau, S., . . Sheldon, K. M. (2005). The Structure of Goal Contents Across 15 Cultures. Journal of Personality and Social Psychology, 89(5), 800-816. doi: 10.1037/0022-3514.89.5.800

Gunderson, L. H., \& Holling, C. S. (2001). Panarcy: Understanding Transformations in Human and Natural Systems: Island Press.

Hale, J., Knapp, C., Bardwell, L., Buchenau, M., Marshall, J., Sancar, F., \& Litt, J. S. (2011). Connecting food environments and health through the relational nature of aesthetics: Gaining insight through the community gardening experience. Social Science \& Medicine, 72, 1853-1863. doi: 10.1016/j.socscimed.2011.03.044

Hall, A. D. (1969). Three Dimensional Morphology of Systems Engineering. IEEE Transactions on Systems Science and Cybernetics, SSC-5(2).

Herman, B. L. (2009). Drum Head Stew The Power and Poetry of Terroir. Southern Cultures, 15(4), 36-49. doi: 10.1353/scu.0.0081

Hinrichs, C. (2000). Embeddedness and local food systems: notes on two types of direct agricultural market. Journal of Rural Studies, 16, 295-303.

Holt, D. B. (1995). How Consumers Consume: A Typology of Consumption Practices. Journal of Consumer Research, 22.

Huneke, M. E. (2005). The Face of the Un-Consumer: An Empirical Examination of the Practice of Voluntary Simplicity in the United States. Psychology \& Marketing, 22(7), 527-550. doi: 10.1002/mar.20072 
Inglehart, R. (1981). Post-Materialism in an Environment of Insecurity. The American Political Science Review, 75(4), 880-900.

Jackson, D. J., L. (2002). The Farm as Natural Habitat: Reconnecting Food Systems with Ecosystems (1 ed.). Washington, D. C.: Island Press.

Kaplan, R. (1973). Some Psychological Benefits of Gardening. Environment and Behavior, 5(2). doi: 10.1177/001391657300500202

Kasser, T. (2003). The High Price of Materialism: MIT Press.

Kasser, T., \& Kanner, A. D. (2004). Psychology and consumer culture : the struggle for a good life in a materialistic world. Washington, D.C.: American Psychological Association.

Kasser, T., \& Ryan, R. M. (1993). A Dark Side of the American Dream: Correlates of Financial Success as a Central Life Aspiration. Journal of Personality and Social Psychology, 65(2), 410-422.

Kasser, T., \& Ryan, R. M. (1996). Further Examining the American Dream: Differential Correlates of Intrinsic and Extrinsic Goals. Personality and Social Psychology Bulletin, 22(3), 280-287. doi: 10.1177/0146167296223006

Kemmer, D. (2000). Tradition and Change in Domestic Roles and Food Preparation. Sociology, 34. doi: 10.1177/S0038038500000201

Kensit, D. A. (2000). Rogerian theory: a critique of the effectiveness of pure clientcentered therapy. Counseling Psychology Quarterly, 13(4), 345-351.

Kiesling, F. M., \& Manning, C. M. (2010). How green is your thumb? Environmental gardening identity and ecological gardening practices. Journal of Environmental Psychology, 30, 315-327.

Kim, D., \& Ohara, K. (2009). A Study on the Role of Gardening and Planning of Green Environments for Daily Use by Residents in Senior Housing. Journal of Asian Architecture and Building Engineering, 61.

King, L. A., Hicks, J. A., Krull, J. L., \& Del Gaiso, A. K. (2006). Positive affect and the Experience of Meaning of Life. Journal of Personality and Social Psychology, 90(1), 179-196. doi: 10.1037/0022-3514.90.1.179

Koestner, R., Horberg, E. J., Gaudreau, P., Powers, T., Di Dio, P., Bryan, C., \& Jochum, R. (2006). Bolstering Implementation Plans for the Long Haul: The Benefits of Simultaneously Boosting Self-Concordance or Self-Efficacy. Personality and Social

References $\quad$ Materialism, Food, and Satisfaction 156 
Psychology Bulletin, 32. doi: 10.1177/0146167206291782

Koestner, R., Lekes, N., Powers, T. A., \& Chicoine, E. (2002). Attaining Personal Goals: Self-Concordance Plus Implementation Equals Success. Journal of Personality and Social Psychology, 83(1), 231-244. doi: 10.1037//0022-3514.83.1.231

Kristeller, J. L. (2003). Mindfulness, Wisdom and Eating: Applying a Multi-Domain Model of Mediation Effects. Journal of Constructism in the Human Sciences, 8(2), 107118.

Kvale, S. (1996). Interviews: an introduction to qualitative research interviewing. Thousand Oaks, CA: Sage.

Lautenschlager, L., \& Smith, C. (2007). Beliefs, knowledge, and values held by inner-city youth about gardening, nutrition, and cooking. Agriculture and Human Values, 24, 245-258. doi: 10.1007/s10460-006-9051-z

Leonard-Barton, D. (1981). Voluntary Simplicity Lifestyles and Energy Conservation. The Journal of Consumer Research, 8(3).

Levenstein, H. (2003). Revolution at the table: the transformation of the American diet. Berkely, CA: University of California Press.

Linstone, H. A. (1999). Decision Making for Technology Executives: Using Multiple Perspectives to Improve Performance. Boston and London: Artech House.

Lockie, S. (2002). 'The Invisible Mouth': Mobilizing 'the Consumer' in Food ProductionConsumption Networks. Sociologia ruralis, 42(4).

Losier, G., \& Koestner, R. (1999). Intrinsic Versus Identified Regulation in Distinct Political Campaigns: The Consequences of Following Politics for Pleasure Versus Personal Meaningfulness. Personality and Social Psychology Bulletin, 25(3), 287-298.

Lyson, T. (2005). Civic Agriculture and Community Problem Solving. Culture and Agriculture, 27(2), 92-98.

Lyubomirsky, S., \& Sheldon, K. M. (2005). Pursuing Happiness: the Architechture of Sustainable Change. Review of General Psychology, 9(2), 111-131. doi: 10.1037/10892680.9.2.111

Macht, M., Haupt, C., \& Salewsky, A. (2004). Emotions and eating in everyday life: application of the experience-sampling method. Ecology of Food and Nutrition, 43(4), 11-21. doi: 10.1080/03670240490454723 
Macht, M., Meininger, J., \& Roth, J. (2005). The Pleasures of Eating: A Qualitative Analysis. Journal of Happiness Studies, 6, 137-160. doi: 10.1007/s10902-005-0287-x

Maclaran, P., \& Brown, S. (2005). The Center Cannot Hold: Consuming the Utopian Marketplace. Journal of Consumer Research, 32.

Maniates, M. (2002). In Search of Consumptive Resistance: The Voluntary Simplicity Movement. In T. Princen, M. Maniates \& K. Conca (Eds.), Confronting Consumption (pp. 382). Cambridge, MA: Massachusetts Institute of Technology.

Maslow, A. H. (1954). Motivation and Personality. New York, NY: Harper.

McLaren, B. D. (2004). A Generous Orthodoxy. Grand Rapids, MI: Zondervan/Youth Specialties.

Meadows, D., Randers, J., \& Meadows, D. (2004). Limits to Growth: The 30-Year Update. White River Junction, Vermont: Chelsea Green.

Moller, A. C., Ryan, R. M., \& Deci, E. L. (2006). Self-Determination Theory and Public Policy: Improving the Quality of Consumere Decisions Without Using Coercion. Journal of Public Policy \& Marketing, 25(1), 104-116.

Morris, C., \& Buller, H. (2003). The local food sector: A preliminary assessment of its form and impact in Gloucestershire. British Food Journal, 105(8), 559-566. doi: 10.1108/00070700310497318

Moustakas, C. (1994). Phenomenological Research Methods. Thousand Oaks, CA: Sage.

Murdoch, J., Marsden, T., \& Banks, J. (2000). Quality, Nature, and Embeddedness: Some Theoretical Considerations in the Context of the Food Sector. Economic Geography, 76(2), 107-125.

New American Dream. (2011). Beyond Consumerism Retrieved October 28, 2011, from http://www.newdream.org/programs/beyond-consumerism

Niemiec, C. P., Ryan, R. M., \& Deci, E. L. (2009). The path taken: Consequences of attaining intrinsic and extrinsic aspirations in post-college life. Journal of Research in Personality, 43, 291-306. doi: 10.1016/j.jrp.2008.09.001

Patton, M. Q. (2002). Qualitative research and evaluation methods. Thousand Oaks, CA: Sage.

Penker, M. (2006). Mapping and measuring the ecological embeddedness of food supply chains. Geoforum, 37, 368-379. doi: 10.1016/j.geoforum.2005.09.001

References

Materialism, Food, and Satisfaction 158 
Petrini, C., \& Padovani, G. (2006). Slow Food Revolution: A New Culture for Eating and Living. New York: Rizzoli.

Pierce, L. B. (2000). Choosing Simplicity: Real People Finding Peace and Fulfillment in a Complex World (1st ed.). Carmel, CA: Gallagher Press.

Pirog, R. (2004). Food Miles: A Simple Metaphor to Contrast Local and Global Food Systems. Hunger and Environmental Nutrition (HEN) Dietetic Practice Group of the American Dietetic Association.

Ragin, C. C., Nagel, J., \& White, P. (2004). Workshop on Scientific Foundations of Qualitative Research: National Science Foundation.

Reeve, J., Jang, H., Hardre, P., \& Omura, M. (2002). Providing a Rationale in an Autonomy-Supportive Way as a Strategy to Motivate Others During an Uninteresting Activity. Motivation and Emotion, 26(3).

Richins, M. L., \& Dawson, S. (1992). A Consumer Values Orientation for Materialism and Its Measurement: Scale Development and Validation. The Journal of Consumer Research, 19(3), 303-316. doi: 0093-5301/93/1903-0001

Richins, M. L., \& Rudmin, F. W. (1994). Materialism and economic psychology. Journal of Economic Psychology, 15, 217-231.

Rivera-Caudill, J., \& Brander, A. A. (2008). Michigan Youth Farm Stand Project: Facets of Participant Motivation. Journal of Career and Technical Education, 24(2).

Robin, V., Dominguez, J., \& Tilford, M. (2008). Your Money Or Your Life: 9 Steps to Transforming Your Relationship with Money and Achieving Financial Independence: Revised and Updated for the 21st Century. New York: Penguin.

Roth, G. (2003). Breaking Free from Emotional Eating. New York, NY: Penguin.

Roth, G. (2010). When You Eat at the Refrigerator, Pull Up a Chair: 50 Ways to Feel Thin, Gorgeous, and Happy (When You Feel Anything But). New York, NY: HarperCollins Publishers, Inc.

Rozin, P. (1996). Towards a Psychology of Food and Eating: From Motivation to Module to Model to Marker, Morality, Meaning, and Metaphor. Current Directions in Psycholocial Science, 5(1), 18-24.

Rozin, P. (2005). The Meaning of Food in Our Lives: A Cross-Cultural Perspective on Eating and Well-Being. Journal of Nutrition Education and Behavior, 37, S107-S112. 
Rozin, P., Kabnick, K., Pete, E., Fischler, C., \& Shields, C. (2003). The Ecology of Eating: Smaller Portion Sizes in France than in the United States Help Explain the French Paradox. Psychological Science, 14(5), 450-454.

Russell, C. A., \& Levy, S. J. (2012). The Temoral and Focal Dynamics of Volition Reconsumption: A Phenomenological Investigation of Repeated Hedonic Experiences. Journal of Consumer Research, 39(2), 341-359.

Ryan, R. M., \& Deci, E. L. (2000). Self-Determination Theory and the Facilitation of Intrinsic Motivation, Social Development, and Well-Being. American Psychologist, 55(1), 68-78. doi: 10.1037110003-066X.55.1.68

Ryan, R. M., Frederick, C. M., Lepes, D., Rubio, N., \& Sheldon, K. M. (1997). Intrinsic Motivation and Exercise Adherence. International Journal of Sports Psychology, 28, 335-354.

Schor, J. (1999). The overspent American: why we want what we don't need: HarperPerennial.

Schwartz, B. (2004). The Paradox of Choice (1st ed.). New York: HarperCollins Publishers Inc.

Seamon, D. (1982). The Phenomenology Contribution to Environmental Psychology. Journal of Environmental Psychology, 2, 119-140.

Seamon, D. (2000). A Way of Seeing People and Place: Phenomenology in EnvironmentBehavior Research Theoretical perspectives in environment-behavior research: underlying assumptions, research problems, and methodologies (pp. 157-178). New York, NY: Plenum.

Senge, P. (2006). The Fifth Discipline: The Art \& Practice of The Learning Organization (Revised Edition ed.). New York: Currency Doubleday.

Shaw, D., \& Newholm, T. (2002). Voluntary Simplicity and the Ethics of Consumption. Psychology \& Marketing, 19(2), 167-185.

Sheldon, K. M., \& Elliot, A. J. (1999). Goal Striving, Need Satisfaction, and Longitudinal Well-Being: The Self-Concordance Model. Journal of Personality and Social Psychology, 76(3), 482-497.

Sheldon, K. M., Elliot, A. J., Kim, Y., \& Kasser, T. (2001). What Is Satisfying About Satisfying Events? Testing 10 Candidate Psychological Needs. Journal of Personality and Social Psychology, 80(2), 325-339. doi: 10.1037//O022-3514.80.2.325 
Sheldon, K. M., Elliot, A. J., Ryan, R. M., Chirkov, V., Kim, Y., Wu, C., . . Sun, Z. (2004). Self-Concordance and Subjective Well-Being in Four Cultures. Journal of CrossCultural Psychology, 35(2), 209-223. doi: 10.1177/0022022103262245

Sheldon, K. M., \& Houser-Marko, L. (2001). Self-Concordance, Goal Attainment, and the Pursuit of Happiness: Can There Be an Upward Spiral? Journal of Personality and Social Psychology, 80(1), 152-165. doi: 10.1037/0022-351480.1.152

Sheldon, K. M., Kasser, T., Smith, K., \& Share, T. (2002). Personal Goals and Psychological Growth: Testing an Intervention to Enhance Goal Attainment and Personality Integration. Journal of Personality, 70(1).

Sheldon, K. M., \& Lyubomirsky, S. (2006). Achieving Sustainable Gains in Happiness: Change Your Actions, Not Your Circumstances. Journal of Happiness Studies, 7, 5586. doi: 10.1007/s10902-005-0868-8

Shellenberger, M., \& Nordhaus, T. (2004). The Death of Environmentalism: Global Warming Politics in a Post-Environmental World (pp. 37): The Breakthrough Institute.

Sumner, J. (2008). Eating as a Pedagogical Act: Food as a Catalyst for Adult Education for Sustainable Development. Paper presented at the Thinking Beyond Borders: Global Ideas, Global Values, University of British Columbia, Vancouver, British Columbia.

Sundie, J. M., Kenrick, D. T., Griskevicius, V., Tybur, J. M., Vohs, K. D., \& Beal, D. J. (2010). Peacocks, Porsches, and Thorstein Veblen: Conspicuous Consumption as a Sexual Signaling System. Journal of Personality and Social Psychology. doi: $10.1037 / \mathrm{a} 0021669$

Thompson, C. J., Locander, W. B., \& Pollio, H. R. (1989). Putting Consumer Experience Back into Consumer Research: The Philosophy and Method of ExistentialPhenomenology. The Journal of Consumer Research, 16(2), 133-146.

Tkach, C., \& Lyubomirsky, S. (2006). How do people pursue happiness?: Relating personality, happiness-increasing strategies, and well-being. Journal of Happiness Studies, 7, 183-225. doi: 10.1007/s10902-005-4754-1

Trubek, A. B. (2008). The Taste of Place: A Cultural Journey into Terroir. London: University of California Press.

Trubek, A. B. (2009). Cooking as Pedagogy: Engaging the Senses through Experiental Learning. Anthropology News, 50(4), 16-16.

Twiss, J., Dickinson, J., Duma, S., Kleinman, T., Paulsen, H., \& Rilveria, L. (2003). 
Community Gardens: Lessons Learned From California Healthy Cities and Communities. American Journal of Public Health, 93(9).

Van Boven, L. (2005). Experientialism, Materialism, and the Pursuit of Happiness. Review of General Psychology, 9(2), 132-142. doi: 10.1037/1089-2680.9.2.132

Van Boven, L., \& Gilovich, T. (2003). To Do or to Have? That Is the Question. Journal of Personality and Social Psychology, 85(6), 1193-1202. doi: 10.1037/00223514.85.6.1193

Vasalampi, K., Salmela-Aro, K., \& Nurmi, J.-E. (2009). Adolescents' Self-Concordance, School Engagement, and Burnout Predict Their Educational Trajectories. European Psychologist, 14(4). doi: 10.1027/1016-9040.14.

Vileisis, A. (2008). Kitchen Literacy: How We Lost Knowledge of Where Food Comes from and Why We Need to Get It Back. Washington, D. C.: Island Press.

Wakefield, S., Yeudall, F., Taron, C., Reynolds, J., \& Skinner, A. (2007). Growing urban health: Community gardening in South-East Toronto. Health Promotion International, 22(2). doi: 10.1093/heapro/dam001

Waliczek, T. M., Zajick, J. M., \& Lineberger, R. D. (2005). The Influence of Gardening Activities on Consumer Perceptions of Life Satisfaction. HortScience, 40(5), 13601365.

Watson, D., Clark, L. A., \& Tellegen, A. (1988). Development and Validation of Brief Measures of Positive and Negative Affect: The PANAS Scales. Journal of Personality and Social Psychology, 54(6), 1063-1070.

Weingarten, H. P., \& Elston, D. (1990). The Phenomenology of Food Cravings. Appetite, 15, 231-246.

Weinstein, N., Przybylski, A. K., \& Ryan, R. M. (2009). Can Nature Make Us More Caring? Effects of Immersion in Nature on Intrinsic Aspirations and Generosity. Personality and Social Psychology Bulletin, 35(10), 1315-1329. doi: 10.1177/0146167209341649

White, R. W. (1959). Motivation Reconsidered: The concept of competence. Psychological Review, 66(5), 297-333.

Zepeda, L., \& Leviten-Reid, C. (2004). Consumers' Views on Local Food. Journal of Food Distribution Research, 35(3). 


\section{Appendix: Methods}

\section{A.1 Recruiting}

Participants were recruited using both intensity and snowballing sampling criterions. The intensity criterion for the study required that participants 1) were citizens of Portland, Oregon, 2) active members of one of the two Brentwood Community Gardens, 3) had significant experiences growing and preparing food, 4) be willing to discuss their experiences in an interview, 5) were willing to be audio and video recorded, and 6) were willing to having their living area and garden space photographed and described.

One participant was a partial exception, since she did not want to be interviewed at her home, and observations were not made of her living space. Her husband was a hoarder and she did not feel comfortable having an interview at her home. She was interviewed at the author's home and was asked a series of additional questions that were usually answered through observations (see the Observation Guide in the Data Collection section of the Appendix).

The author started recruiting by volunteered in the community orchard adjacent to the community gardens. The garden manager for one of the community gardens, Sue, had also volunteered for work in the community orchard, and agreed to send out a recruiting flyer to the members of her community garden, and contact the garden manager of the other community garden, Annie. Snowballing sampling was used when Sue agreed to be interviewed and helped recruit more participants, and when Sue helped recruit Annie, who helped recruit more participants from the community garden 
members from her community garden. Both garden managers were provided with electronic and paper versions of the recruiting flyers that they agreed to disseminate to their members. 


\section{A.2 Demographics}

The demographics for the participants are included in each journal article, but are somewhat abridged to fit the journal styles. Table A.1, below, shows a more complete set of demographics. The participants did not all live in the same neighborhood where the community garden was located, but they did all live in Portland. Seven of them lived in South East Portland, while one of them lived in North West Portland. Two of them lived in the same neighborhood as the community garden, Brentwood Darlington. The participants are listed in the order that they were interviewed. 


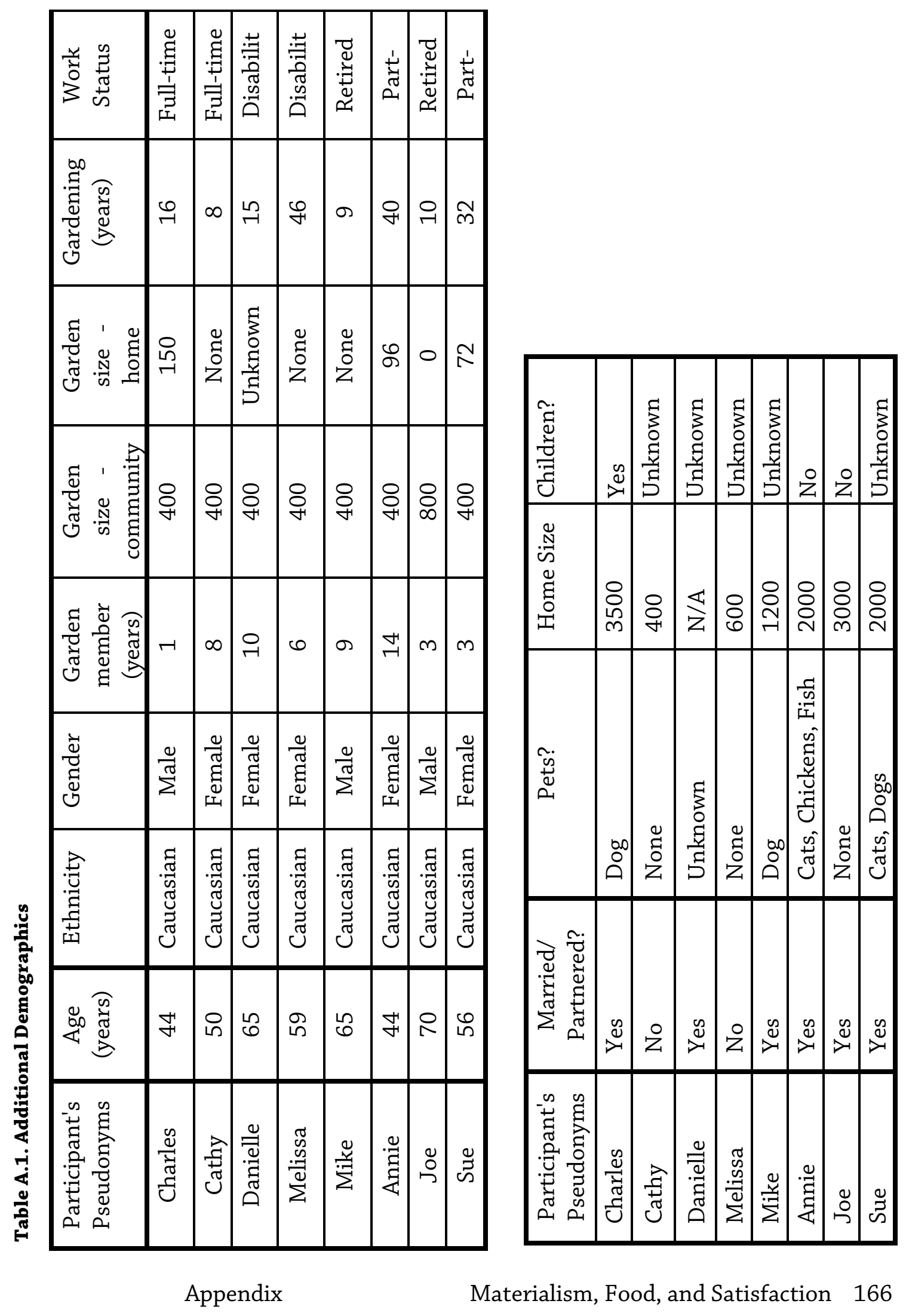




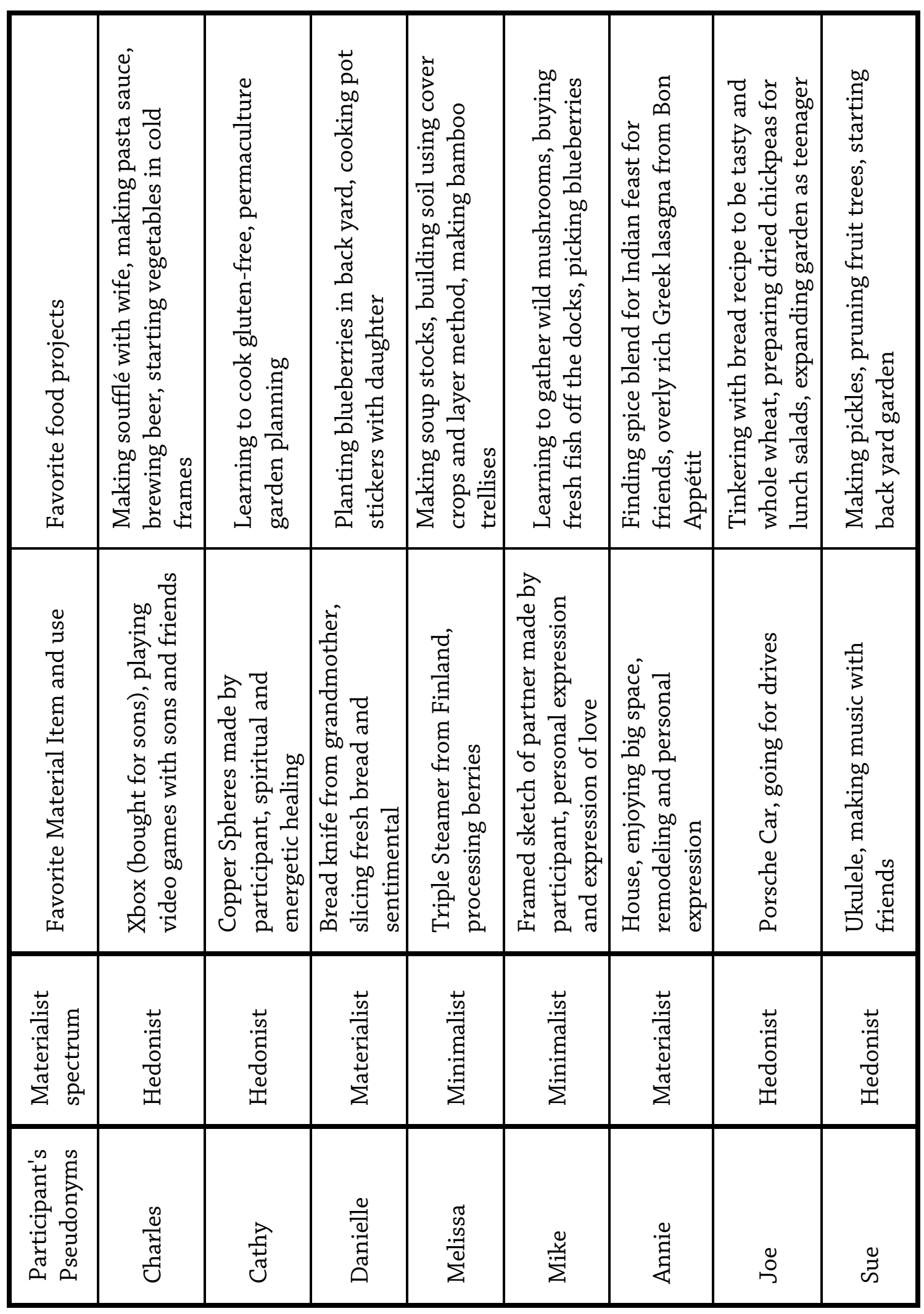

Appendix Materialism, Food, and Satisfaction 167 


\section{A.3 Data Collection}

Semi-structured interviews were conducted during February and March, 2011, and in all cases but one, the interviews took place at the gardener's home. The interview that did not take place at the participant's home was conducted at the author's home, since the participant did not feel comfortable having the author in her home because her husband was a hoarder. Most interviews lasted between 1-2 hours, while one lasted just over 2 hours. The interviews were audio and video recorded, and fully transcribed by the author. The interviews with each participant was guided by a series of questions, designed to explore the participant's experiences of food projects:

- Tell me about the last time you completed a project involving food and tell me anything you can about the situation, about what you felt, did or said.

- Tell me about the last time you purchased a material possession and tell me anything you can about the situation, about what you felt, did or said.

- Tell me about the last time you purchased food and ate it, and tell me anything you can about the situation, about what you felt, did or said.

In addition to interview transcripts and audio and video recordings of the interviews, observational data were collected, including field note observations of the participants during and after the interview, and photographic and field note observations of the participant's home and garden spaces. Pseudonyms were used in the transcripts for all participants, participant's spouses, and/or children.

At the time of the interviews, observations were made of the participant's living space, including photographs of relevant food projects. Since the interviews took place in the Winter, the participant's community garden plots were not very active, so 
observations of gardens were not made then, although half of participants had garden spaces at their homes in addition to their community garden plot. For these home gardeners, observations were made of the home garden spaces.

In early Summer 2012, observations were made in one of the participant's community garden spaces, since the gardener was working on their plot when the author was volunteering in the neighboring community orchard. In late Summer 2012 the participants were contacted again to inquire if a guided tour of their community garden space could take place. Three participants responded, and observations of their garden space were made.

Additionally, for triangulation, two more participant's plots was identified in the community garden, from information given during the interview, and observations were made without the participants being present. The remaining three participants were not reachable. In total, there were 104 single-spaced pages of transcripts, 330 photographic observations, and 30 pages of field notes, in addition to the audio and video recordings of the interviews. An observation guide was developed for the participant's home and garden, to assess materialism and for triangulation. The observation guide was as follows:

\section{A.3.1. Observations of Favorites (photographs of each):}

- Participant and Favorite Material Possession

- Participant and Favorite Food Project / Food Prepared

- Participant in Garden 


\section{A.3.2. Observations of Materialism (photographs and written notes):}

During the visit(s) to the co-researcher's home, observations were made in common

living areas such as living room, dining room, and kitchen, regarding the locations,

qualities, and quantities of:

- Small (in size or worth) material goods (that may or may not be impulse purchases),

- Survey of the refrigerator, freezer, and food storage areas in terms of produce quality and quantity, presence or absence of meat products (and quality and quantity), level and type of processed or pre-prepared foods, types of brands of foods (to evaluate qualities of local, socially responsible, or ethical production), i.e., a food survey.

- Material goods within the common living spaces (to evaluate clutter, production sources, such as local or handmade)

- Magazines, newspapers, and coupons (as possible sources of advertisements)

- Transportation devices and related gear such as cars, car keys, bicycles, helmets, motorcycles, bus passes or tickets, rain gear, and shoes/walking gear.

- Waste, recycling, an compost bins in common living areas

- Television (if in common living area)

- Material goods or physical spaces related to spiritual practices within common living areas, including images, books, decorative items, and items or spaces that could be used for spiritual practices (candles, incense, shrines, etc.)

- Flyers, books, images, or other indications of participation in community events

- Items indicating individuals in addition to the co-research living in the space, such as extra shoes, coats, types of foods, sets of keys, seating spaces in dining and living areas, or transportation methods for multiple individuals (such as two bicycle helmets).

\section{A.3.3. Observations of Food Activities (photographs and written notes):}

- Cooking equipment such as pots and pans, stovetops, ovens, and microwaves

- Cooking ingredients such as fats, vinegars, and seasonings 
- Preparation equipment such as cutting boards, knives, mixers, food processors, bowls, sifters, rolling pins, graters, dehydrators, drying racks, and food mills

\section{A.3.4. Observations of Participant in Garden Space during summer (photographs and written notes):}

Participant gave tours of plants in garden space including favorite plants, new techniques being tried, previous problems, plans for food grown, and previous experiences. Observations were made of the participant's attitude and demeanor during garden tour. 